Deforestation and agriculture in the tropics:

carbon emissions and options for mitigation

Sarah Carter 


\section{Deforestation and agriculture in the tropics: carbon emissions and options for mitigation}

Sarah Carter 


\section{Thesis committee}

\section{Promotor}

Prof. Dr. M. Herold

Professor of Geo-information Science and Remote Sensing

Wageningen University \& Research

\section{Co-promotors}

Dr L. Kooistra

Associate professor, Laboratory of Geo-information Science and Remote Sensing

Wageningen University \& Research

Prof. Dr M. C. Rufino

Professor of Agricultural Systems

Lancaster University, UK

Dr L. Verchot

Director, Soils and Landscapes for Sustainability (SoiLS)

International Center for Tropical Agriculture (CIAT), Cali, Colombia

\section{Other members}

Prof. Dr C. Kroeze, Wageningen University \& Research

Prof. Dr A. Angelsen, Norwegian University of Life Sciences (NMBU), Ås, Norway

Dr A. Gupta, Wageningen University \& Research

Dr I. Jonckheere, Food and Agriculture Organization of the United Nations, Rome, Italy

This research was conducted under the auspices of the C.T. de Wit Graduate School of Production Ecology \& Resource Conservation (PE\&RC) 


\title{
Deforestation and agriculture in the tropics: carbon emissions and options for mitigation
}

\author{
Sarah Carter
}

\author{
Thesis \\ submitted in fulfilment of the requirements for the degree of doctor \\ at Wageningen University \\ by the authority of the Rector Magnificus, \\ Prof. Dr A.P.J. Mol, \\ in the presence of the \\ Thesis Committee appointed by the Academic Board \\ to be defended in public \\ on Wednesday 21 March 2018 \\ at 4 p.m. in the Aula.
}




\section{Sarah Carter}

Deforestation and agriculture in the tropics: carbon emissions and options for mitigation 164 pages.

PhD thesis, Wageningen University, Wageningen, the Netherlands (2018)

With references, with summary in English

ISBN: 978-94-6343-832-2

DOI: https://doi.org/10.18174/428320 


\section{Contents}

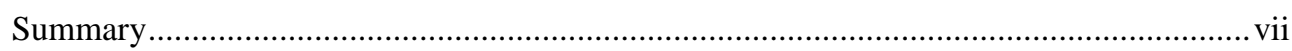

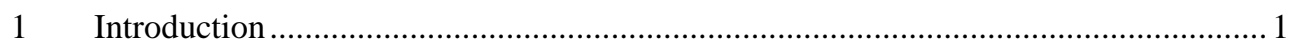

2 Emissions from agricultural-driven deforestation ................................................... 9

3 Mitigation of agricultural emissions: forest land-sparing .......................................... 33

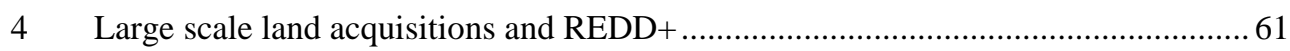

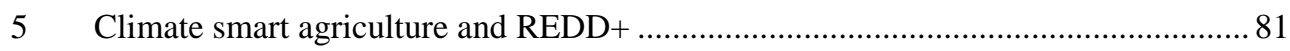

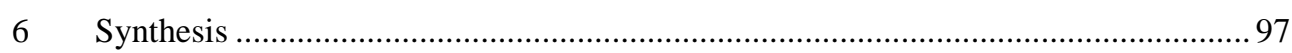

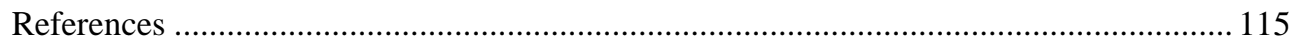

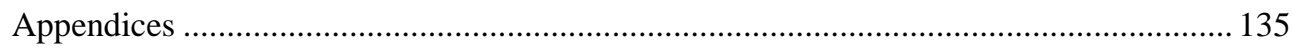

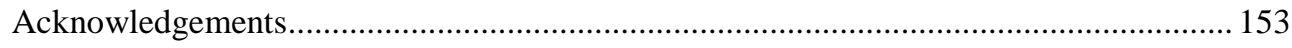

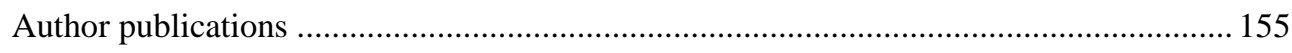

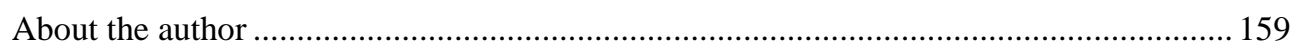

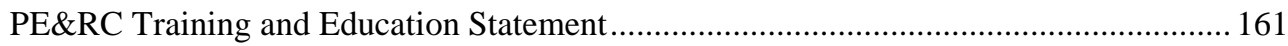




\section{Summary}

Agriculture is the largest driver of deforestation globally, and this conversion of land from forests to agriculture, results in emissions which are contributing to climate change. This thesis focuses on exploring agriculture-driven deforestation at the country level, from the perspective of quantifying emissions, estimating the potential for mitigation, including identifying potential barriers to success, and highlighting enabling conditions for mitigation of these emissions. Efforts to reduce deforestation are being undertaken, for example through the mechanism REDD+; reducing emissions from deforestation and forest degradation and the role of conservation, sustainable management of forests and enhancement of forest carbon stocks in developing countries. At the same time, efforts are underway to try to reduce hunger by increasing food security (for example through the sustainable development goals (SDGs)). Competition for land can result when both these goals are pursued at the same time, because forested land is protected for carbon storage, while agricultural land is expanded (often into forests) to provide sufficient land for growing food. There are several ways in which both goals, forest protection and food security might be achieved together, and we focus on assessing the potential of two approaches which can potentially spare forested land. These approaches are: increasing production on existing agricultural land, and expanding agriculture onto non-forested available land. Emerging phenomena such as Large Scale Land Acquisitions (LSLA, otherwise known as land grabs) add to the complexity of the challenge, and we discuss the potential threat which LSLA has on forested land, and how to avoid LSLA for agriculture in forested land. A transformational change of the land sector is proposed to ensure that both goals can be met. Several ingredients are required to achieve a transformational change, and linking REDD+ to Climate Smart Agriculture (CSA) approaches is discussed. CSA interventions are those which are able to reduce emissions or store carbon while increasing the adaptive capacity of agriculture to climate change and increasing food production.

Chapter 2 provides new estimates of emissions from agriculture-driven deforestation in 91 countries using a data-driven approach. Latin America was found to have the highest emissions, and these emissions peaked between 2000 and 2005 and then declined. Emissions in Africa has been rising since 1990, with the countries in the Congo Basin being particular contributors to this rise in emissions. Uncertainties of these country emission estimates are $\pm 62.4 \%$ (average for 1990-2015), and emissions from Asia are the most uncertain. The uncertainty of the input datasets was used to estimate the uncertainty of the emissions estimate, and the area of deforestation, and fraction which agriculture is driving deforestation 
were found to be the largest contributors to uncertainty of the emissions estimates. Increasing the certainty of these two data types should be a priority, and will lead to an increased certainty for the emissions estimates.

Chapter 3 compares direct and indirect emissions from agriculture at the national level, where direct are emissions from existing agricultural land, and indirect emissions are those from agriculture-driven deforestation. A decision tree was produced which can be used to guide decision making by identifying priority countries for mitigation initiatives. The decision tree uses several indicators related to the potential for mitigation, enabling environment, and associated risks to livelihoods to identify countries which have the most potential for the mitigation of either direct or indirect agricultural emissions. Six priority countries are highlighted as having a good mitigation potential for agriculture-driven deforestation while having a good enabling environment (in this case engagement in REDD+) and which also have low risks to livelihoods from the implementation of interventions in the agriculture sector. They are: Panama, Paraguay, Ecuador, Mexico, Malaysia and Peru.

Chapter 4 focusses on LSLA, and their potential impacts on forests. A country level analysis was carried out, and the characteristics which are typically found in countries which have LSLA were described. Countries which have these characteristics and which do not yet have LSLA are for example considered to be at risk from LSLA. Countries which have LSLA or are at risk from LSLA were assessed for the risk of LSLA-driven deforestation. Other key targets for interventions to reduce deforestation are highlighted, such as those countries with large numbers of LSLA and which already have a lot of agriculture-driven deforestation. The potential conflicts between LSLA and REDD+ are discussed, and investor-side policies such as zero deforestation pledges from commodity producers, green procurement policies, and initiatives such as the Roundtable For Sustainable Palm Oil are highlighted as potential solutions to these conflicts. Lessons learned from implementing REDD+, which has a number of shared characteristics with LSLA, can be applied in order to reduce the negative impacts of LSLA.

Chapter 5 discusses the potential for forest-land sparing interventions to be implemented in the agriculture sector. A transformative change which incorporates multiple interventions and brings together the forest and agriculture sectors is proposed. Climate Smart Agriculture approaches should be considered, but only when they do not lead to expansion of agriculture into forests. The need for supporting policies to avoid this occurring is discussed. Policy coherence is a barrier to this change as policies favouring both conversion to agriculture (including those which enable LSLA), and forest protection can occur in the same place. The use of the landscape approach as a platform to address this challenge is discussed. Landscapelevel emissions accounting, which takes into consideration both direct and indirect emissions from agriculture, can be used to evaluate the impact of mitigation interventions across 
sectors. The need for transparency in the land sector, in relation to emissions reporting in particular is introduced, and is a key requirement for access to carbon finance which can potentially support forest land-sparing interventions.

Chapter 6 concludes the thesis, and discusses the wider implications for this work. The link between the findings in this thesis and the SDGs is explored. The SDGs may lead to future competition for land due to goals which focus on reducing hunger, protecting forests and increasing the proportion of renewable energy unless action is taken. Future data needs are discussed, as although we provide (in chapter 2) new data on agriculture-driven deforestation, they are still uncertain and data on potential future trends in agriculture-driven deforestation are not available. The need for consideration of emissions related to the impact of agriculture on forest degradation and on carbon losses in soils is another data gap, and relates to recent efforts to restore degraded land - which could be one of the most promising mitigation efforts which can also support the production of more food for growing global populations. The urgent need to address climate change highlights the opportunities in the land sector, not only to mitigate emissions, but also to promote food security. 

1 Introduction 


\subsection{Background}

\subsection{Background}

There are two challenges which are arguably the greatest threats to the future of humanity of our time. The challenges are mitigating climate change (IPCC 2013), and producing food for a growing world population (Godfray et al. 2010). These challenges urgently need to be addressed together, as they are inextricably linked. Firstly on climate change, to quote the Intergovernmental Panel on Climate Change (IPCC), it is "unequivocal" that global temperatures have been rising, and that recent warming is "unprecedented" (IPCC 2013). It is also "extremely likely" that human influence has been the dominant cause of this warming, which has resulted from increasing concentrations of greenhouse gasses (GHGs) in the atmosphere (IPCC 2013). Most GHG emissions in the last century were due to the increasing use of fossil fuels (345-405 $\left.\mathrm{GtC} \mathrm{yr}^{-1}\right)$, but, the second largest source was deforestation and other land use change (100-260 GtC $\mathrm{yr}^{-1}$ ) (IPCC 2013). Emissions from deforestation alone account for around 12\% of anthropogenic emissions (Houghton et al. 2012). The second challenge; producing food to meet the needs of increasing populations is also linked to increasing consumption. Populations have increased from over 2.5 billion people in 1950 to 7.3 billion people in 2015 (FAO 2017a). Changes in consumption, food waste, and increases in bioenergy use, mean that meeting this challenge is becoming increasingly difficult (Foley et al. 2011). The effects of climate change and of forest loss, for example increasing droughts (IPCC 2013) can also hinder food production, one of the linkages between the two challenges. The other link and focus of this thesis, is that deforestation is in general driven by agriculture.

Forest management potentially has a major role towards limiting global warming to $2^{\circ} \mathrm{C}$; an internationally agreed target (Bastos Lima et al. 2015). One mechanism through which deforestation can be reduced is the performance-based financing mechanism REDD+; reducing emissions from deforestation and forest degradation and the role of conservation, sustainable management of forests and enhancement of forest carbon stocks in developing countries (UNFCCC 2013). REDD+ was envisaged as a form of payments for ecosystem services (PES), where incentives (in this case cash payments) are provided to protect an ecosystem service (in this case carbon storage in forests). Although this structure has not yet been widely realized, and in general REDD+ has evolved thus far with donor finance, REDD+ has received notoriety, as one of the most well developed elements of the UNFCCC convention, and has already received several billion dollars in investments (Agrawal et al. 2011). REDD+ has also been considered among the most cost effective mechanisms to address climate change (Stern 2006; Strassburg et al. 2008).

The second challenge of feeding 9 billion people is related in part to food insecurity, which can be defined as not having adequate physical, social or economic access to sufficient, safe 
and nutritious food (FAO 2003). Food production is only one component of food security, with access to food being important, as both undernutrition and obesity are prevalent today (Gordon et al. 2017), and food waste being another important component (FAO 2015). Increasing food production can be achieved by increasing the area under agricultural production, and also through intensification (producing more from the same area of production). Major changes in agricultural production have occurred in the past century, for example widespread use of fertilizer and mechanization (Stevenson et al. 2013), which have contributed to increased outputs. In addition to this, agricultural areas have also been expanding, and although net area increases were only 3\% between 1985 and 2005, agriculture has moved from temperate to tropical areas meaning this figure is higher in the tropics (Foley et al. 2011).

\subsection{The conflict; how to reduce deforestation while feeding people}

Food production is closely linked with deforestation, as it requires land, and agriculture has been identified as the largest driver of deforestation in the tropics (Hosonuma et al. 2012). Agricultural exports' (value) per $\mathrm{km}^{2}$ was found to be significantly correlated to deforestation at the country level (Leblois et al. 2017), and about $80 \%$ of agricultural expansion in the tropics has been into forests (Gibbs et al. 2010). Competition for land has been a key question for researchers for many years (Smith et al. 2010), and agricultural and forests are often the focus of studies on competition for land, as they are the two major land uses in the planet. In 2014 agricultural land accounted for about $38 \%$ of the earth's surface, and forest land around $30 \%$ (FAO 2017a). The challenge is to address both food security and deforestation together, without one impeding the other. The Borlaug hypothesis states that food production can increase without increases in the area of land under production, and this has occurred in the past and can occur in the future (Borlaug 2007). This type of intensification is often termed land sparing, and although there is a debate as to whether it is likely to happen in future, some circumstances have been identified under which it is likely to occur (Angelsen 2010; Burney et al. 2010). The available resources (for example yield gap, which can be closed to intensify production (van Ittersum et al. 2013)) will influence whether land sparing can occur. Project activities aimed at supporting agricultural intensification can also potentially lead to emissions outside the project boundary (known as leakage) meaning that overall emissions savings are not made. Leakage is related to the scale of the investigation, as it could be that sparing occurs at the local level, but that land claims stemming from economic development, and market forces stimulated by high productivity in intensified systems, will lead to increased land acquisitions elsewhere (Angelsen \& Kaimowitz 2001; Meyfroidt \& Lambin 2011; Pirard \& Belna 2012). A mixture of mechanisms which include both land sparing policies and forest protection policies (such as REDD+) has been suggested to reduce 
agriculture-driven deforestation (Mertz \& Mertens 2017; Rudel et al. 2009), which highlights the need to address both of the challenges together, and at the right scale. Another potential way to spare forests, is expanding agriculture into non-forested areas, such as degraded lands. As with intensification, scale is important as leakage can occur where activities are displaced by this intervention.

Agriculture can be divided into two broad types: smallholder agriculture, and large-scale agriculture. These agriculture types have different characteristics which influence how and whether land sparing will occur. Smallholder agriculture includes agriculture for subsistence, and practices such as shifting cultivation are used. Large-scale commercial agriculture is in most tropical countries a larger driver of deforestation than smallholder agriculture (Hosonuma et al. 2012). Large-scale agriculture can include a large scale land acquisition (LSLA), which are commonly known as Land Grabs. LSLA can be defined as an acquisition of a large area (>200 ha) of land, which results in a transfer of rights and ownership of the land (The Land Matrix Global Observatory 2013). The scale of LSLA is significant, with 1410 concluded deals, of an average of over 34,690 ha recorded by November 2017 (The Land Matrix Global Observatory 2013). Most of these are intended for agriculture, with mining and tourism among the other intentions, and can occur into forested land. This variation in agriculture types, scales and practices, means that different approaches are required from country to country to reduce deforestation while maintaining food production.

\subsection{Carbon emissions from deforestation}

In order to reduce emissions from deforestation, a baseline or status of both deforestation and related emissions needs to be established. Emissions from deforestation should then be monitored over time to track progress, and for this, a number of data inputs are required. Typically two main data types are utilized: activity data, or the area of forest loss; and emissions factors, which relate to the amount of carbon or biomass in forests. These data are then multiplied which provides emissions estimates. Many countries are monitoring these emissions already, as it is a requirement for REDD+ and other interventions, which are intended to reduce deforestation. Measuring, monitoring, reporting and verification (MRV) in REDD+ is essentially the process of calculating the emissions reductions delivered by a project. Accurate estimates are required to ensure the credibility of REDD+ (Angelsen et al. 2012). Until recently however, a number of key MRV related issues (monitoring drivers and non-carbon benefits, and verification) remained unresolved (Sanz-Sanchez et al. 2013). Advances in data availability among other things, have however led to improvements in monitoring in the last few years (Romijn et al. 2015). A number of recent advances have occurred in remote sensing including the availability of free satellite data (Wulder et al. 2012), and increasing computing power from for example the emergence of readily available 
cloud computing options, for example SEPAL and the Google Earth Engine (FAO 2017c; Gorelick et al. 2017). The opening of the Landsat archive, plus access to cloud computing opportunities, has led to the production of global maps which are useful for monitoring. Global maps of forest change for example, have proved useful for forest monitoring, although there is some debate about their applicability to all areas (Tropek et al. 2014; Hansen et al. 2014). A number of land use/land cover maps are available (see: Vancutsem et al. 2012), and these can provide vital information about forest area and in some cases changes in forest area. Maps of biomass have contributed to knowledge on emissions factors and are useful for calculating emissions from deforestation. A number of pan tropical biomass maps exist, although there is some debate as to their accuracy in some areas (Mitchard et al. 2013; Avitabile et al. 2016).

\subsection{Carbon emissions from agriculture-driven deforestation}

Although new satellite data has undoubtedly been useful for providing information needed to calculate emissions from deforestation (for example area of deforestation and forest biomass), these data do not provide all the information required to understand the relationships between forests and agriculture, or the extent to which agriculture is driving deforestation. When monitoring specific agricultural drivers (for example commercial vs smallholder agriculture), additional data on land uses is also required. The identification of and monitoring of land uses (rather than land cover) and their changes is a major challenge. At present, there are few (if any) operational methodologies for monitoring drivers of deforestation. Studies have assessed drivers using satellite data, however the satellite data requires interpretation, which has been done manually thus far (for example: De Sy 2016; Heinimann et al. 2017). This is by nature, time consuming and costly. Visual interpretation of satellite images is also not able to provide ancillary information about land dynamics such as who the deforestation agents are, and changes in tenure, which can be important to understand the agricultural driver fully. For example, in the case that deforestation is driven by LSLA, information such as the intention for use is important -which is available in the Land Matrix database (The Land Matrix Global Observatory 2013). In terms of predicting future deforestation drivers, a number of studies have modelled future land use change (see for example: Schmitz et al. 2014; Valin et al. 2013; Frank et al. 2017).

One option, for addressing food security and deforestation together, is intensification of agriculture, which can potentially lead to forest land-sparing. Intensification requires either a change of inputs, management, or agricultural activities. These changes can potentially lead to increased emissions, for example emissions related to an increase in fertilizer use. Climate smart agriculture (CSA) is a potential for intensification in these cases, as in addition to mitigating climate change, CSA provides adaptation benefits, while also increasing 
production, thus supporting food security efforts (FAO 2010a). Understanding the emissions balance of any proposed change is important, in order to estimate the overall impact of changes in both the agriculture and forest sectors. In this case, a landscape approach for emissions assessments could be considered. The landscape is typically understood to be the scale at which analysis is undertaken, and the systems, and stakeholders which are included (Reed et al. 2016). This approach combines multiple disciplines, and moves away from the concept of silos, or single sectors, which are in this case forests and agriculture, which is the philosophy used in this thesis.

\subsection{Research gaps}

Agriculture is the main driver of deforestation, but long-term data on emissions from agriculture-driven deforestation are not available. Data on these emissions, at the national level, with known uncertainties would be extremely valuable for understanding the true impact of agriculture on emissions. Often direct agriculture emissions are the focus of assessments of emissions and related mitigation opportunities, with indirect emissions (for example from agriculture-driven deforestation) receiving less focus (Wollenberg et al. 2016). National mitigation potentials for agriculture-driven deforestation are also not available, and are essential to objectively assess the impact of mitigation strategies, which are often made at the national level. The Nationally Determined Contributions (NDCs) for example are actions which countries intend to carry out as their contribution to the Paris Climate Agreement. Data on relative mitigation potentials at the national level can be used to inform future NDC revisions or other mitigation aims, as they highlight countries where the greatest mitigation benefits can potentially occur. This information can also be used in the allocation of funds to support such initiatives. There is an ongoing debate as to whether land-sparing can occur, and often these debates focus on sub-national case studies. However in the context of national mitigation actions, information on the land-sparing potential of different countries is required and is not available. Finally, there is little guidance on how to practically link interventions in the forest and agriculture sectors. In the case of mitigating agriculture-driven deforestation in the tropics, a number of complexities arise, such as the potential for negative impacts to communities, and due to emerging phenomena such as LSLA. Further guidance on these risks, particularly at the national level can be used to adjust or create new national mitigation plans which are in development or are being implemented in many countries (Richards et al. 2015). 


\subsection{Research objectives}

This thesis explores land-use changes from forests to agriculture, and the emissions from these changes over time using a data-driven approach in the tropics (tropical eco-regions plus some additional countries - see chapters 2, 3 and 4 for details). Emissions from agriculturedriven deforestation are quantified, and specifically explore the role of remote sensing data in this process. Several available datasets are utilized, and their reliability and usefulness for this purpose is also evaluated. Following on from this, mitigation options are assessed, and the mitigation potential of forest-sparing interventions is quantified. Thereafter, the impact of LSLA are explored, as a potential driver of deforestation. The relationship between LSLA and REDD+ is explored in order to identify synergies and conflicts between the two. The need for, and methods to integrate the agriculture and forest sectors and their approaches to reducing emissions from agriculture-driven deforestation are then discussed. Finally, the implications of the work, and next steps for the future are proposed.

Three research questions (RQs) are addressed:

A. What are the emissions and their uncertainties of agriculture-driven deforestation in the tropics?

B. In which countries can forest-land sparing interventions be best introduced to mitigate these emissions?

C. How can interventions in both the forest and agricultural sectors be better integrated to achieve emissions reductions?

\subsection{Thesis structure}

This thesis has 6 chapters, which address one or more of the research questions, and are described below.

Chapter 2 focusses on RQ A. This chapter explores the availability and uncertainties related to datasets which can contribute to this question. Comparable estimates of agricultural-driven deforestation are produced for 91 countries in the tropics.

Chapter 3 explores the mitigation potential from forest-land sparing opportunities, and also explores the potential for CSA interventions to reduce other agricultural emissions. Both RQs $\mathrm{A}$ and $\mathrm{B}$ are addressed. The paper provides guidance on the decision making process; specifically a systematic framework to select mitigation interventions by considering 


\subsection{Thesis structure}

sequentially the level of emissions from agriculture and agriculture-driven deforestation, the mitigation potential of interventions which would address these emission, and enabling environment and associated risks to livelihoods at the national level.

Chapter 4 looks in-detail at the occurrences of LSLA at the country level, and identifies countries which may be potential future targets of LSLA. Both RQs B and C are explored. The risk of agriculture-driven deforestation from LSLA is assessed, as well as the potential for interventions such as REDD+ to take into account the potential impacts from LSLA. Several host country and investor-side policies were identified which specifically address the potential conflict between REDD+ and LSLA.

Chapter 5 looks at the potential for REDD+ and CSA to support the mitigation and adaptation targets of the Paris Climate Agreement. Opportunities to strengthen the ties between the two interventions were identified in terms of practical solutions, policies and research agendas. Key elements of climate-smart land use are described, which addresses RQ C in detail.

Chapter 6 concludes this thesis, and highlights the major findings, the implications for related topics such as the Sustainable Development Goals, and potential avenues for further research. 


\section{Emissions from agricultural-driven deforestation}

This chapter is based on: S Carter, M Herold, V Avitabile, S de Bruin, V De Sy, L Kooistra and MC Rufino. 2017. Agriculture-driven deforestation in the tropics from 1990 to 2015: emissions, trends, and uncertainties. Environmental Research Letters 13 (1), 014002.

Supplementary materials to this chapter can be found in the appendix of this thesis and in the online publication. 


\section{Abstract}

Limited data exists on emissions from agriculture-driven deforestation, and available data are typically uncertain. In this paper, we provide comparable estimates of emissions from both all deforestation and agriculture-driven deforestation, with uncertainties for 91 countries across the tropics between 1990 and 2015. Uncertainties associated with input datasets (activity data and emissions factors) were used to combine the datasets, where most certain datasets contribute the most. This method utilizes all the input data, while minimizing the uncertainty of the emissions estimate. The uncertainty of input datasets was influenced by the quality of the data, the sample size (for sample-based datasets), and the extent to which the timeframe of the data matches the period of interest. Area of deforestation, and the agriculture-driver factor (extent to which agriculture drives deforestation), were the most uncertain components of the emissions estimates, thus improvement in the uncertainties related to these estimates will provide the greatest reductions in uncertainties of emissions estimates. Over the period of the study, Latin America had the highest proportion of deforestation driven by agriculture (78\%), and Africa had the lowest (62\%). Latin America had the highest emissions from agriculture-driven deforestation, and these peaked at $974 \pm 148$ $\mathrm{Mt} \mathrm{CO}_{2} \mathrm{yr}^{-1}$ in 2000-2005. Africa saw a continuous increase in emissions between 1990 and 2015 (from $154 \pm 21$ to $412 \pm 75 \mathrm{Mt} \mathrm{CO}_{2} \mathrm{yr}^{-1}$ ), so mitigation initiatives could be prioritized there. Uncertainties for emissions from agriculture-driven deforestation are $\pm 62.4 \%$ (average over 1990-2015), and uncertainties were highest in Asia and lowest in Latin America. Uncertainty information is crucial for transparency when reporting, and gives credibility to related mitigation initiatives. We demonstrate that uncertainty data can also be useful when combining multiple open datasets, so we recommend new data providers to include this information.

\subsection{Introduction}

Emissions from land use change, and particularly deforestation have had a major impact on global carbon budgets (Le Quéré et al. 2015). The net flux of carbon from land use and land cover change between 1990 and 2010, was $12.5 \%$ of anthropogenic carbon emissions (Houghton et al. 2012). Most of these emissions resulted from forest loss (Le Quéré et al. 2015). Reducing deforestation can potentially play a large role in efforts to limit global temperature increases (Zarin et al. 2016; Wollenberg et al. 2016), through mechanisms such as reducing emissions from deforestation and forest degradation and the role of conservation, sustainable management of forests and enhancement of forest carbon stocks in developing countries (REDD+). Information on what drives deforestation can provide input for policies 
such as REDD+, as actions to reduce deforestation should directly address the specific drivers (Salvini et al. 2014). In order to be eligible for payments related to REDD+, reporting standards which include providing information on uncertainties related to emissions estimates must be adhered to. Uncertainty information is also a requirement for national greenhouse gas inventories (IPCC 2006). Uncertain estimates make informed choices on mitigation approaches difficult, and also threaten the credibility of initiatives which seek to address these emissions (Pelletier et al. 2015), such as REDD+.

Emissions from deforestation have been estimated using a variety of methods and data sources (Houghton et al. 2012). Most approaches use activity data (area estimates for land use change) and emissions factors (changes in carbon stock due to a land use transition, expressed per unit area). Input data for these estimates includes ground observations, usually derived from forest inventory data, and remote sensing data. Countries report detailed information on deforestation, and this is compiled every 5 years in the Global Forest Resources Assessments (FRA) (FAO 2017d). Data used in the FRA include both inventorybased and remote-sensing-based estimates. Remote sensing data are considered particularly useful for forest monitoring (De Sy et al. 2012; Goetz et al. 2015). Increased access to remote sensing data (through for example the opening of the Landsat archive), allowed for the production of multiple estimates of activity data and emissions factors. Besides the IPCC Tier 1 default factors providing the average forest biomass per ecozone, which may not always fit the country circumstances (Avitabile et al. 2011), emission factors can be derived from several maps of forest carbon density (see for example: Avitabile et al. 2016; Baccini et al. 2012; Saatchi et al. 2011; Zarin et al. 2016; Tyukavina et al. 2015). Sample data are also useful for regional assessments of deforestation and emissions factors (De Sy et al. 2015; Achard et al. 2014). Since datasets use different input data types and methodologies (see for example: Harris et al. 2012b, Mitchard et al. 2013, Grace et al. 2014, Grainger 2008), a large number of different estimates exist, which can be confusing for policy makers (Harris, et al. 2012b). Currently, there is a lack of comprehensive data on the agricultural drivers of deforestation. De Sy (2016) however, produced estimates of the fraction of deforestation which is driven by agriculture using a sample-based approach. The synthesis by Hosonuma et al. (2012) also provides estimates based on country reported data, but the data have large uncertainties, so making conclusions from their findings is difficult. Gibbs et al. (2010) also provide information on the dynamics between agriculture and forests, and conclude that $83 \%$ of agriculture expansion between 1980 and 2000 was into forests. Since forest loss worldwide as well as in the tropics is mainly driven by agricultural expansion (Kissinger et al. 2012), our study aims at providing a quantitative assessment of agriculture-driven deforestation including uncertainties.

Forest loss is one of the most uncertain components of global carbon budget (Houghton et al. 2012; Canadell et al. 2010). Many datasets do not provide uncertainty information (for 
example the FRA). Remote sensing derived estimates often provide information about the uncertainties of datasets, but different methods result in different outcomes (see for example Schepaschenko et al. 2017). Many estimates do not indicate how the results were calculated, or do not use uncertainties to provide better estimates (Olofsson et al. 2013). Uncertainty can be quantified using empirical and statistical approaches (for example in the case of remote sensing; pixel level uncertainty estimates, or map accuracies), and also expert judgement. The IPCC and other sources provide guidelines on how to produce and report these estimates (GOFC-GOLD 2016; IPCC 2006). It is not only the input datasets for which uncertainty data is required, but also the final emissions estimates. This means that uncertainty for the input datasets must be correctly combined to produce the emission uncertainty (for example when using activity data with an emissions factor).

Our objectives are to (1) quantify uncertainty associated with input datasets (activity data and emissions factors) used in emissions calculations; (2) calculate a best estimate of emissions from deforestation and agriculture-driven deforestation based on the most certain datasets, to compare trends in space and time; (3) calculate the uncertainty of the best emissions estimates, and identify the input component which contributes most to uncertainty, and (4) to make recommendations for use/selection of data and further improvements on the estimation of emissions from deforestation.

\subsection{Data and methods}

For 91 countries in the tropics, $\mathrm{CO}_{2}$ emissions from all deforestation (D) and from only agriculture-driven deforestation (ADD) were calculated. Agriculture-driven deforestation, a subset of deforestation, is defined as deforestation where the follow-up land-use is agriculture. Agriculture is defined broadly in this study, and includes subsistence agriculture, and large-scale pastures, as well as tree crops (De Sy et al. 2015; Hosonuma et al. 2012). A land-use definition of gross deforestation from the FAO was therefore used (see Appendix $\mathrm{S} 1)$ to assess if the change was driven by agriculture. It was assumed that emissions resulted from loss of above- and below-ground biomass, a fraction of which remained (or is replaced by new biomass) following deforestation. The datasets and data availability are described in Table 2.1 and Figure 2.1.

Emissions were calculated from activity data and an emission factor. Activity data were deforestation area (A) for $\mathrm{D}$, and for ADD, they also included the agriculture driver fraction $\left(f_{\mathrm{AAgri}}\right)$, representing the fraction $(f)$ of forest area replaced by agricultural land use. The emissions factor comprised: the carbon in above- and below-ground forest biomass (AGB + $\mathrm{BGB}$; converted to $\mathrm{CO}_{2}$ ) (CB) (before deforestation), and the fraction of this biomass which 
is lost on the land following deforestation in either all land uses $\left(f_{\mathrm{CBLU}}\right)$, or only agricultural land uses $\left(f_{\mathrm{CBAgri}}\right)$ (Eqs. 2.1 and 2.2).

$$
\begin{gathered}
D=A \cdot C B \cdot f_{C B L U} \\
A D D=A \cdot f_{\text {AAgri }} \cdot C B \cdot f_{C B A g r i}
\end{gathered}
$$

The deforestation area (A) datasets use different definitions of deforestation, and some are more suited to our purposes than others (Table 2.2). The datasets not matching our (the FAO) deforestation definition needed to be harmonized (see Keenan et al. 2015). Three differences in the definitions make the estimates thematically mismatched; (1) the use of a net change, rather than only forest loss data, (2) the use of a land cover rather than land use definition and (3) only accounting losses in forest with a tree cover larger than $30 \%$ rather than using the $10 \%$ threshold. The data were harmonized using available data from which the mismatch was estimated (see Appendix S1 for details).

Outputs were generated for four time periods between 1990 and 2015. The variable A was assumed to be potentially dynamic over the time periods, but the other variables were assumed to remain constant (though uncertain).

Table 2.1. Description of input data for emissions estimates from deforestation and

\begin{tabular}{|c|c|}
\hline Source 'abbreviation' & Description \\
\hline \multicolumn{2}{|l|}{ Deforestation area $(\mathrm{A})$} \\
\hline 'FRA' The Global & Country reported data on gross area of deforestation \\
\hline Forest Resource & (deforestation), and net changes in forest area (net). Uses FAO \\
\hline Assessment (FAO & forest land-use definition of forests and forest change. Net \\
\hline 2015b) & data cover the years $1990-2000,2000-2005,2005-2010,2010-$ \\
\hline & $\begin{array}{l}\text { 2015; and deforestation 1988-1992, 1998-2002, 2003-2007, } \\
\text { 2008-2012. }\end{array}$ \\
\hline 'RSS' Remote & A sample-based dataset comprising $10 \times 10 \mathrm{~km}$ squares at \\
\hline Sensing Survey (FAO & intersections of every degree line of latitude and longitude. \\
\hline \& JRC 2012) & $\begin{array}{l}\text { FAO forest land-use definition of forests and forest change are } \\
\text { used. Data cover the years 1990-2000, and 2000-2005. }\end{array}$ \\
\hline $\begin{array}{l}\text { 'Kim' (Kim et al. } \\
\text { 2015) }\end{array}$ & $\begin{array}{l}\text { Map based on } 30 \text { m resolution Landsat data. Forest-cover loss } \\
\text { in forests }>30 \% \text { canopy cover, and parcels }>1 \text { ha. Data cover } \\
\text { the years } 1990-2000,2000-2005 \text {, and } 2005-2010 \text {. }\end{array}$ \\
\hline
\end{tabular}
agriculture-driven deforestation. 


\begin{tabular}{ll}
\hline $\begin{array}{l}\text { 'Hansen' (Hansen et } \\
\text { al. 2013) }\end{array}$ & $\begin{array}{l}\text { Map based on 30 m resolution Landsat data of gross forest } \\
\text { cover loss. 10\% canopy cover threshold for forests and 0\% for } \\
\text { deforestation. Data from 2000-2014 (all years) are available. }\end{array}$ \\
\hline Forest biomass (CB) & \\
\hline $\begin{array}{l}\text { 'Baccini' (Baccini et } \\
\text { al. 2012) }\end{array}$ & $\begin{array}{l}\text { Map of biomass in aboveground woody vegetation (AGB) in } \\
\text { the tropics at a } 500 \text { m resolution. In this study, AGB with a } \\
\text { conversion factor from Saatchi et al., (2011) is used to } \\
\text { calculate BGB. The map is representative of the time period } \\
\text { 2007-2008. }\end{array}$ \\
\hline 'Saatchi' (Saatchi et & $\begin{array}{l}\text { Map of forest carbon contained in AGB and BGB in the } \\
\text { continental tropics at a } 1 \text { km resolution. The map is } \\
\text { representative of the early 2000s }\end{array}$ \\
\hline 'Avitabile' (Avitabile & $\begin{array}{l}\text { Map of biomass in aboveground woody vegetation (AGB) in } \\
\text { the tropics at } 1 \text { km resolution obtained by the integration of } \\
\text { the Baccini and Saatchi maps with an extensive reference } \\
\text { dataset. In this study, AGB with a conversion factor from } \\
\text { Saatchi et al., (2011) is used to calculate BGB. The map is } \\
\text { representative of the 2000s. }\end{array}$
\end{tabular}

Lost biomass fraction $\left(f_{C B A g r i} / f_{C B L U}\right)$

'De Sy1' (De Sy 2016) Deforested areas of the RSS dataset were interpreted using / (FAO \& JRC 2012) / high resolution satellite imagery to assess the land use after (Zarin et al. 2016) / deforestation (follow-up land-use). For this study follow-up (Hansen et al. 2013) land uses were aggregated to agriculture $\left(f_{\mathrm{CB} A g r i}\right)$ or to other land uses ( $\left.f_{\mathrm{CBLU}}\right)$. The fraction of biomass lost due to forest conversion were derived from a 30 m biomass map from Zarin et al., (2015). The Hansen dataset was used as an additional forest mask. Data cover the years 1990-2000.

\begin{tabular}{ll}
\hline Agriculture-driven deforestation fraction $\left(\boldsymbol{f}_{\text {AAgri }}\right)$ \\
\hline 'Hosonuma' & $\begin{array}{l}\text { Literature, country reports, and the country forest transition } \\
\text { (Hosonuma et al. }\end{array}$ \\
curve provided information on the drivers of deforestation. \\
Most data are representative of the years 2000-2010.
\end{tabular}


Table 2.2. Suitability of area data to estimate agriculture-driven deforestation in this study

\begin{tabular}{ll}
\hline Dataset & Characteristics \\
\hline FRA & $\begin{array}{l}\text { Some countries have gross deforestation data which matches the FAO } \\
\text { definition, and all time periods are covered, but net rather than gross data is } \\
\text { provided in many cases. }\end{array}$ \\
RSS & $\begin{array}{l}\text { Some countries have few sample units, so data are generally best suited to } \\
\text { regional estimates, however the deforestation definition matches ours. Data } \\
\text { are only available for the first two time periods. }\end{array}$ \\
Kim & $\begin{array}{l}\text { Few countries have data available, and the dataset uses a land cover rather } \\
\text { than land use definition, and canopy cover threshold differs. Data cover the } \\
\text { entire time period. }\end{array}$ \\
Hansen & $\begin{array}{l}\text { Land cover definition rather than land use, however data for all canopy } \\
\text { covers are available, so our chosen threshold can be used. Data cover the last } \\
\text { three time periods. }\end{array}$ \\
&
\end{tabular}


(a) Deforestation area
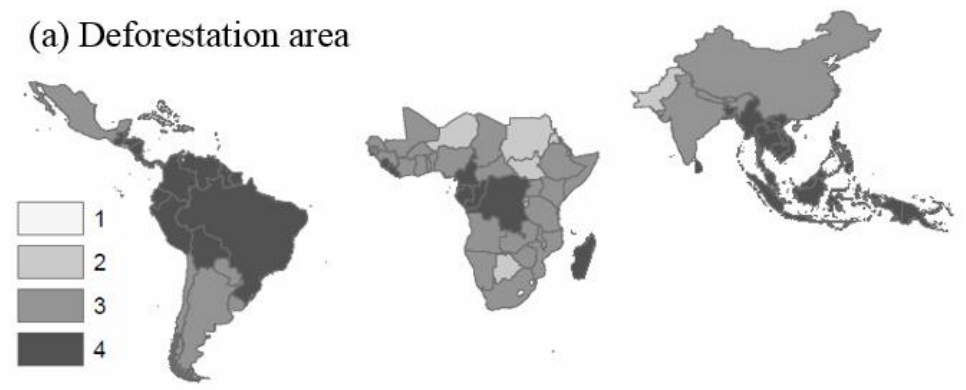

(b) Forest biomass
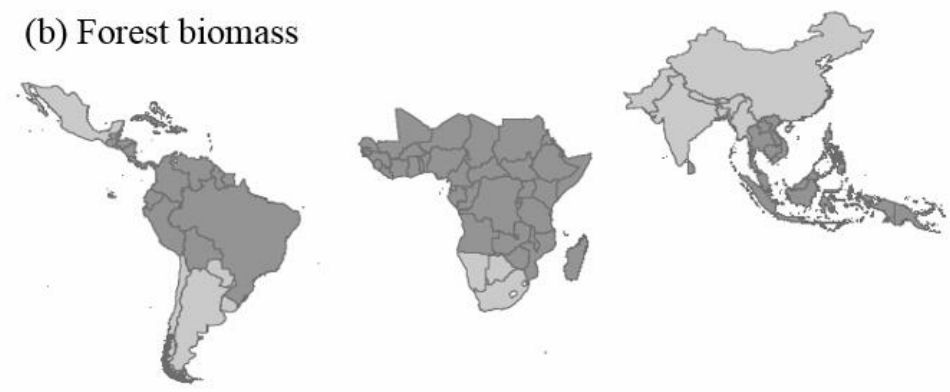

(c) Agriculture-driven deforestation fraction
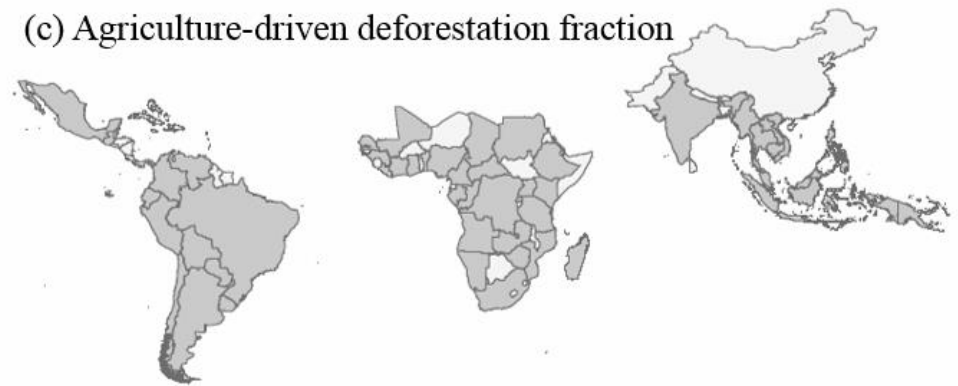

Figure 2.1. Number of datasets available per country per component (a), (b), and (c) for 2000-2005.

For each component $(x)$ (only $\mathrm{A}, \mathrm{CB}$, and $f_{\mathrm{AAgri}}$, as $f_{\mathrm{CBLU}}$, and $f_{\mathrm{CBAgri}}$ only had one available estimate) a best estimate $(\bar{x})$ was calculated using a weighted mean of available datasets. This weighted mean $(\bar{x})$ was calculated (Eq. 2.3), with weights $\left(w_{i}\right)$ being proportional to the inverse of the error variance $\left(\sigma_{\mathrm{i}}^{2}\right)$ for the $i$ th dataset (so more certain estimates have larger weights) (Eq. 2.4). Variance for the weighted mean $\left(\sigma_{\bar{x}}^{2}\right)$ is then calculated (Eq. 2.5).

$$
\begin{gathered}
\bar{x}=\frac{\sum_{i=1}^{n} x_{i} w_{i}}{\sum_{i=1}^{n} w_{i}} \\
w_{i}=\frac{1}{\sigma_{i}^{2}}
\end{gathered}
$$




$$
\sigma_{\bar{x}}^{2}=\frac{1}{\sum_{i=1}^{n} w_{i}}
$$

We produced time-series of A by starting with the best estimate of A at the country level calculated for the 2000-2005 period, since most data are available for this time period. The variable $\mathrm{A}$ is then reconstructed forwards and backwards from this starting point. In other words, estimates of A for other periods were only used to identify the relative difference to the time periods 2000-2005 and not their absolute values. The trend for the change between periods 1990-2000 and 2000-2005 was calculated from either or both FRA and RSS. The trend for the change between periods 2000-2005 and 2005-2010, and between 2005-2010 and 2010-2015 was calculated from either or both FRA and Hansen. Kim was not included in this part of the analysis, since few countries were covered in that study. Where two datasets were used, a weighted average was used, with weights (Eq. 2.4), relating to the uncertainty of each dataset. The mean of the weights for the two time periods relevant to the trend was used (i.e. trend between 2000-2005 and 2005-2010 would use a mean of the weights of the two time periods 2000-2005 and 2005-2010).

\subsubsection{Identifying and quantifying uncertainty}

The terms error and uncertainty, are often used interchangeably (Taylor 1997; Heuvelink 2005), and in this study both are used; error to represent the difference between an estimate and the true value, and uncertainty to represent a quantification of the distribution of error. If uncertainty information is not available, potential error sources contributing to uncertainty were identified and the magnitude of each source estimated for each input dataset. All datasets were assessed for the broad causes of uncertainty described by the IPCC (2006) (summarized in Table 2.3). 
Table 2.3. Error sources leading to uncertainty in the datasets

\begin{tabular}{|c|c|}
\hline Type of error & Explanation \\
\hline Lack of data & $\begin{array}{l}\text { Data do not cover the required time period, but data from } \\
\text { other time periods are available and were used to fill the gap } \\
\text { in data lacking time periods by the data provider, or in this } \\
\text { study. }\end{array}$ \\
\hline $\begin{array}{l}\text { Measurement-error: } \\
\text { data quality }\end{array}$ & $\begin{array}{l}\text { Data may be approximated based on limited information, for } \\
\text { example a country may lack the capacity to report forest area } \\
\text { accurately, as they lack recent satellite data, or do not have } \\
\text { recent forest inventories. Where visual interpretation of } \\
\text { satellite data is used to produce information, there is an error } \\
\text { associated with this process. }\end{array}$ \\
\hline $\begin{array}{l}\text { Measurement-error: } \\
\text { Adjustment for } \\
\text { thematic mismatch and } \\
\text { bias removal. }\end{array}$ & $\begin{array}{l}\text { Data were harmonized and the adjustment leads to error, as } \\
\text { the true value of the thematic mismatch is unknown. Also } \\
\text { error related to bias removal of } \mathrm{CB} \text {. }\end{array}$ \\
\hline $\begin{array}{l}\text { Statistical sampling } \\
\text { error }\end{array}$ & $\begin{array}{l}\text { The effect of the sampling size, and the variability between } \\
\text { sample units contribute to errors in the estimate. }\end{array}$ \\
\hline
\end{tabular}

For each country, the uncertainties identified in each dataset are defined for each time period (Table 2.4).

Table 2.4. Causes of error considered $(\checkmark)$ in each dataset

\begin{tabular}{|c|c|c|c|c|c|c|c|c|c|}
\hline $\begin{array}{l}\text { Data source / } \\
\text { type of error }\end{array}$ & $\underset{\alpha}{\alpha}$ & $\mathscr{\mathscr { A }}$ & 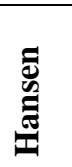 & 跣 & 要 & • & 䞤 & $\begin{array}{l}\vec{\Omega} \\
\text { ڤ̆ }\end{array}$ & 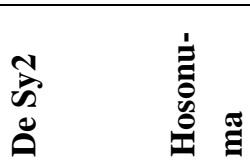 \\
\hline $\begin{array}{l}\text { Data } \\
\text { use/type }\end{array}$ & \multicolumn{4}{|c|}{$\begin{array}{c}\text { Deforestation } \\
\text { area }(A)\end{array}$} & \multicolumn{3}{|c|}{$\begin{array}{c}\text { Forest } \\
\text { biomass } \\
\text { (CB) }\end{array}$} & $\begin{array}{c}\text { Lost } \\
\text { biomass } \\
\text { fraction } \\
\left(f_{C B A g r i} /\right. \\
\left.f_{C B L U}\right) \\
\end{array}$ & $\begin{array}{c}\text { Agriculture- } \\
\text { driven } \\
\text { deforestation } \\
\text { fraction }\left(f_{A A g r i}\right)\end{array}$ \\
\hline Lack of data & $\sqrt{ }^{\mathrm{a}}$ & & & $\sqrt{ }^{\mathrm{cd}}$ & & & & & $\sqrt{ }^{\mathrm{cd}}$ \\
\hline $\begin{array}{l}\text { Measurement } \\
\text {-error: data } \\
\text { quality }\end{array}$ & $\checkmark$ & & $\checkmark$ & $\checkmark$ & & $\checkmark$ & $\checkmark$ & $\checkmark$ & $\checkmark$ \\
\hline
\end{tabular}




\begin{tabular}{|c|c|c|c|c|c|}
\hline $\begin{array}{l}\text { Measurement } \\
\text {-error: } \\
\text { adjustment } \\
\text { for thematic } \\
\text { mismatch } * *\end{array}$ & $\sqrt{*}$ & $\checkmark \quad \checkmark$ & $\begin{array}{llll}\checkmark & \checkmark & \checkmark\end{array}$ & & \\
\hline $\begin{array}{l}\text { Statistical } \\
\text { sampling } \\
\text { error }\end{array}$ & $\checkmark$ & & & $\checkmark$ & $\checkmark$ \\
\hline
\end{tabular}

* only 'net' data; $a=1990-2000 ; b=2000-2005 ; c=2005-2010 ; d=2010-2015$ (no letter indicates that uncertainty applies to all time periods). ** and bias adjustment in CB datasets

For many datasets, it was not possible to quantify uncertainty using data (e.g., with statistical approaches), so data from additional sources and expert judgement were used (Appendix S2). The overall uncertainty $\left(\sigma^{2}\right)$ was calculated by combining the uncertainties associated with each error source $\left(\sigma^{2}{ }_{i}\right)(i \ldots n)$ (Eq. 2.6). Where all terms (error sources) are assumed to additively contribute to total uncertainty.

$$
\sigma^{2}=\sigma_{i}^{2}+\sigma_{i i}^{2}+\ldots+\sigma_{n}^{2}
$$

Following guidelines from the IPCC, upper and lower estimates correspond to a 95\% confidence interval (CI), as a percent of the mean (IPCC 2006) (Eq. 2.7).

$$
C I \pm=\sqrt{\sigma^{2}} \cdot 1.96
$$

In case the estimate for the area of deforestation (A) was zero for a particular country, when calculating the confidence interval, A was substituted by the mean deforestation estimate from other (non-zero) time-periods in that dataset.

\subsubsection{Propagating uncertainty}

Once errors have been calculated for each dataset, they must be propagated to derive uncertainties for D and ADD. Errors associated with the inputs A, EF and ADF were assumed to be independent, normally distributed, and without bias. We used the exact equation for the variance of the product of three and four independent random variables (Goodman 1962) (Eqs. 2.8 and 2.9) to calculate the output variance $\left(\sigma^{2}\right)$. 


$$
\begin{gathered}
\sigma^{2}(D)=\sigma^{2}\left[A \cdot C B \cdot f_{C B L U}\right]=\left(\sigma^{2}(A)+\right. \\
\left.A^{2}\right) \cdot\left(\sigma^{2}(C B)+C B^{2}\right) \cdot\left(\sigma^{2}\left(f_{C B L U}\right)+f_{C B L U}^{2}\right)-A^{2} \cdot C B^{2} \cdot f_{C B L U}{ }^{2} \\
\sigma^{2}(A D D)=\sigma^{2}\left[A \cdot E F \cdot f_{C B A g r i} \cdot f_{A A g r i}\right]=\left(\sigma^{2}(A)+\right. \\
\left.A^{2}\right) \cdot\left(\sigma^{2}(C B)+C B^{2}\right) \cdot\left(\sigma^{2}\left(f_{C B A g r i}\right)+f_{C B A g r i}{ }^{2}\right) \cdot\left(\sigma^{2}\left(f_{A A g r i}\right)+f_{A A g r i}{ }^{2}\right)- \\
A^{2} \cdot C B^{2} \cdot f_{C B A g r i}{ }^{2} \cdot f_{A A g r i}{ }^{2}
\end{gathered}
$$

\subsubsection{Contribution of input uncertainty to uncertainty of the emissions estimate}

The contribution of each component was assessed as the reduction in the output variance when the corresponding input variance was set to zero. In other words, we recalculated (Eqs. 2.8 and 2.9) multiple times, setting for each recalculation one of $\sigma^{2}(\mathrm{~A}), \sigma^{2}(\mathrm{CB}), \sigma^{2}\left(\mathrm{f}_{\mathrm{CBLU}}\right)$ or $\sigma^{2}\left(f_{\mathrm{CBLU}}\right), \sigma^{2}\left(\mathrm{~F}_{\mathrm{AAgri}}\right)$ to zero. The lowest output variance for which the variance of that element $\left(\mathrm{A}, \mathrm{CB}, \mathrm{f}_{\mathrm{CBLU}}\right.$ or $\left.\mathrm{f}_{\mathrm{CB} \text { Agri }}, \mathrm{f}_{\mathrm{AAgri}}\right)$ is set to zero, is the one with the largest contribution to the uncertainty.

Some of the uncertainty estimates were based on expert judgment. We used a sensitivity analysis to explore how a different judgement would alter the uncertainty of the final value. Initial assumptions (section 2.2.1), were compared to three adjustments (Table 2.5). For each adjustment, the emissions are recalculated, and the change in emissions estimate uncertainty calculated.

Table 2.5. Parameters for the sensitivity analysis. The original expert judgement, and adjusted uncertainties as a $\%$ of the estimate) for several sources of uncertainty are shown.

\begin{tabular}{lllll}
\hline $\begin{array}{l}\text { Assumptions made for } \\
\text { errors / Type of error }\end{array}$ & $\begin{array}{l}\text { Original } \\
\text { expert } \\
\text { judgement } \\
\text { of }\end{array}$ & $\begin{array}{l}\text { Adjustment } \\
\mathbf{1} \text { (high } \\
\text { extrapolation } \\
\text { error) }\end{array}$ & $\begin{array}{l}\text { Adjustment 2 } \\
\text { (high visual } \\
\text { interpretation } \\
\text { error) }\end{array}$ & $\begin{array}{l}\text { Adjustment } \\
\mathbf{3} \text { (high } \\
\text { error from } \\
\text { adjustment } \\
\text { for bias or } \\
\text { thematic } \\
\text { mismatch) }\end{array}$ \\
\hline Lack of data & 15 & 30 & & 15 \\
\hline $\begin{array}{l}\text { Measurement-error: } \\
\text { visual interpretation } \\
\text { error }\end{array}$ & 5 & 5 & 15 & 5 \\
\hline
\end{tabular}




\begin{tabular}{lllll}
\hline $\begin{array}{l}\text { Measurement-error: } \\
\text { adjustment for thematic } \\
\text { mismatch or bias }\end{array}$ & 3 & 3 & 3 & 30 \\
\hline
\end{tabular}

\subsection{Results}

\subsubsection{Data selection}

We used all available datasets to calculate emissions giving higher weight to the most certain dataset available. Figure 2.2 shows the weight given to the datasets for each component, based on their uncertainty.

(a) FRA

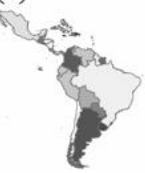

(b) RSS

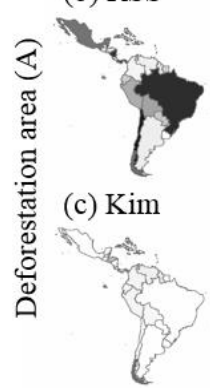

(d) Hansen

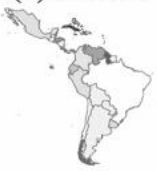

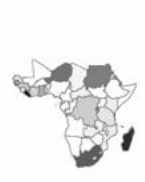
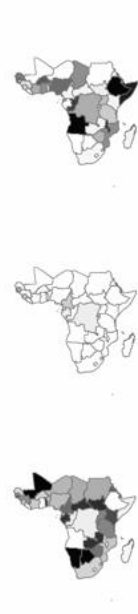
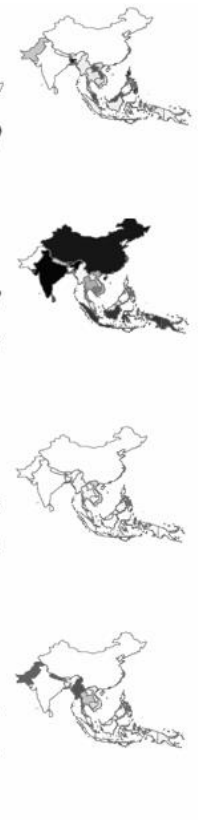

(e) Baccini

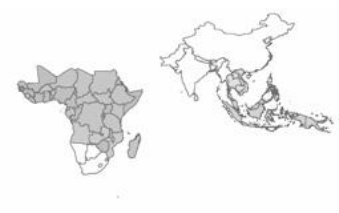

(f) Saatchi

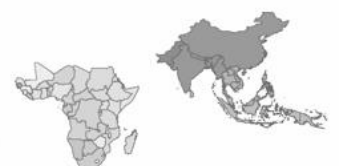

(g) Avitabile

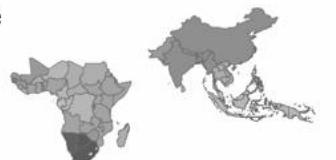

$100 \%$

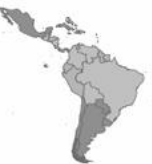

(h) Hosonuma

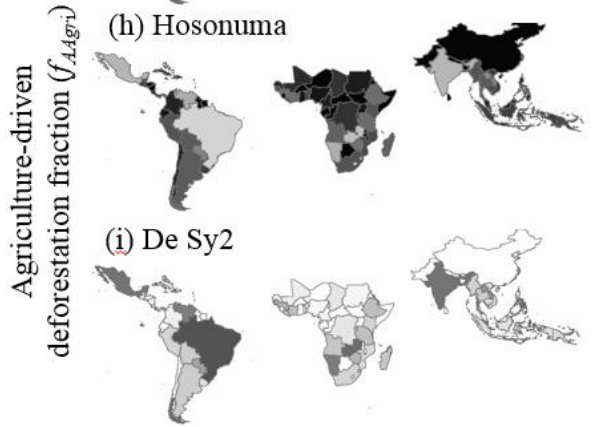

Figure 2.2. Contribution (\%) of (a) FRA, (b) RSS, (c) Kim, and (d) Hansen to estimates of A, and of (e) Baccini, (f) Saatchi, and (g) Avitabile to estimates of CB, and of (h) Hosonuma, and (i) De Sy2 to estimates of fAAgri in 2000-2005. 


\subsection{Results}

Figure 2.2 is driven by both the availability of data, and the weight of each dataset. For component A, RSS and FRA have the highest weighting for the most countries (33 each). Large countries (Brazil, India, China) tend to have a higher weighting for the RSS data, since they have a larger number of sample units, which increases the certainty of the data. The weighting of the RSS data is also driven by the variability in the proportion of deforestation in each sample within a country. Countries which have better data (indicated by higher capacities, or access to better data and support), for example the majority of countries in South and Central America, have a higher weighting for the FRA data. In Africa, more countries (20 out of 43 countries) have the highest weighting for the Hansen data. These tend to be countries with lower capacity, and relatively few RSS sample units. Kim consistently gets low weightings, as although the uncertainties in terms of the CI when expressed as a percent of the estimation are the same as Hansen, the estimates tend to be higher, so variances are also higher. For the biomass in forests, these datasets generally have a more equal weighting, however the Avitabile dataset is more certain, and carries the highest weight in 85 of the 91 countries. For the remaining 6 countries, Saatchi has the highest weight. For the fraction of deforestation which is driven by agriculture, in 43 out of 91 countries only the Hosonuma data are available. For the remaining countries, most (42 of 48) have a higher weight for the Hosonuma data. The countries where De Sy2 has a higher weight are larger countries, which as a result have more sample units (Brazil, India, Mexico, Namibia, Venezuela and Zambia).

\subsubsection{Trend in area of deforestation}

The area of deforestation is dynamic and drives most of the trend of the emissions calculations. Between the first two time periods (1990-2000 and 2000-2005), RSS more frequently has the highest weighting. The last two trends (between the last three periods) show a more even distribution, where FRA and Hansen are almost equally likely to contribute the most to the estimate of deforestation. However FRA tends to dominate in Latin America and Asia, while Hansen dominates in Africa, with the exception of some countries including Democratic Republic of Congo, South Africa, and Madagascar most notably (Figure 2.3, Table 2.6). 
$1990-2000$ to $2000-2005$

(a) FRA
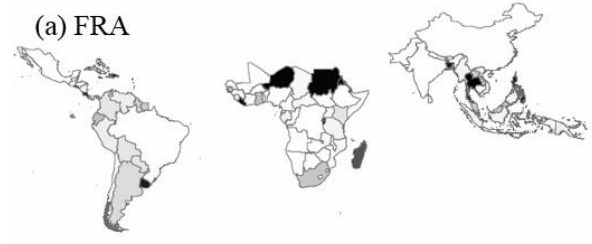

(d) RSS
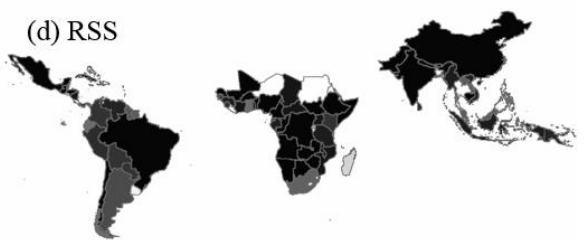

2000-2005 to $2005-2010$

(b) FRA
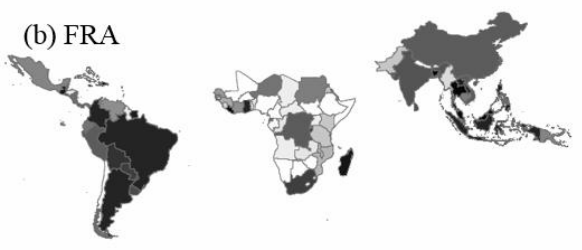

(e) Hansen
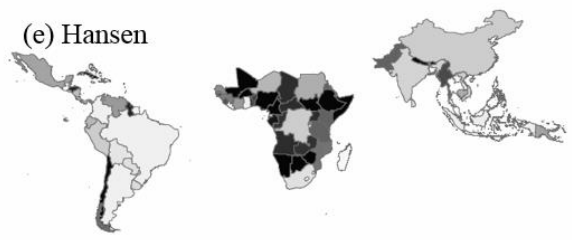

2005-2010 to 2010-2015

(c) FRA

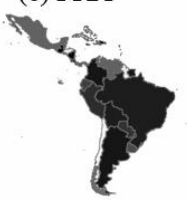

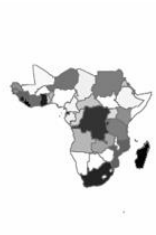

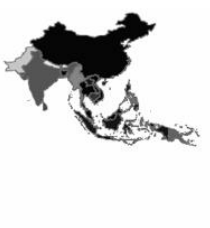

(f) Hansen
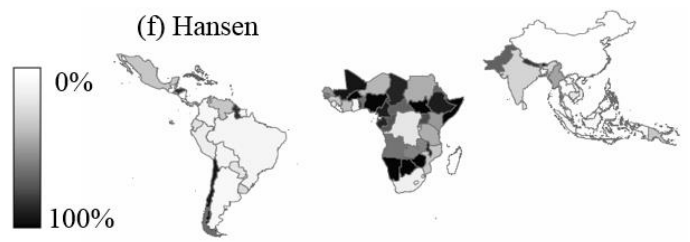

Figure 2.3. Contribution (\%) of FRA to the trend of deforestation area (A) between (a) 19902000 and 2000-2005, (b) 2000-2005 and 2005-2010, and (c) 2005-2010 and 2010-2015, RSS to the trend between (d) 1990-2000 and 2000-2005, and Hansen to the trend between (e) 2000-2005 and 2005-2010, and (f) 2005-2010 and 2010-2015.

Table 2.6. The number of countries whose trend of deforestation area (A) was derived from each dataset or combination of datasets.

\begin{tabular}{lccc}
\hline & $\begin{array}{l}\mathbf{1 9 9 0 - 2 0 0 0} \text { and } \\
\mathbf{2 0 0 0 - 2 0 0 5}\end{array}$ & $\begin{array}{l}\mathbf{2 0 0 0 - 2 0 0 5} \text { and } \\
\mathbf{2 0 0 0 - 2 0 0 5}\end{array}$ & $\begin{array}{c}\mathbf{2 0 0 5 - 2 0 1 0} \text { and } \\
\mathbf{2 0 1 0 - 2 0 1 5}\end{array}$ \\
\cline { 2 - 4 } & \multicolumn{4}{c}{ Datasets used to derive the trends } \\
\hline FRA & 21 & 5 & 4 \\
RSS & 1 & - & - \\
FRA \& RSS & 69 & - & - \\
Hansen & - & 1 & 1 \\
FRA \& Hansen & - & 85 & 86 \\
\hline & Dataset with the highest contribution to the trend \\
\hline FRA & 27 & 46 & 53 \\
RSS & 64 & - & - \\
Hansen & - & 45 & 38 \\
\hline
\end{tabular}




\subsection{Results}

The trends for the same time period derived from two different datasets (either FRA \& RSS or FRA \& Hansen) can disagree in the direction or the magnitude of the change. This difference can be relatively large (mean absolute trend difference is 1.47), with the FRA and RSS being on average more different (absolute difference of 1.9 between the periods 19902000 and 2000-2005), and FRA and Hansen being more similar. In many cases, the trend direction is the same for both datasets, and the trend between the last time periods (20052010 and 2010-2015) has the most agreement from the contributing datasets, with only $16 \%$ of countries having conflicting trends. For the trend between the first two time periods (19902000 and 2000-2005) 28\% of countries have conflicting trends from FRA and RSS.

A number of countries in Asia have the highest agriculture-driven deforestation between 1990 and 2005. In Africa, the majority of countries had their highest period of agriculturedriven deforestation in 2010-2015 (Figure 2.4).
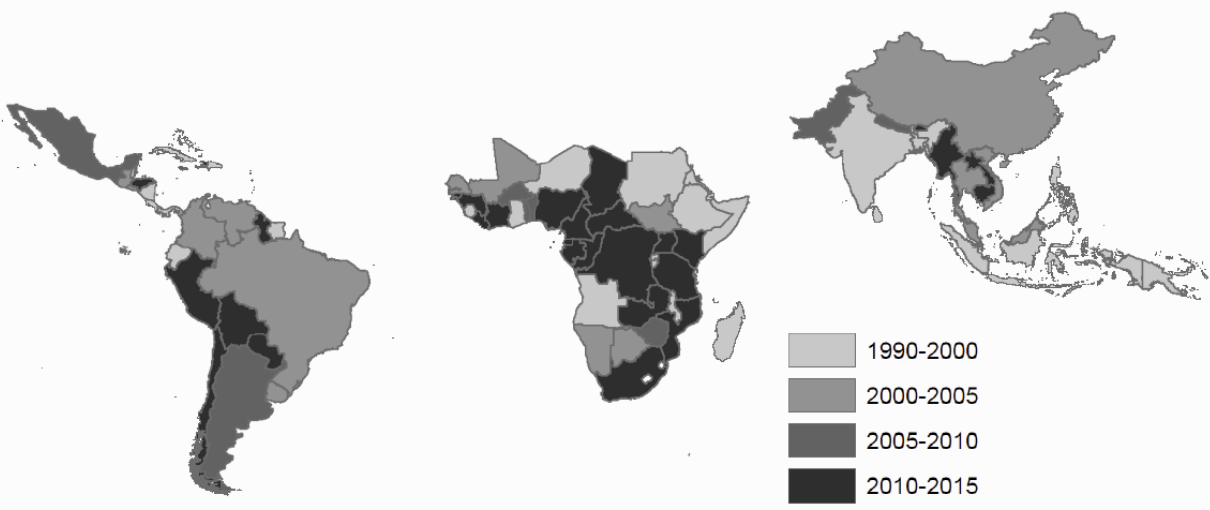

Figure 2.4. Period (years) of highest agriculture-driven deforestation.

\subsubsection{Emissions from deforestation and agriculture-driven deforestation}

Latin America is the greatest contributor to global emissions from deforestation and agriculture-driven deforestation, while Africa is the lowest but shows a continual growth in emissions (Figure 2.5). In Africa, the highest emission rates (412 $\pm 75 \mathrm{Mt} \mathrm{CO}_{2} \mathrm{yr}^{-1}$ ) occur in the 2010-2015 period, whereas for Asia and Latin America the emissions peaked during 2000-2005 (971 $\left.\pm 148 \mathrm{Mt} \mathrm{CO}_{2} \mathrm{yr}^{-1}\right)$ and decreased afterwards. Overall, the highest annual emission rates $\left(1792 \pm 133 \mathrm{Mt} \mathrm{CO}_{2} \mathrm{yr}^{-1}\right)$ occurred in 2005-2010, with the lowest in 1990-2000 $\left(1511 \pm 174 \mathrm{Mt} \mathrm{CO}_{2} \mathrm{yr}^{-1}\right)$. Although Brazil's emissions have declined since 2005, these emissions still dominate in the region. Emissions from agriculture-driven deforestation are 
on average $72 \%$ of emissions from all deforestation. This is highest in Latin America (78\%), and lowest in Africa (62\%). In Asia it is 67\%. The remainder of Latin America has the highest proportion of agriculture-driven deforestation (94\%), and Indonesia has the lowest (52\%).

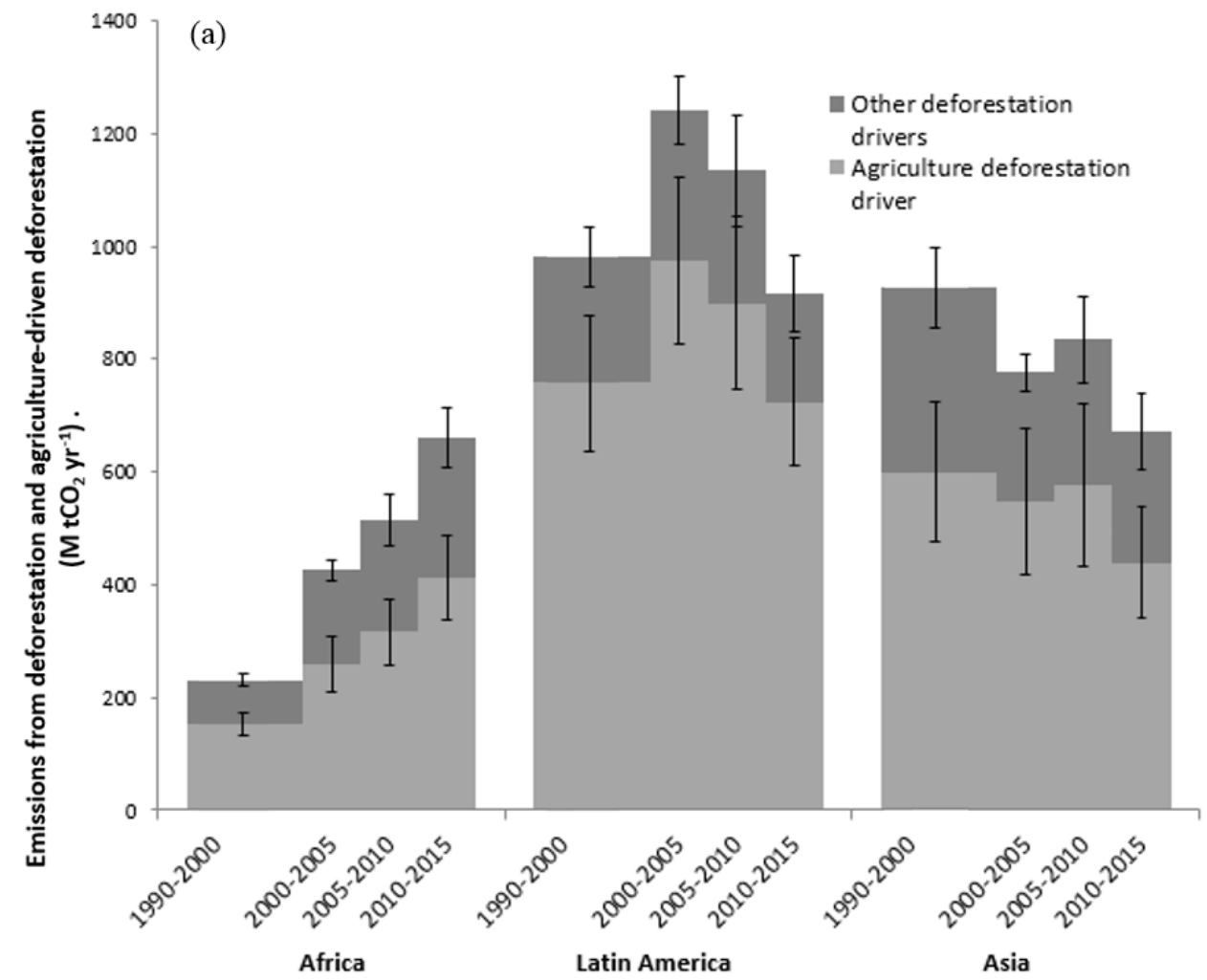

This figure is continued on next page. 


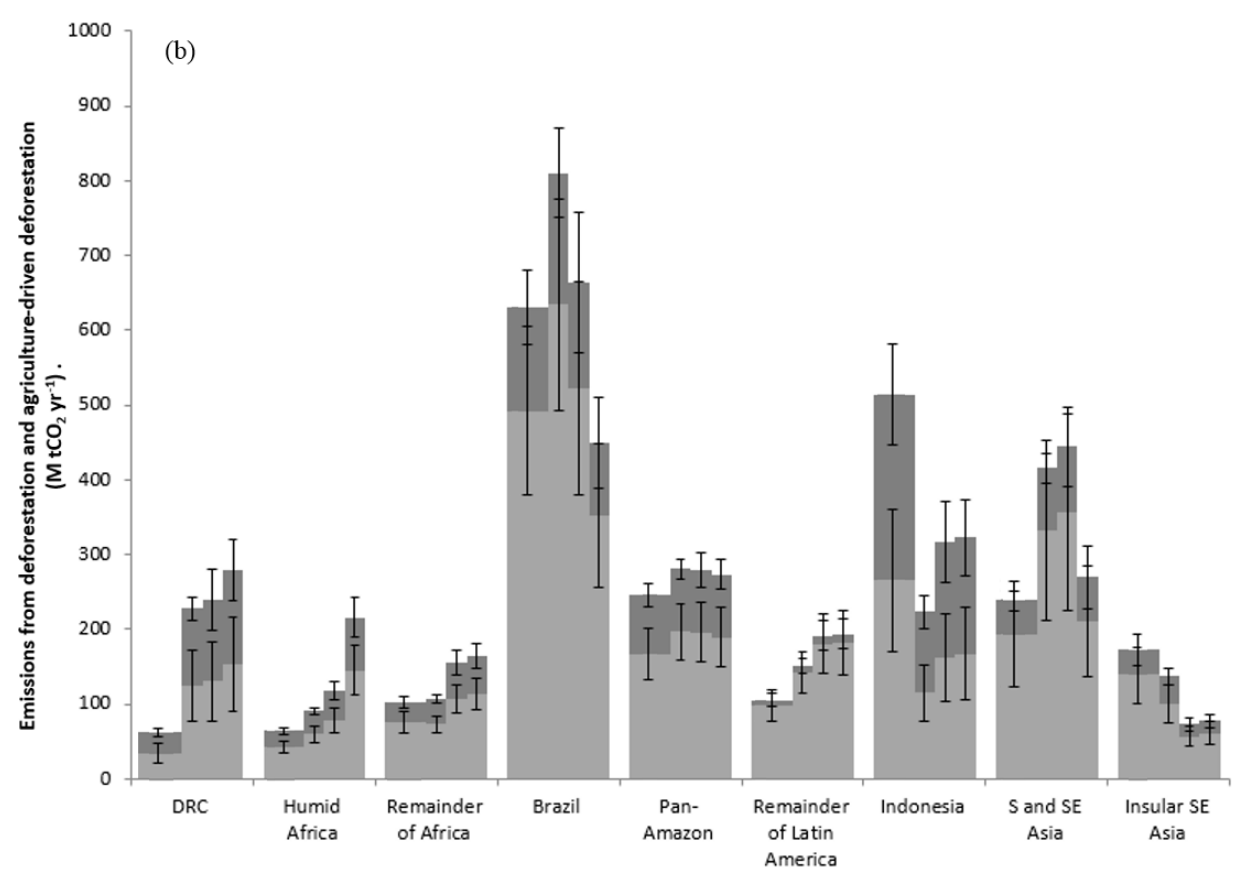

Figure 2.5. Annual emissions from agriculture-driven deforestation $\left(\mathrm{M} \mathrm{tCO}_{2}\right)$, in (a) Africa, Latin America and Asia and (b) a breakdown of those groups to Democratic Republic of the Congo (DRC), Humid Tropical Africa, The remainder of Sub-Saharan Africa, Brazil, PanAmazon, The remainder of Latin America, Indonesia, Mainland South and South-east Asia, Insular Southeast Asia. Error bars represent the 95\% confidence intervals (or range which represents the uncertainty around the estimate) for emissions from agriculture-driven deforestation and total deforestation. The regions for are defined by Tyukavina et al., (2015).

\subsubsection{Uncertainties}

The uncertainty of the emissions estimates of agriculture-driven deforestation range between \pm 24.9 to $\pm 283.1 \%$ of the estimate, with a mean of $\pm 62.4 \%$ per country (Figure 2.6 ). The uncertainty for estimates of emissions from deforestation range from \pm 10.7 to $\pm 260.9 \%$, with a mean of $\pm 29 \%$. At the country level, typically Latin America has lower uncertainties than Africa or Asia, however the highly forested countries in Asia and Africa (for example Indonesia and Democratic Republic of Congo) also have lower uncertainties. Uncertainties for agriculture-driven deforestation emissions are higher than uncertainties for deforestation emissions (Figure 2.5). When country uncertainties are aggregated, uncertainties for emissions are higher in Asia $( \pm 22.5 \%$ for $\mathrm{ADD}$ and $\pm 7.7 \%$ for $\mathrm{D})$, followed by Africa 
( $\pm 16.7 \%$ for $\mathrm{ADD}$ and $\pm 6.1 \%$ for $\mathrm{D}$ ), and Latin America $( \pm 15.9 \%$ for ADD and $\pm 6.1 \%$ for D). Uncertainties for global aggregates are $\pm 11.4 \%$ for ADD and $\pm 4.3 \%$ for D.
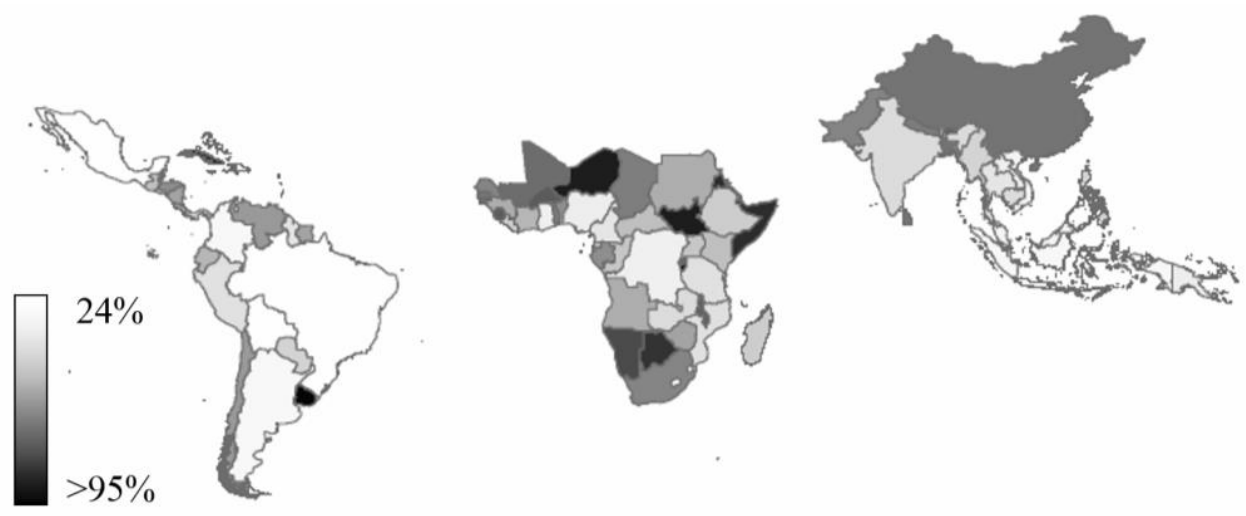

Figure 2.6. Uncertainty ( $\pm \%$, which represents a $95 \% \mathrm{CI}$ ) of estimates of emissions from agriculture-driven deforestation. The colour scale is in quantiles (equal frequency of observations per group, in order to better show the differences between countries).

For estimates of emissions from deforestation, $\mathrm{A}$ is more frequently the largest contributor to the uncertainty, and $f_{\mathrm{CBLU}}$ is more frequently the smallest contributor. In the case of emissions from agriculture-driven deforestation, $\mathrm{f}_{\mathrm{AAgri}}$ is more frequently the largest contributor to the uncertainty, and CB is more frequently the smallest contributor. This pattern is clear in all continents, with some exceptions, including a number of countries in Latin America, where the forest biomass fraction and lost biomass fraction contribute to a relatively large amount of the uncertainty (Figure 2.7). 
Deforestation

(a) Area of deforestation

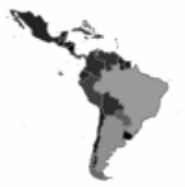

(b) Forest biomass

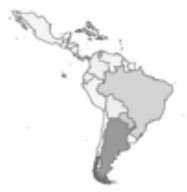

(c) Remaining biomass fraction
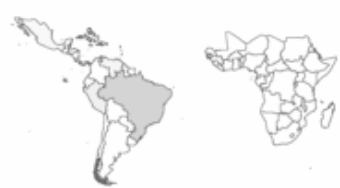

Agriculture-driven deforestation

(d) Area of deforestation
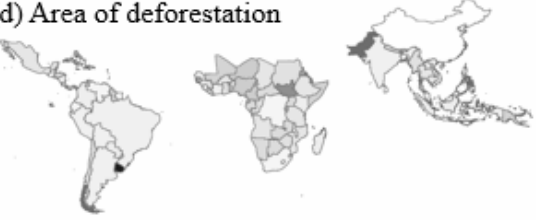

(e) Forest biomass
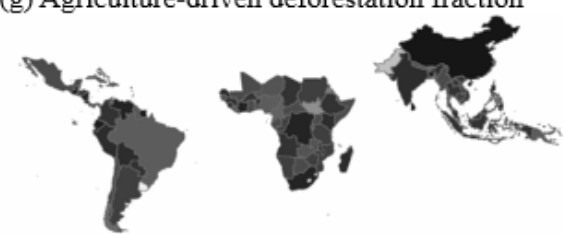
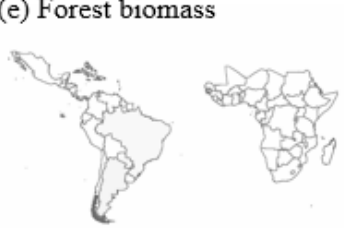

(f) Remaining biomass fraction
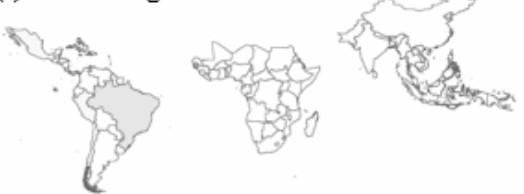

(g) Agriculture-driven deforestation fraction
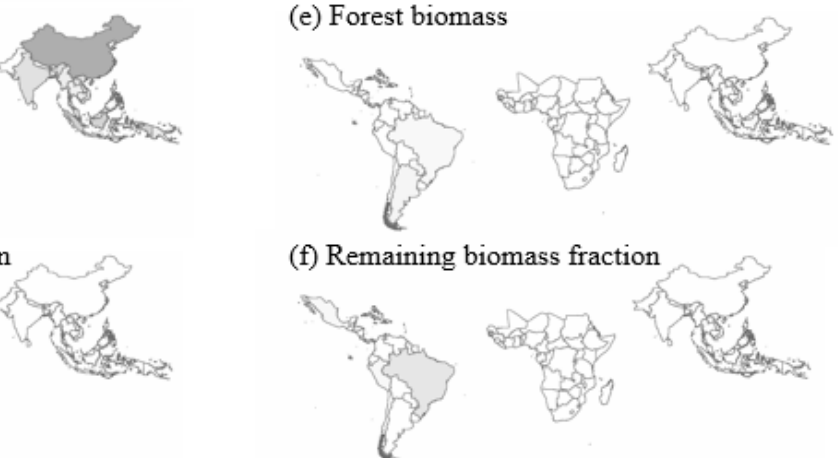

$\prod_{100 \%}^{0 \%}$

Figure 2.7. Contribution (\%) to uncertainty of estimates of emissions from deforestation (D) (left side of figure) from a) $\mathrm{A}, \mathrm{b}$ ) $\mathrm{CB}$, c) $\mathrm{f}_{\mathrm{CBLU}}$, and emissions from agriculture-driven deforestation (ADD) (right side of figure) from d) $A, e) C B, f$ ) $f_{C B A g r i}$, and $g$ ) $f_{\text {AAgri }}$. The darker colours therefore represent the main sources of uncertainty in the two emissions estimates.

Sensitivity analysis was implemented to determine how changes to the uncertainty estimates for each input variable influence the uncertainty of the emissions estimates. Increasing the estimated uncertainty associated with the adjustment for the thematic mismatch or bias adjustment leads to the largest change in the uncertainty of the emissions estimate, and increasing the extrapolation error leads to the smallest change to the uncertainty. A 10 fold increase in the uncertainty related to the adjustment of the thematic mismatch or bias adjustment leads to a $\pm 17.74 \%$ change in the final uncertainty estimate, which accounts for $63.73 \%$ of the original uncertainty for emissions from agriculture-deforestation. Doubling the extrapolation error from $\pm 15 \%$ to $\pm 30 \%$ leads to the smallest change in uncertainty for deforestation emissions; only $\pm 0.37 \%$, which accounts for $1.5 \%$ of the original uncertainty estimate (Appendix S2). 


\subsection{Discussion}

We firstly compare the results of this study to the results of other studies. Then we discuss several implications from this study.

\section{Deforestation estimates}

In general, our results for area of forest loss are similar (73 - 108\%) to other published data (see Appendix S3 for details). All the studies used in the comparison use a land cover definition, and thus report forest losses in land where there is no change in use, which would not be included in our study. Our emissions from deforestation are 52-75\% lower than those from other studies because we take into account the new biomass which replaces forest biomass, or the biomass from the forest which remains on the land, whereas other studies assume that all the biomass is lost following deforestation. This makes a large difference in Asia, where due to tree crops often replacing forests, the biomass lost is replaced by more new biomass than in other land use conversions. The definition of forests can also explain some of the differences. Tyukavina et al. (2015) have a higher canopy cover threshold (25\%), while Harris et al. (2012) look at the removal of any forest cover. This particular difference would lead to an underestimation from our study in comparison to Tyukavina et al. (2015), and an overestimation in comparison to Harris et al. (2012). Achard et al. (2014) distinguishes between forests and tree cover mosaics ( $>70 \%$ and 30-70\% tree cover respectively), and also 'other wooded land' (OWL). OWL is defined as "all other woody vegetation (height $<5 \mathrm{~m}$ ), including shrubs and forest regrowth". OWL is also likely to be found in dry forests, which are difficult to measure, and there is more disagreement over their extent (Bastin et al. 2017). Data from Achard et al. (2014) used for the comparison could include OWL which is not included in the definition of forests in this study, so we would expect this to lead to higher results from Achard et al. (2014). The results for South and Central America are more in agreement in these two studies than those for Africa and Asia. Proportionately, according to Achard et al. (2014) there is more OWL in Africa: 58\% of the total forest in 2010, in comparison to South and Central America and South East Asia, which have 18\% and 31\%, so this could explain the differences.

\section{Data selection for emissions estimates}

The best combination of data for emissions estimates differed from country to country (Figure 2.2 and Figure 2.3). Input data were weighted according to their uncertainty, and these weights can guide decision makers on data selection in similar contexts to this study. It should also be noted that in addition to the uncertainty of the dataset influencing the weight, the magnitude of the estimate also influences the weight. For example, the Kim dataset 


\subsection{Discussion}

consistently had lower weights than Hansen, even though the two datasets had similar percent confidence intervals, due to the higher estimates of Kim. For biomass, the Avitabile dataset is most often selected, unless it is not available, where Saatchi is selected. However all datasets have similar uncertainties so could all be considered useful. For the agriculturedriver fraction, the results of this study suggest that only large countries should use De Sy2 above the Hosonuma data. We however suggest that an individual examination of both datasets at the national level may lead to different conclusions about the reliability of the datasets. In fact, both Hosonuma and De Sy2 were found to have large uncertainties.

\section{Reducing emissions from agriculture-driven deforestation}

The urgent need to limit global temperature increases below $2^{\circ} \mathrm{C}$ will require actions to reduce all emissions sources, and as a major source of deforestation emissions, reducing agricultural expansion into forests should be considered as a mitigation priority. Latin America currently has the largest emissions from the regions in this study, however emissions have been reducing over the period of the study (Figure 2.4 and Figure 2.5). Africa has seen a consistent increase in emissions between 1990 and 2015, as predicted by past studies (Barnes 1990). Countries or regions with the largest increase in emissions could be targeted for mitigation actions, for example DR Congo which saw a large increase between 1990 and 2005, and Humid Africa which saw a large increase between 2005 and 2015. In order to address agriculture-driven deforestation, targeted interventions should be developed which address specific agricultural activities. In these cases, interventions in the agriculture sector to mitigate emissions from agriculture-driven deforestation can be effective. Areas with either a yield gap which can be reduced, or with available degraded land which can potentially be rehabilitated have been highlighted for their mitigation potential (Carter et al. 2015). There is some debate on the conditions under which these agricultural interventions will be successful (see for example Angelsen \& Kaimowitz 2001), however implementation of forest protection activities such as REDD+ are highlighted as being essential to ensure that forests are protected (Mertz \& Mertens 2017). Although in all the countries included in this study, agriculture was found to be the largest driver of deforestation, it could be the case that in the future other drivers become more important, and we acknowledge the need to monitor all drivers. In this paper we do not address emissions related to other carbon pools (such as soil), or indirect emissions for example those related to the life cycle of agricultural products (which may lead to further deforestation). These will result in additional emissions above those considered in this study. Additionally we do not include emissions from forest degradation, which may be significant as estimated by (Baccini et al. 2017), and can also result from agriculture. 


\section{Limitations of this study}

Estimates of the trend in area of deforestation were provided by two datasets for each time period, and were in some cases very different (section 2.3.2). We used a weighted mean to prioritize the most certain estimate, however in the case that the two datasets predict an opposite trend (one increasing and one decreasing), the weighted average will thus produce a trend which is closer to 1 , which may not reflect the actual trend. This effect will be most seen in the first time period, where there is more disagreement between datasets. Another challenge in this study was the production of comparable uncertainty estimates. Using uncertainties from the data providers themselves, could lead to better results. The current method relies on assumptions about the uncertainties related to the datasets, as many were lacking information or had uncertainty information which could not be used in this study. Our research estimated uncertainties which aimed to capture all the sources of error for each dataset, and it could be that errors exist which were not included in the study. In some cases, expert judgement was used to quantify the uncertainty, which may be erroneous. However sensitivity analysis confirmed (section 2.3.4) that in many cases the change in uncertainty was not large following a change in the assumptions which were based on expert judgement. Hence, if our uncertainty estimates based on expert judgement are incorrect, this will not substantially influence the overall uncertainty estimates. Additional uncertainties exist in the ancillary data are used to harmonize the datasets (due to thematic mismatch) but we chose not to include those uncertainties, as they are unknown, although some error is assumed to be included during harmonization. Future studies could explore this further. Lack of available data also limited the study. Only the area dataset was considered to be dynamic, with the remaining datasets assumed to be constant over time. Because there is not available data over time for emissions factors or drivers of deforestation, we were not able to capture this dynamic in our end results. This means that the trend in emissions is determined mainly by the area data, and in reality it may be influenced by changes over time in the other inputs, for example emissions factors.

\section{Reducing uncertainties in estimates of emissions from agriculture-driven deforestation}

Uncertainties associated with our estimates of D and ADD are in some cases very high at the country level (for example Uruguay is $\pm 182 \%$ for ADD), although the average for ADD is much lower $( \pm 62 \%$ ) (Figure 2.6). Large uncertainties are in line with findings in Houghton et al. (2012), and Roman-Cuesta et al. (2016) who found that uncertainties from forest loss contribute to $98 \%$ of the uncertainty of AFOLU emissions, while only contributing to $69 \%$ of the emissions. The authors recommend that uncertainties are reported in future datasets (to increase transparency), and that improvements in datasets (increased certainty) should be pursued. Since area data and agriculture-driver factors are the least confident, improvement in the uncertainties related to these estimates will also provide the greatest reductions in 
uncertainties of emissions estimates. There are two ways to address these uncertainties when reporting for mechanisms such as REDD+. Either the upstream uncertainties are reduced by improving the input datasets, or the emissions estimates are adjusted downstream, by discounting or reducing the estimates (a conservative approach) to avoid overestimating emissions reductions (Pelletier et al. 2015). The findings of this study suggest that the upstream adjustments should be made to avoid having to implement downstream adjustments, which reflect negatively on the credibility of the mechanism.

\section{Acknowledgements}

This research is part of CIFOR's Global Comparative Study on REDD+ (www.cifor.org/gcs). The funding partners that have supported this research include the Norwegian Agency for Development Cooperation (Norad) [Grant no. QZA-16/0110 No. 1500551] and the International Climate Initiative (IKI) of the German Federal Ministry for the Environment, Nature Conservation, Building and Nuclear Safety (BMUB) [Grant no. KI II 7 - 42206-6/75], and the CGIAR Research Program on Forests, Trees and Agroforestry (CRP-FTA), and Climate Change Agriculture and Food Security (CCAFS) with financial support from the CGIAR Fund Donors. The authors thank Louis Verchot for his contribution to the inception of the paper and his helpful insights on the topic; Mathieu Decuyper, Ben Devries and Johannes Reiche for technical assistance; and Erika Romijn for providing data. The authors thank two anonymous reviewers for their comments which have substantially improved the manuscript. 


\section{Mitigation of agricultural emissions: forest land-sparing}

This chapter is based on: S Carter, M Herold, MC Rufino, K Neumann, L Kooistra, L Verchot. 2015. Mitigation of agriculture emissions in the tropics: comparing forest landsparing options at the national level. Biogeosciences 12, 4809-4825.

Supplementary materials to this chapter can be found in the online publication. 


\section{Abstract}

Emissions from agriculture-driven deforestation are of global concern, but forest landsparing interventions such as agricultural intensification and utilization of available nonforest land offer opportunities for mitigation. In many tropical countries, where agriculture is the major driver of deforestation, interventions in the agriculture sector could reduce deforestation emissions as well as reducing emissions in the agriculture sector. Our study uses a novel approach to quantify agriculture-driven deforestation and associated emissions in the tropics between 2000 and 2010. Emissions from agriculture-driven deforestation in the tropics (97 countries) are $4.3 \mathrm{Gt} \mathrm{CO}_{2} \mathrm{e} \mathrm{y}^{-1}$. We investigate the national potential to mitigate these emissions through forest land-sparing interventions, which can potentially be implemented under REDD+. We consider intensification and utilization of available nonforested land as forest land-sparing opportunities since they avoid the expansion of agriculture into forested land. In addition, we assess the potential to reduce agriculture emissions on existing agriculture land. The use of a systematic framework demonstrates the selection of mitigation interventions by considering sequentially the level of emissions, mitigation potential of various interventions, enabling environment and associated risks to livelihoods at the national level. Our results show that considering only countries with high emissions from agriculture-driven deforestation, with potential for forest-sparing interventions and a good enabling environment (e.g. effective governance or engagement in REDD+), there is a potential to mitigate $1.3 \mathrm{Gt} \mathrm{CO}_{2} \mathrm{e} \mathrm{y}^{-1}$ (20 countries of 78 with sufficient data). For countries where we identify agriculture emissions as a priority for mitigation, up to $1 \mathrm{Gt} \mathrm{CO}_{2} \mathrm{e} \mathrm{y}^{-1}$ could be reduced from the agriculture sector including livestock. Risks to livelihoods from implementing interventions based on national level data call for detailed investigation at the local level to inform decisions on mitigation interventions. Three casestudies demonstrate the use of the analytical framework. The inherent link between the agriculture and forestry sectors due to competition for land suggests that these sectors cannot be considered independently. Our findings highlight the need to include the forest and the agricultural sector in the decision making process to mitigate deforestation.

\subsection{Introduction}

The agriculture and forestry sectors, including deforestation and forest degradation, are major contributors of global greenhouse gas (GHG) emissions, accounting for approximately half of low income countries' total GHG emission budgets (Edenhofer et al. 2014). Estimates

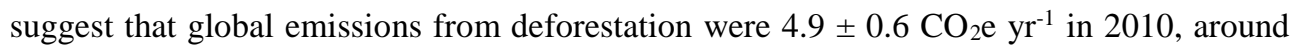
$8 \%$ of anthropogenic GHG emissions (Tubiello et al. 2015). According to Hosonuma et al. (2012), in 13 countries agricultural expansion is the only driver of deforestation. Natural 
vegetation is at a higher risk than other land cover types, and a quarter is under threat from expansion of agriculture (Creed et al. 2010). Between 1980 and 2000, 83\% of agricultural expansion in the tropics occurred in forested land causing major environmental impacts including loss of carbon stocks and habitats (Gibbs et al. 2010). Agriculture itself has been an increasing source of emissions, growing at around $1 \%$ annually since 1990 to $5.4 \mathrm{Gt}_{\mathrm{CO}_{2} \mathrm{e}}$ $\mathrm{yr}^{-1}$ in 2012 (Tubiello et al. 2015).

Land-sparing interventions are supposed to increase the output on agricultural land reducing the need to increase agricultural areas promoting deforestation (Stevenson et al. 2013). Agricultural intensification which reduces the gap between potential yield and actual yield (Neumann et al. 2010; van Ittersum et al. 2013; Wilkes et al. 2013; Byerlee et al. 2014) can contribute to land sparing. The potential yield is the maximum yield given the biophysical conditions - with the absence of any limitations (Neumann et al. 2010). The agricultural yield gap can be reduced by interventions into the farming system for example by altering the timing or method of applying agricultural inputs, or increasing cropping frequency. Depending on the introduced change, the intervention will require one or a combination of an increase in labour, capital, technology or a methodological change. Yield gap data provides information on where feasible improvements can lead to increased production (Neumann et al. 2010). The tropics, where yields are typically lower than in temperate regions (West et al. 2010), are often characterized by a high yield gap.

Increasing agricultural production on underutilized lands or introducing production on nonforested land provides another opportunity to spare forests. There is generally a consensus that non-utilized, non-forested land is available for agriculture although there is active debate as to the extent (Eitelberg et al. 2015). Available land includes land with potential for intensification, for example degraded grasslands or abandoned cropland.

These interventions can be potentially included in REDD+ strategies and when implemented with climate smart agriculture (CSA) principles, can reduce emissions from agriculture as well as avoiding deforestation (FAO 2013). There is also a potential for community benefits to accompany agricultural expansion and developments, however they can also negatively affect local communities. Access to land can be compromised, and interventions may not offer equitable distribution of benefits to stakeholders, excluding vulnerable communities (Mbow 2010).

REDD+ is a results-based financing mechanism which funds activities to reduce emissions from deforestation and forest degradation while promoting forest conservation, sustainable management of forests and enhancing carbon stocks (UNFCCC 2013). Interventions in the agriculture sector, for example agroforestry, are considered promising options to reduce emissions under REDD+ (Grieg-Gran 2010), and by 2012, 42 national governments 


\subsection{Introduction}

considered agriculture in their REDD+ readiness strategies (Kissinger et al. 2012). However, many countries do not establish REDD+ interventions which address the drivers of deforestation, including agricultural expansion (Salvini et al. 2014).

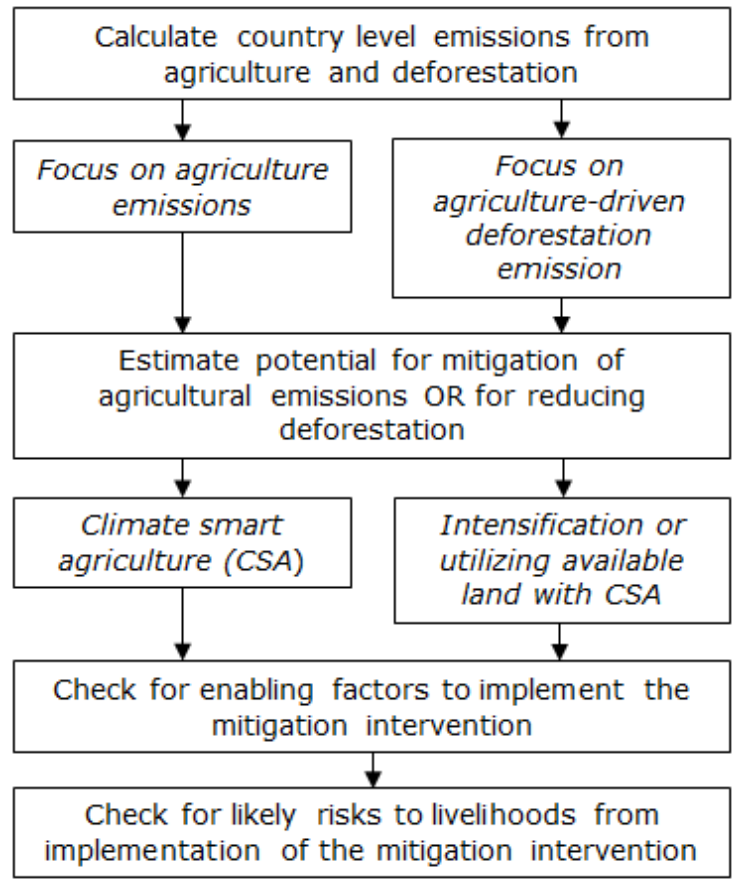

Figure 3.1. National-scale assessment of the need, potential and risk of implementing interventions to reduce emissions from agriculture and agricultural driven deforestation.

To evaluate land-sparing interventions, our study systematically compares countries to show which have the largest potential to mitigate GHG emissions from agriculture-driven deforestation, and from agriculture (Figure 3.1). Firstly, we quantify emissions from agriculture-driven deforestation and agriculture in each country. Secondly, we pose the question whether closing the yield gap and utilizing available land could be potentially incorporated into the REDD+ context to address these emissions. In addition, we assess the potential for reducing emissions directly from existing agricultural land using CSA. We indicate countries which are likely to require increased support to implement mitigation initiatives by assessing their capacity to implement interventions. Lastly, we assess risks to livelihoods from the implementation of interventions. Mitigation pathways in three selected countries are explored in depth to illustrate the applications of this framework and to 
demonstrate that decisions made using the framework at the global level are relevant for the country level.

\subsection{Data and methodology}

This study considered all tropical (within the tropics, or with a tropical biome) (Olson et al. 2001) non-annex 1 countries or countries who are engaged in REDD+. Not all had data available to assess the mitigation potential (Figure 3.1), leaving 78 countries which represent $85 \%$ of the forest area in the tropics for the study. However, 97 countries had data available to calculate emissions from agriculture-driven deforestation and of those, all but two had data on emissions from agriculture ( $\mathrm{n}=95$ for total emissions), so these results are presented (in Section 3.3.1).

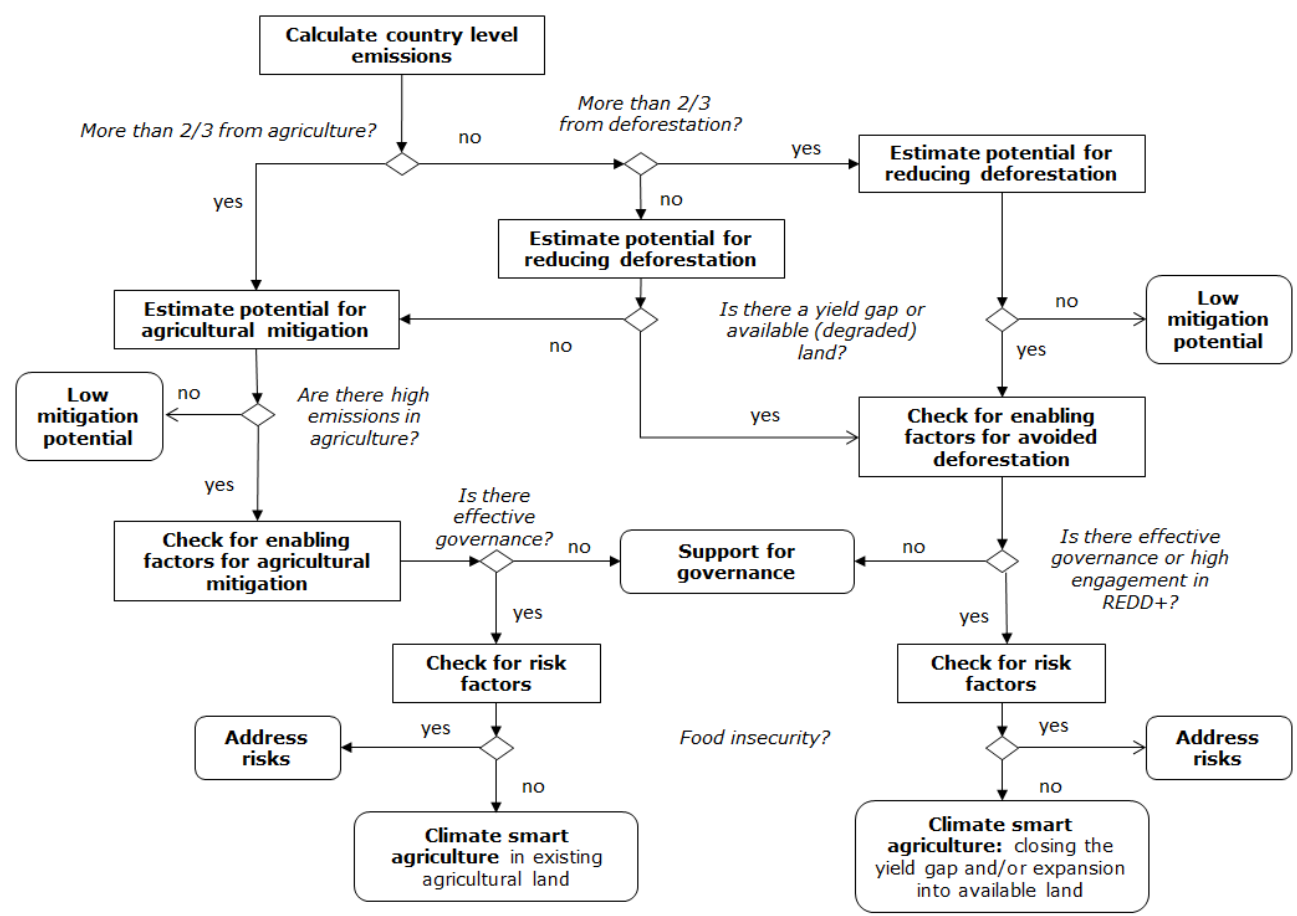

Figure 3.2. Decision tree to identify priority areas for mitigation interventions. Data required for decision making are described in Table 3.1.

We developed a framework to assess the current potential of each country to mitigate GHG emissions from agriculture-driven deforestation and agricultural activities (Figure 3.2). We looked at the potential for mitigation through sparing land by (1) closing the yield gap and 
(2) by utilising non-forested land suitable for agricultural activities. It is possible that synergies occur between closing the yield gap and utilizing available land that can provide benefits when both mitigation approaches are implemented within the same country. However, in this study we assume there is potential to mitigate agriculture-driven deforestation when either one of the two approaches is feasible, and we do not consider any additional mitigation benefits in countries with potential for both approaches. Where agricultural emissions are largest, we estimated the potential to mitigate these emissions. For countries with a high potential for mitigation, we assessed the potential for a mitigation intervention to be implemented successfully, by considering constraints to effective implementation (poor governance, lack of engagement in REDD+). Risks to livelihoods as a result of interventions (indicated by food insecurity) were then considered. Countries were divided into three groups using each data source, and groups were defined by dividing the data at the $1 / 3^{\text {rd }}$ and $2 / 3^{\text {rd }}$ percentiles. Percentiles were calculated accounting for all the countries with available data for that data source within the tropics (Table 3.1).

Table 3.1. Data sources for the identification of target countries for mitigation interventions. Categories are selected by thresholds at the $1 / 3^{\text {rd }}$ and $2 / 3^{\text {rd }}$ percentiles.

\begin{tabular}{|c|c|c|c|c|}
\hline \multicolumn{2}{|l|}{ Decision step } & \multicolumn{3}{|l|}{ Categories } \\
\hline \multicolumn{2}{|c|}{ Emissions assessment } & Agriculture & Deforestation & Both \\
\hline $\begin{array}{l}\text { Total } \\
\text { emissions }(\mathrm{t} \\
\left.\mathrm{CO}_{2} \mathrm{e}\right)\end{array}$ & $\begin{array}{l}\text { Emissions }\left(\mathrm{CO}_{2}\right) \text { which come } \\
\text { from agriculture-driven } \\
\text { deforestation (multiple data } \\
\text { sources - see section } 2.2) \text { and from } \\
\text { agriculture }\left(\mathrm{CH}_{4}, \mathrm{~N}_{2} \mathrm{O}, \mathrm{CO}_{2}\right) \\
\text { (Emissions from agriculture } 2010 \\
\text { [or most recent data point } \\
\left.\text { available] }\left[\mathrm{t} \mathrm{CO}_{2} \mathrm{e}\right]^{1}(\mathrm{FAO} 2014 \mathrm{~b})\right)\end{array}$ & $\begin{array}{l}>66 \% \text { is emissions } \\
\text { from agriculture- } \\
\text { driven } \\
\text { deforestation }\end{array}$ & $\begin{array}{l}>66 \% \text { is } \\
\text { agriculture } \\
\text { emissions }\end{array}$ & $\begin{array}{l}33-66 \% \text { is } \\
\text { emissions from } \\
\text { agriculture- } \\
\text { driven } \\
\text { deforestation } \\
\text { and agriculture }\end{array}$ \\
\hline \multicolumn{2}{|c|}{ Mitigation potential } & Low & Medium & High \\
\hline $\begin{array}{l}\text { Yield gap (t } \\
\left.\mathrm{ha}^{-1}\right)\end{array}$ & $\begin{array}{l}\text { Area weighted yield gap of major } \\
\text { grains (Neumann et al. 2010) } \\
\text { based on the area under } \\
\text { production (Monfreda et al. 2008). }\end{array}$ & $<2.21$ & $2.21-3.6$ & $>3.6$ \\
\hline $\begin{array}{l}\text { Available } \\
\text { land }(\%)\end{array}$ & $\begin{array}{l}\text { Area of non-forested, non- } \\
\text { protected, unused land, with minor } \\
\text { slopes }<15 \% \text { and a potential for } \\
>3.5 \mathrm{t} \mathrm{ha}^{-1} \text { agricultural production. } \\
\text { Expressed as a percentage of } \\
\text { forested land (multiple data } \\
\text { sources - see table } 2 \text { ). }\end{array}$ & $<17$ & $17-44$ & $>44$ \\
\hline $\begin{array}{l}\text { Agricultural } \\
\text { emissions (t } \\
\left.\mathrm{CO}_{2} \mathrm{e} \mathrm{ha}^{-1}\right)\end{array}$ & $\begin{array}{l}\text { Emissions }\left(\mathrm{CH}_{4}, \mathrm{~N}_{2} \mathrm{O}, \mathrm{CO}_{2}\right) \text { from } \\
\text { agriculture } 2010 \text { (or most recent } \\
\text { data point available) (FAO 2014b) }\end{array}$ & $<0.72$ & $0.72-1.68$ & $>1.68$ \\
\hline
\end{tabular}




\begin{tabular}{lllll}
\hline Enabling environment & Low & Medium & High \\
\hline Governance & $\begin{array}{l}\text { Governance index (government } \\
\text { effectiveness, regulatory quality, } \\
\text { rule of law and control of } \\
\text { corruption) (World Bank 2012) }\end{array}$ & $<-0.72$ & $-0.72--0.24$ & $>-0.24$ \\
& $\begin{array}{l}\text { Index of engagement in national } \\
\text { and sub-national REDD+ } \\
\text { REDD+ } \\
\text { engagement }\end{array}$ & $<0.14$ & & \\
& see section 2.4) & & & \\
& & & & \\
\hline Risk assessment & Low & Medium & High \\
\hline Food & $\begin{array}{l}\text { Global Food Security Index } \\
\text { security }\end{array}$ & $>51$ & $34-51$ & $<34$ \\
\hline
\end{tabular}

${ }^{1} \mathrm{CO}_{2} \mathrm{e}$ - equivalent concentrations of other GHGs in terms of radiative forcing as carbon dioxide.

\subsubsection{Calculation of emissions}

The source of emissions was assessed by our framework based on the relative contribution of agricultural emissions and emissions from agriculture-driven deforestation to the sum of the two, which is hereafter referred to as 'total emissions' (Table 3.1).

\subsubsection{Area of forest loss}

To estimate current deforestation driven by agriculture, we first estimated total deforestation areas based on a combination of historical datasets covering forest changes from 2000-2012 (Table 3.2). Since we focus on land-use changes (from forest to agriculture), deforestation data based on a forest land-use definition is required. Gross change data are required since, for example in China, India and Vietnam, large-scale afforestation projects will lead to an underestimation of deforestation if net data are used (FAO 2010). So far, no single data source exists which provides gross forest change with a forest land-use definition; the Forest Resources Assessment Remote Sensing Survey (FRA RSS) is sample data which does not cover the whole of the tropics. Therefore, we combined remote sensing based forest-cover change data from Hansen or FRA RSS to derive a ratio of net forest change to forest loss 'Net:Loss' (Figure 3.3). We used this factor to estimate gross forest loss from the Food and Agriculture Organization of the United Nations Forest Resources Assessment (FAO FRA) data (Eq. 3.1).

Gross forest loss $=$ net forest change $e_{F A O F R A} *$ Net: LoSS $_{\text {Hansen or FRA RSS }}$ 
Table 3.2. Description of data sources used to derive deforestation at the national level.

\begin{tabular}{|c|c|c|c|c|c|c|}
\hline Data & Source & $\begin{array}{l}\text { Gross / } \\
\text { Net }\end{array}$ & $\begin{array}{l}\text { Forest- } \\
\text { use / } \\
\text { Forest- } \\
\text { cover }\end{array}$ & Coverage & Resolution & $\begin{array}{l}\text { Temporal } \\
\text { coverage }\end{array}$ \\
\hline FAO & (FAO & Net & Forest- & Complete & Country & $2000-$ \\
\hline FRA & 2010b) & & use & & & 2010 \\
\hline FRA RSS & $\begin{array}{l}\text { (FAO \& } \\
\text { JRC } \\
2012)\end{array}$ & Gross & $\begin{array}{l}\text { Forest- } \\
\text { use }\end{array}$ & Sample & $\begin{array}{l}\text { Based on } \\
\text { Landsat }\end{array}$ & $2000-2005$ \\
\hline Hansen & $\begin{array}{l}\text { (Hansen } \\
\text { et al. } \\
\text { 2013) }\end{array}$ & Gross & $\begin{array}{l}\text { Forest- } \\
\text { cover }\end{array}$ & Complete & $\begin{array}{l}\text { Based on } \\
\text { Landsat }\end{array}$ & 2000-2012 \\
\hline
\end{tabular}

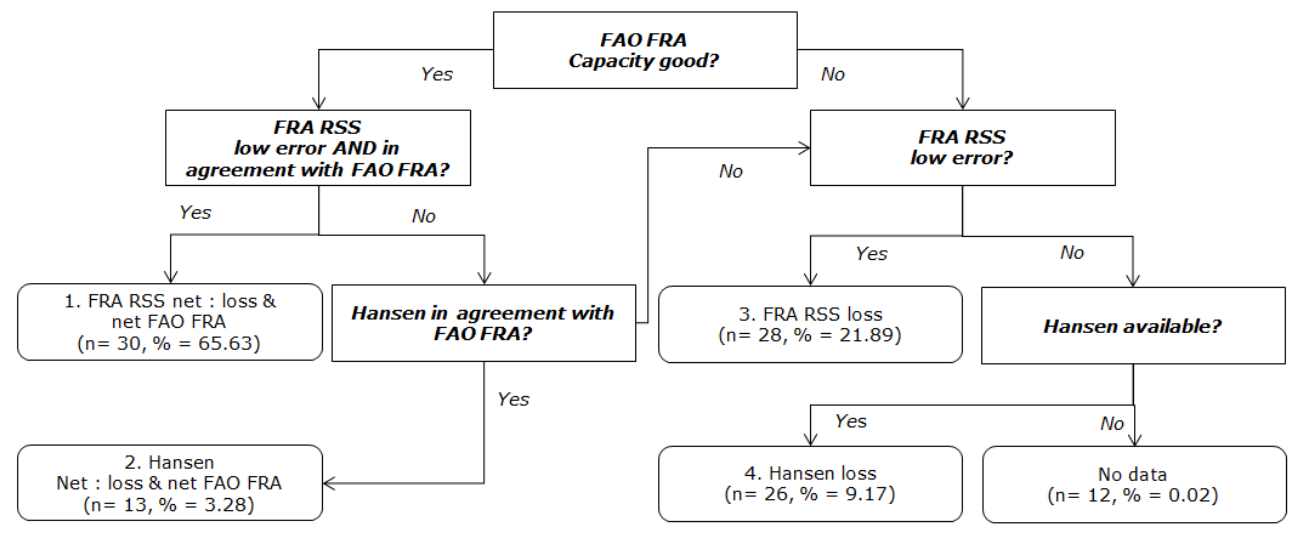

Figure 3.3. The decision tree for the selection of deforestation data. The decision numbers represent 'quality flags', 1 for the highest quality data and 4 for the lowest. $\mathrm{N}=$ number of countries in that group, and $\%=$ percentage of forest in that group.

The Net:Loss factor was only calculated where both datasets (FAO FRA and Hansen or FAO FRA and FRA RSS) were in agreement about the direction of net change, i.e. both giving negative, or both positive or both no change. Since the number of samples within a country in the FRA RSS varied substantially (from 0 to 930) we used the standard error to determine if the FRA RSS should be used in the analysis. Where the mean was smaller than the standard error for either the loss or gain in that time period, we did not use the FRA RSS data. We prioritized the Net:Loss ratio for land-use (FRA RSS) over land-cover (Hansen) (Figure 3.3). 
Data from the FAO FRA are nationally reported and their accuracy is linked to the capacity of the country to provide the data (Romijn et al. 2012). We used this data only when the country was considered to be able to produce reliable data. Countries whose data we considered reliable were either high income countries (World Bank 2013), or countries which in 2010 had either an intermediate, high, or very high capacity to measure forest area change (Romijn et al. 2012). Romijn et al. (2012) evaluated the existing monitoring capacities of countries taking into consideration challenges such as the area of forest which the country has to monitor and availability of data.

Where the conditions described above were not met, and equation 3.1 is therefore unsuitable, we selected first the FRA RSS alone to provide the loss, and if this did not meet the error criteria based on the number of samples, we used the Hansen data alone, where it was available. Otherwise we recorded no-data (no data was also recorded where only FAO FRA net change is available). Data are available for most of the tropics, and the 12 no-data countries (out of 109 countries) account for only $0.02 \%$ of forest area considered in this study. For the majority of the data (countries which hold more than $69 \%$ of forest in the tropics), loss was calculated using FAO FRA in combination with either FRA RSS or Hansen (Figure 3.3).

For future projections of deforestation areas, a historical baseline period which is sufficiently long to compensate for any anomalous high and low years is required (Santilli et al. 2005). Here, we considered a period of 10 years, which is in line with other studies (e.g. Rideout et al. 2013).

\subsubsection{Area of forest loss due to agriculture}

Based on the national total area of deforestation we calculated the area that was deforested due to agriculture. In this study, we used the definition of deforestation drivers used by Hosonuma et al. (2012) and Kissinger et al. (2012). Drivers can be separated into direct and indirect drivers. Since the definition for deforestation considers a change in land use, timber extraction is not considered as a driver, as the forest is expected to regrow. Direct drivers relate to an intended land use (for example, urban expansion, mining, agriculture and infrastructure). Indirect drivers include international markets and population growth that influence the land change. We used national data from Hosonuma et al. (2012) describing the importance of agriculture as a direct driver of deforestation. Agriculture includes cropland, pasture, tree plantations, and subsistence agriculture including shifting cultivation (Hosonuma et al. 2012). The authors derived the importance of deforestation drivers from a synthesis of nationally self-reported data, country profile reports from the Center for International Forestry Research (CIFOR) and other literature, most of them reflecting the 
timeframe between 2000 and 2010. The relative importance of the drivers mentioned in the reports is quantified either as a ratio, ordinal, or nominal scale. These were scaled from 0 to 1 (representing minimal to high influence), to indicate the proportion of deforestation which is driven by agriculture (see Hosonuma et al. 2012 for details). We multiplied this 'agricultural driver factor' by the area of forest loss 'deforestation' to infer the area of loss driven by the agriculture: 'agriculture-driven deforestation' (Eq. 3.2).

$$
\begin{gathered}
\text { Agriculture driven deforestation } \\
=\text { deforestation } * \text { agricultural driver factor }
\end{gathered}
$$

According to the method used in Harris et al. (2012), we calculated emissions by multiplying the area of forest loss by an emissions factor. For the biomass emissions factor, we use the sum of above ground biomass (AGB) and below ground biomass (BGB). We averaged two AGB datasets derived from remote sensing and ground measurements; a tropical dataset (Saatchi et al. 2011) and, a continental dataset (Baccini et al. 2012). Using an average of the two maps is preferred (where there is coverage from both datasets), since the accuracy of both approaches is yet to be determined (Zolkos et al. 2013). Where only one map has data, we used the dataset available. The mean AGB in each country was calculated in forested areas, which were selected using the ESA Global Land Cover map of 2010 developed in the Climate Change Initiative (CCI) (ESA 2013). BGB was calculated from AGB using tree root to shoot ratios equations (Mokany et al. 2006).

\subsubsection{Emissions from agriculture}

We used national emission data from FAO (2012) to calculate total emissions from agriculture, covering enteric fermentation, manure management, rice cultivation, synthetic fertilizers, manure applied to soils, manure left on pasture, crop residues, cultivation of organic soils, burning - savanna, burning - crop residues and agricultural soils. We do not account for sinks such as those which occur from crop re-growth. We excluded energy use in agriculture. According to FAO (FAO 2014a) agriculture includes livestock, and agricultural land is defined as fallow land, temporary crops, temporary meadows for mowing and pasture, permanent crops and permanent meadows and pasture.

\subsubsection{Mitigation potential}

We consider two approaches to mitigate agriculture-driven deforestation; closing the yield gap and utilizing non-forest land for agricultural expansion. Additionally, where the majority of a country's total emissions are from agriculture, we estimate the potential to reduce these 
emissions through climate smart approaches in the agriculture sector. We define mitigation potential as the total mitigation which could be achieved over time. We do not consider practical constraints (technical potential), or cost limitations (economic potential) (Baede et al. 2007).

\subsubsection{Closing the yield gap}

Production of maize, wheat and rice provides about two-thirds of all energy in human diets (Cassman 1999) and therefore, we focus on these three crop types in our analysis. First, we calculated the average yield gap of these three cereals for each country based on Neumann et al. (2010). Second, we derived the crop-specific production area per country based on Monfreda et al. (2008). In our study, the yield gap at national level is calculated by the following function (Eq. 3.3), using yield gaps and production areas of each crop $(x)$.

$$
\text { cereal yield gap }=\sum \frac{\text { mean yield gap } x}{\text { total cereal area }} * \text { cereal area }_{x}
$$

\subsubsection{Non-forested land suitable for agriculture}

We used a number of conditions to identify suitable agricultural land, where data are available across the tropics (Table 3.3, and Figure 1S, of the supplementary materials of the online publication). These conditions include (1) the biophysical potential; at minimum a moderate rainfed yield, low slope, and not barren and (2) the availability of land; not forested, not used for another purpose (agriculture, urban etc.), not used exclusively for agriculture (for example mosaic use with a non-use) and no protected areas. This is likely to result in an optimistic estimate of available land since socio-economic and regulatory barriers to land cultivation have not been considered. 
Table 3.3. Land available for agriculture - data sources and availability conditions.

\begin{tabular}{|c|c|c|}
\hline $\begin{array}{l}\text { Availability } \\
\text { factor }\end{array}$ & Availability condition & Data description \\
\hline $\begin{array}{l}\text { Yield potential } \\
\text { for rainfed } \\
\text { agriculture }\end{array}$ & crop productivity $>3.5 \mathrm{t} \mathrm{ha}^{-1}$ & $\begin{array}{l}10 \text { arc minute climate dataset } \\
\text { combined with soil water storage } \\
\text { map and a dynamic water and crop } \\
\text { model (Droogers et al. } 2001 \text { ) }\end{array}$ \\
\hline $\begin{array}{l}\text { Land is not used } \\
\text { and non-forested }\end{array}$ & $\begin{array}{l}\text { Mosaic cropland / tree } \\
\text { cover, mosaic herbaceous / } \\
\text { tree cover, shrubland and } \\
\text { grassland cover classes }\end{array}$ & $\begin{array}{l}300 \mathrm{~m} \text { resolution land cover map } \\
\text { based on a global surface reflectance } \\
\text { (SR) composite time series. Data for } \\
2010 \text { available (ESA 2013) }\end{array}$ \\
\hline $\begin{array}{l}\text { Suitable } \\
\text { topography for } \\
\text { agriculture }\end{array}$ & Slopes $<15 \%$ & $\begin{array}{l}30 \text { arc second aggregate based on } 90 \\
\mathrm{~m} \text { resolution digital terrain map from } \\
\text { the Shuttle Radar Topographic } \\
\text { Mission (SRTM) (Fischer et al. } \\
\text { 2008) }\end{array}$ \\
\hline $\begin{array}{l}\text { Land does not } \\
\text { have protected } \\
\text { area status }\end{array}$ & No protected status & $\begin{array}{l}\text { Globally spatially referenced } \\
\text { database of protected areas (IUCN } \\
\text { UNEP-WCMC 2014) }\end{array}$ \\
\hline
\end{tabular}

\subsubsection{Potential for reduction of agricultural emissions}

Where the majority of emissions are in the agriculture sector (Figure 3.1), we calculated the emissions $\mathrm{t} \mathrm{CO}_{2} \mathrm{e}$ per hectare of agricultural land using national emissions data (Section 3.2.1.3), and agricultural area data (FAO 2014b). High emissions shows that there are emissions which could potentially be reduced.

\subsubsection{Enabling environment}

To represent the enabling environment for mitigating deforestation we used two indicators: governance and engagement in REDD+. To indicate governance, we summed the following components of a governance index, available from the World Bank (2012): government effectiveness, regulatory quality, rule of law and control of corruption.

We produced an index of REDD+ engagement taking into account (1) national engagement in international REDD+ initiatives, (2) sub-national engagement in REDD+ initiatives through project development, and (3) amount of funding acquired. We gave equal weight to 
the following international programmes: UN-REDD (United Nations Collaborative initiative on Reducing Emissions from Deforestation and forest Degradation (REDD) in developing countries), FCPF (Forest Carbon Partnership Facility), CIF-FIP (Forest Investment Plan (FIP) within the Climate Investment Funds (CIF)), GEF (The Global Environment Facility), and the Governors' Climate and Forests Task Force. Due to varying levels of participation in some initiatives, weightings were given. We weighted countries receiving support from the UN-REDD by one, and partner countries by one-half. There are several steps in the process to gaining an emissions reduction purchase agreement (ERPA) within the FCPF Carbon Fund, so we weighted countries who participate (signing a partnership agreement, but yet to submit any documents) by one-third, countries who submitted the RPIN (Readiness Plan Idea Note) by two-thirds, and countries with a finalized R-PP (Readiness Preparation Proposal) by one. Funding acquisition data were acquired from the Climate Funds Update (www.climatefundsupdate.org), we allocated scores between 0 and 1 depending on the amount secured. The number of REDD+ projects which are occurring in a country are available from the CIFOR database (www.forestclimatechange.org/redd-map/), and we gave scores between 0 and 1 depending on the number of projects (Table $1 \mathrm{~S}$ in the supplementary materials of the online publication). We summed all the scores per country and divided by 7 (the maximum summed score) to create the index for REDD+ engagement with a final score of between 0 and 1 .

\subsubsection{Risk assessment}

We assessed the risk to livelihoods potentially resulting from the implementation of the mitigation interventions. Risk is dependent on many elements, which can be grouped into three components: hazard (physical realization of the risk), exposure (elements exposed to the risk) and vulnerability (susceptibilities of the exposed elements) (Cardona et al. 2012). We consider that the hazard (a system change leading to changes to land use) occurs, and that the exposed elements are local communities. We then use a food security index as a proxy for vulnerability, reflecting risk as a whole (http://foodsecurityindex.eiu.com/).

\subsection{Results}

\subsubsection{Sources of emissions}

In the tropics, a total of $104,260 \mathrm{~km}^{2} \mathrm{yr}^{-1}$ of forest on average was lost between 2000 and 2010/12 (dependent on data input; see Figure 3.3) to agriculture (97 countries), which resulted in $4.26 \mathrm{Gt} \mathrm{CO}_{2} \mathrm{y}^{-1}$ emitted to the atmosphere (Figure 3.4). The largest forest loss due 


\subsection{Results}

to agriculture occurred in Brazil $\left(29,470 \mathrm{~km}^{2} \mathrm{y}^{-1}\right)$. On average, countries lost $0.52 \% \mathrm{yr}^{-1}$ of their forest to agriculture, with the highest percent loss in Togo $\left(3.71 \% \mathrm{y}^{-1}\right)$.

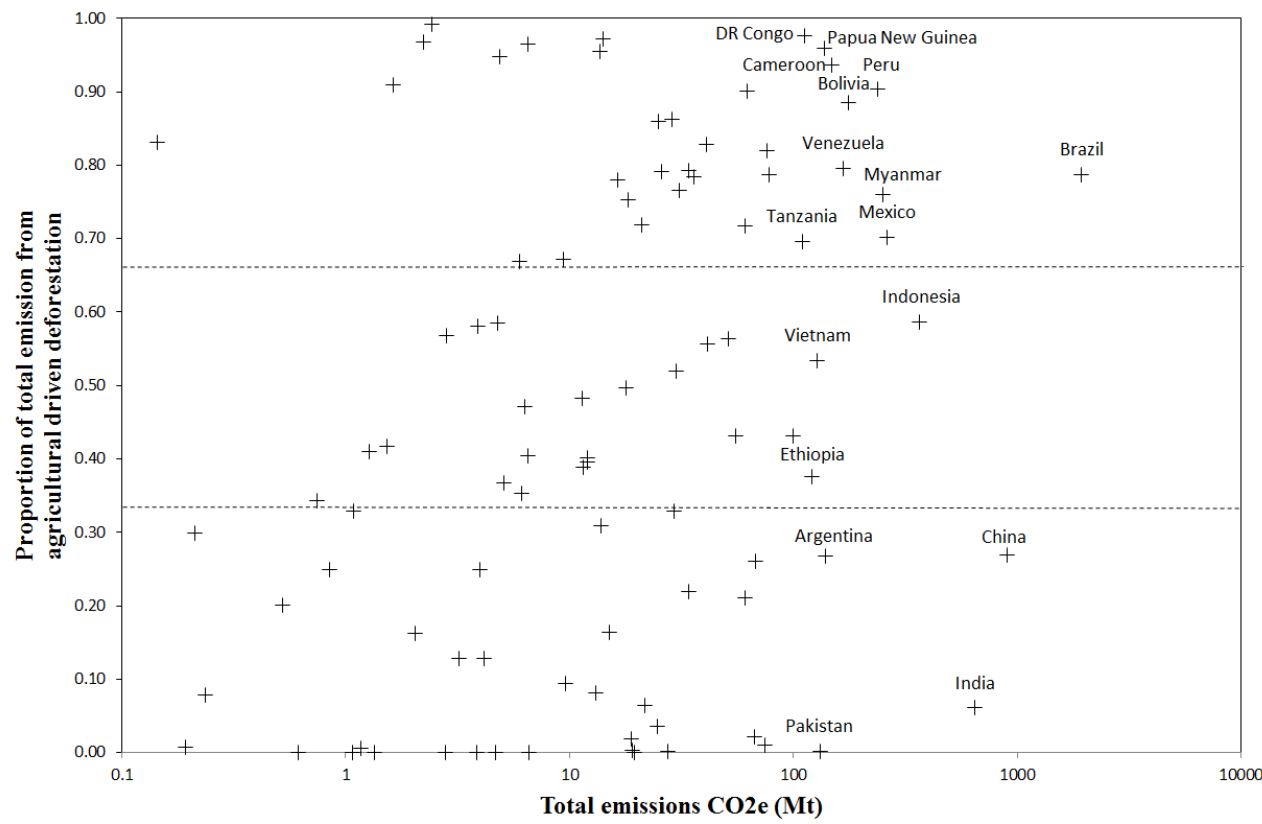

Figure 3.4. Total $\mathrm{CO}_{2} \mathrm{e}$ emissions (annual $\mathrm{AGB}$ and $\mathrm{BGB}$ removals on forest land converted to agriculture (2000-2010/12) plus annual agricultural emissions (2010)), and the proportion of the total emissions from agricultural driven deforestation $(1=100 \%$ emissions from agricultural driven deforestation, $0=100 \%$ emissions from agriculture). The 17 countries with emissions $>100 \mathrm{Mt}$ are labelled $(\mathrm{n}=95)$. The horizontal lines distinguish the groups where total emissions are: $>66 \%$ from agriculture (lower third), 33-66\% from agriculturedriven deforestation and agriculture (middle third) and $>66 \%$ (middle third) from agriculturedriven deforestation. 


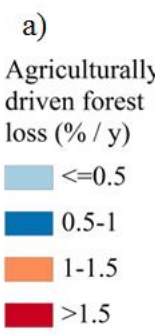

b)

Proportion of emissions from agriculture and agriculturally driven deforestation

Agriculture

Both

Deforestation
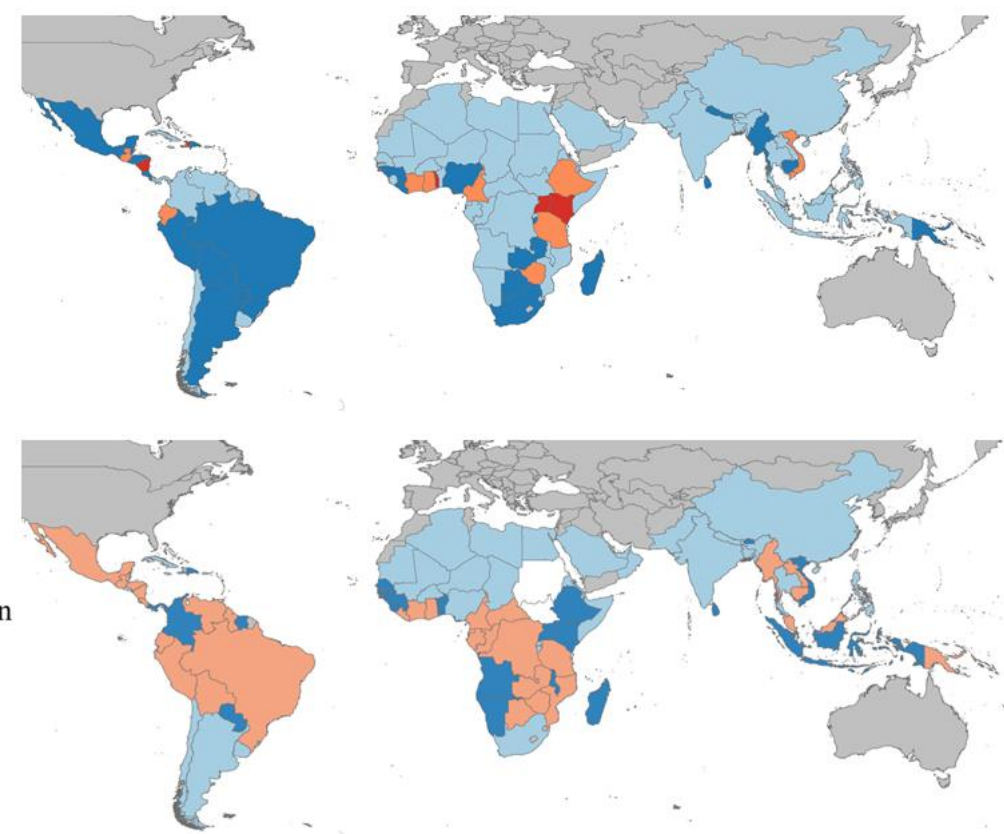

Figure 3.5. Emissions sources (a) \% agriculturally driven forest area loss (b) proportion of emissions from agriculture and agriculture-driven deforestation (expressed as a proportion of the total emissions 'agriculture' $=>66 \%$ from agriculture, 'both' $=33-66 \%$ from agriculturedriven deforestation and agriculture and 'deforestation' $=>66 \%$ from agriculture-driven deforestation). Grey areas are outside the study area, and white areas had no available data.

The emissions are categorized as follows (Table 3.1): (1) agriculture-driven deforestation emissions are the main source of the total emissions (>66\%); (2) agricultural emissions are the main source of the total emissions $(>66 \%)$ and (3) agriculture-driven deforestation and agriculture each contribute $33-66 \%$ to the total emissions. Those countries where emissions from deforestation are highest include those which have high forest losses due to agricultural expansion, e.g., Zimbabwe $1.35 \% \mathrm{yr}^{-1}\left(2548 \mathrm{~km}^{2} \mathrm{y}^{-1}\right)$, and those with a large forest area, e.g., Brazil which loses $0.54 \% \mathrm{yr}^{-1}$ (Figure 3.4 and 3.5). Some countries with high agricultural emissions have no deforestation due to agriculture (United Arab Emirates, Djibouti, Eritrea, Mauritania, Niger, Oman, Saudi Arabia). Haiti is an exception which has a high forest loss due to agriculture $\left(>2 \% \mathrm{y}^{-1}\right)$ but most emissions are from the agricultural sector due to the small forest area remaining $\left(1090 \mathrm{~km}^{2}\right.$ in $2000, \sim 4 \%$ of the country area). 


\subsubsection{Mitigation potential of agriculture-driven deforestation}

In total, 78 countries were classified according to their mitigation potential using the decision tree (Figure 3.2); the main results are presented in Table 3.4. Out of 44 countries with $>33 \%$ of the total emissions from agriculture-driven deforestation, 33 countries also have either a high yield gap or a large area of available land compared to forest land (Table 3.4). Available land is highest in South East Asia and West Africa (Figure 3.6). The yield gap is highest in East and Central Africa and Central America with the yield gap being already closed in much of Asia and South America (Figure 3.6). Of those countries with a high yield gap or large area of available land 20 countries have a good enabling environment in terms of effective governance or engagement in REDD+. These countries have a mitigation potential of 1.32 $\mathrm{Gt} \mathrm{CO}_{2} \mathrm{y}^{-1}$ from reducing agriculture-driven deforestation. Most countries in Asia and South and Central America have strong enabling environments for interventions, with either effective governance or involvement in REDD+ (Figure 3.6). Central Africa has high engagement in REDD+ and some countries in Southern Africa have a high governance scores. Sub-Saharan Africa has the weakest enabling environment for mitigation interventions. Food insecurity indicates a risk to livelihoods when implementing mitigation interventions, and 14 out of the remaining 20 countries have high risks (Table 3.4). Six priority countries have been identified, which have potential to mitigate agriculture-driven deforestation, and also have a good enabling environment and low risks associated with implementing an intervention: Panama, Paraguay, Ecuador, Mexico, Malaysia and Peru (Table 3.4).
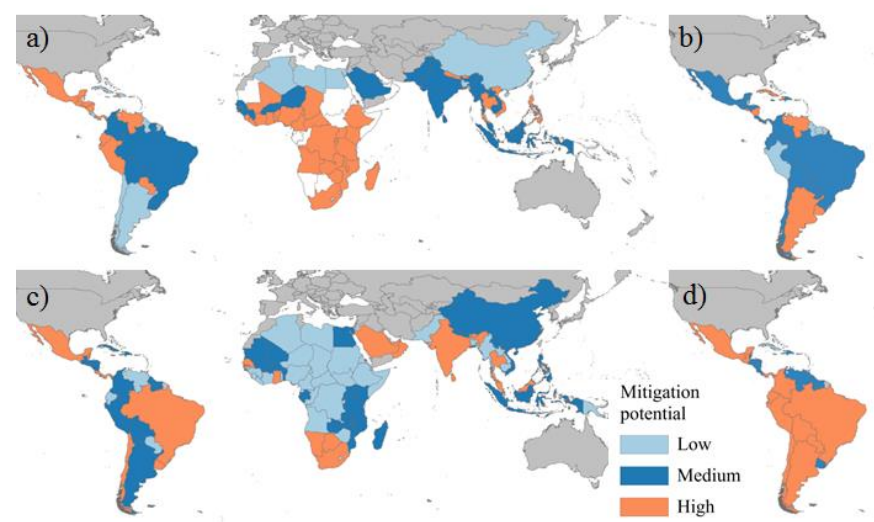

Figure 3.6. Mitigation potential through (a) closing the yield gap, and (b) utilizing available land, and enabling environment through (c) Governance and (d) REDD+ engagement. Grey areas are outside the study area, and white areas had no available data. 
Table 3.4. Countries are categorized into mitigation intervention classes according to the results of the decision making tree (Figure 3.1) which identifies target countries for mitigation interventions using thresholds for input data (Table 3.1). Priority countries (with low risks) for interventions are emboldened (countries for which data are unavailable for the full analysis are not included).

\begin{tabular}{|c|c|c|c|c|c|}
\hline \multirow{2}{*}{$\begin{array}{l}\text { Contribution of } \\
\text { emissions to total } \\
\text { Potential for } \\
\text { mitigation (sector) }\end{array}$} & \multicolumn{2}{|c|}{ Agriculture $>66 \%$} & \multicolumn{2}{|c|}{$\begin{array}{l}\text { Agriculture and agricultural } \\
\text { driven deforestation } \\
\text { emissions } 33-66 \%\end{array}$} & \multirow{2}{*}{$\begin{array}{l}\text { Agricultural } \\
\text { driven } \\
\text { deforestation } \\
>66 \% \\
\text { Forest }\end{array}$} \\
\hline & Agriculture & & Agriculture & Forest & \\
\hline $\begin{array}{l}\text { High potential and } \\
\text { effective governance } \\
\text { (or engagement in } \\
\text { REDD+ in the case of } \\
\text { the agriculture } \\
\text { mitigation sector) for } \\
\text { mitigation } \\
\text { intervention (low risk } \\
\text { countries are } \\
\text { emboldened) }\end{array}$ & $\begin{array}{l}\text { Thailand } \\
\text { India }\end{array}$ & & & $\begin{array}{l}\text { Panama } \\
\text { Paraguay } \\
\text { Indonesia } \\
\text { Kenya } \\
\text { Sri Lanka } \\
\text { Madagascar } \\
\text { Senegal } \\
\text { Uganda } \\
\text { Viet Nam }\end{array}$ & $\begin{array}{l}\text { Ecuador } \\
\text { Mexico } \\
\text { Malaysia } \\
\text { Peru } \\
\text { Côte d'Ivoire } \\
\text { Cameroon } \\
\text { DR Congo } \\
\text { Ghana } \\
\text { Guatemala } \\
\text { Mozambique } \\
\text { Tanzania }\end{array}$ \\
\hline $\begin{array}{l}\text { High potential but } \\
\text { support for } \\
\text { governance required } \\
\text { (countries are not } \\
\text { assessed for risk) }\end{array}$ & $\begin{array}{l}\text { Bangladesh } \\
\text { Egypt } \\
\text { Gambia } \\
\text { Haiti } \\
\text { Nepal } \\
\text { Pakistan } \\
\text { Philippines } \\
\text { El Salvador }\end{array}$ & & $\begin{array}{l}\text { Dominican } \\
\text { Republic } \\
\text { Suriname }\end{array}$ & $\begin{array}{l}\text { Angola } \\
\text { Benin } \\
\text { Ethiopia } \\
\text { Guinea } \\
\text { Malawi } \\
\text { Sierra Leone } \\
\text { Togo }\end{array}$ & $\begin{array}{l}\text { Honduras } \\
\text { Liberia } \\
\text { Nicaragua } \\
\text { Venezuela } \\
\text { Zambia } \\
\text { Zimbabwe }\end{array}$ \\
\hline $\begin{array}{l}\text { Low potential } \\
\text { (countries are not } \\
\text { assessed for } \\
\text { governance or risk) }\end{array}$ & $\begin{array}{l}\text { Argentina } \\
\text { Burundi } \\
\text { Burkina Faso } \\
\text { Chile } \\
\text { China } \\
\text { Comoros } \\
\text { Cuba } \\
\text { Djibouti } \\
\text { Algeria } \\
\text { Eritrea } \\
\text { Jamaica } \\
\text { Libya } \\
\text { Mali } \\
\text { Mauritania } \\
\text { Mauritius } \\
\text { Niger } \\
\text { Nigeria } \\
\text { Oman }\end{array}$ & $\begin{array}{l}\text { Saudi Arabia } \\
\text { Rwanda } \\
\text { Somalia } \\
\text { Chad } \\
\text { Uruguay } \\
\text { South Africa }\end{array}$ & $\begin{array}{l}\text { Colc } \\
\text { Guir }\end{array}$ & $\begin{array}{l}\text { ia } \\
\text { Bissau }\end{array}$ & $\begin{array}{l}\text { Bolivia, } \\
\text { Brazil } \\
\text { Costa Rica } \\
\text { Guyana } \\
\text { Cambodia } \\
\text { Lao PDR } \\
\text { Myanmar }\end{array}$ \\
\hline
\end{tabular}




\subsubsection{Mitigation potential of agricultural emissions}

Thirty-eight countries with either $>66 \%$ of total emissions from agriculture or $33-66 \%$ of total emissions from agriculture and no mitigation potential through land-sparing (Figure 3.2) were assessed for the potential to mitigate emissions from agriculture. Of those 38 countries,

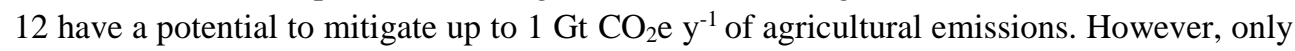
two countries have a good enabling environment, and of those only Thailand has low risks associated with the implementation of interventions, so mitigation potential is low. Implementing intervention in countries with risks associated would require an emphasis on safeguarding.

\subsubsection{Priority areas for increased support}

A number of countries have either little engagement in REDD+ or poor governance which represents a barrier to a successful implementation of interventions. There are 13 countries with more than $33 \%$ of their emissions originating from agriculture-driven deforestation, which have a high potential for mitigation through land-sparing but lack a supportive enabling environment. This accounts for $8 \%$ of emissions from agriculture-driven deforestation. These countries should be assessed for the potential to implement interventions along with capacity building initiatives. Priority candidates for increased support in REDD+ activities are those which have $>66 \%$ of total emissions from agriculture-driven deforestation and which have a high potential for mitigation of agriculture-driven deforestation (Honduras, Liberia, Nicaragua, Venezuela, Zambia and Zimbabwe). Where the mitigation potential in the agriculture sector is highest, there are a number of countries which would require increased support (Bangladesh, Egypt, Gambia, Haiti, Nepal, Pakistan, Philippines and El Salvador).

\subsection{Discussion}

\subsubsection{The potential for mitigation of emissions from agriculture-driven deforestation and agriculture}

Our results quantify annual forest losses which are driven by agriculture. Converting forest loss to emissions, and comparing this to emissions from agriculture allows mitigation approaches for the main source to be considered. We consider emissions to indicate the need for mitigation rather than forest area loss, which gives a focus on countries with high carbon forests. This can lead to valuable wooded ecosystems being neglected (Mbow 2014). 
However, countries with low carbon forests do appear in our study and are highlighted as priorities for action (e.g. Zambia, Togo).

Following this, we consider the enabling environment and risks to identify priority countries. This assessment can be used as a starting point for national priority setting and policy processes. However countries with a low potential for mitigation should also be assessed at the sub-national level for opportunities. In addition, risks should be assessed at the local level and even where low risks are identified, activities should be accompanied by safeguards that ensure that the rights and livelihoods of local communities and biodiversity are respected (Peskett \& Todd 2013). REDD+ interventions can potentially bring benefits to communities, but can also bring negative impacts resulting from restrictions on access to forests, changes to permitted land management practices (Peskett \& Todd 2013), or altered agricultural practices (Smith et al. 2013). The likelihood that negative impacts will result is dependent on, among other things, the safeguarding systems implemented with the intervention (Peskett \& Todd 2013).

Table 3.5. Mitigation potential for DR Congo, Indonesia and Argentina.

\begin{tabular}{llll}
\hline & DR Congo & Indonesia & Argentina \\
\hline Emissions source & Deforestation & Both & Agriculture \\
\hline $\begin{array}{l}\text { Mitigation } \\
\text { potential }\end{array}$ & $\begin{array}{l}\text { Reducing } \\
\text { deforestation }\end{array}$ & $\begin{array}{l}\text { Reducing } \\
\text { deforestation }\end{array}$ & Agricultural sector \\
\hline Yield gap & High & Medium & Low \\
Available land & Low & High & High \\
Agricultural & Low & High & Low \\
emissions & & & No \\
\hline $\begin{array}{l}\text { Enabling } \\
\text { environment }\end{array}$ & Yes & Yes & Medium \\
\hline $\begin{array}{l}\text { Governance } \\
\text { REDD+ }\end{array}$ & Low & Medium & High \\
engagement & High & High & No \\
\hline Risk factor & Yes & Yes & Low \\
\hline Food insecurity & High & Medium & \\
\hline
\end{tabular}

We explored three national case studies in more detail, providing recommendations for the mitigation of emissions from both agriculture-driven deforestation and from agriculture (Table 3.5). Two cases represent the potential to mitigate deforestation related emissions (Democratic Republic of Congo (DR Congo) and Indonesia), and one case study highlights the case for targeted interventions within the agricultural sector (Argentina). All countries 


\subsection{Discussion}

have emissions $>1 \mathrm{Gt} \mathrm{CO}_{2} \mathrm{e} \mathrm{yr}^{-1}$ (Figure 3.2), and have supporting data available to evaluate the use of the framework for the assessment of the mitigation potential.

\subsubsection{Case study: DR Congo}

Emissions from agriculture-driven deforestation in the DR Congo account for $98 \%$ of the total emissions (emissions from agriculture plus agriculture-driven deforestation). There is a strong consensus that the major direct driver of deforestation in DR Congo is agriculture, and due to increasing populations and weak governance, deforestation rates are likely to increase in the future (Ickowitz et al. 2015). A high mitigation potential exists to reduce agriculturedriven deforestation given the high yield gap, although available land is rated low $(\sim 12 \%)$. Reports suggest that one of the major barriers to the implementation of interventions in agriculture is the lack of transport infrastructure and access to markets (Ickowitz et al. 2015). However, engagement in REDD+ is high, suggesting a strong enabling environment for landuse related interventions. Vulnerable communities may be affected by land based activities, since DR Congo is food insecure. Roots, tubers and plantains comprise more than the half of the dietary requirements in the DR Congo and a fall in production over recent years has led to fall in the average caloric intake (Alexandratos \& Bruinsma 2012). Together with the country's state of post-conflict recovery this suggests that food insecurity will remain in the near future.

\subsubsection{Case study: Indonesia}

In Indonesia $41 \%$ of the total agriculture and agriculture-driven deforestation emissions originate from agriculture. Since Indonesia has available land approximately half the area of its forests, and a relatively small yield gap $\left(2.22 \mathrm{t} \mathrm{h}^{-1}\right)$, the identification of unused land could be explored as a priority. Caution should be taken since the conversion of Indonesia's high carbon peat swamps to can lead to a large flux of emissions - in the case of oil palm this is a change from a net of -1.3 to $30.4 \mathrm{Mg} \mathrm{CO}_{2} \mathrm{e} \mathrm{ha}^{-1} \mathrm{y}^{-1}$ (Hergoualc'h \& Verchot 2013). Amongst all countries included in our analysis Indonesia has the highest engagement in REDD+, and has already implemented national policy interventions designed to protect forests from conversion to agriculture, such as a moratorium on forest conversion (Angelsen et al. 2012). However Indonesia is a major producer of oil palm and this has led to an expansion of agricultural land (Alexandratos \& Bruinsma 2012) so coordination from the agriculture and forestry sectors is required where there is competition for land. In terms of risks, Indonesia faces some food insecurity, so this should be considered and monitored to ensure that unwanted trade-offs do not result from interventions. 


\subsubsection{Case study: Argentina}

In Argentina, $73 \%$ of the total emissions from agriculture-driven deforestation and agriculture, originate from agriculture. Argentina has the $8^{\text {th }}$ highest (average 1990-2011) agriculture emissions in the world - largely resulting from livestock keeping (FAO 2014b), and it is expected that these emissions will continue to rise due to increasing beef demand, so advances in the livestock sector need to be explored for assessing the potential for emissions reductions. In terms of addressing the proportion of emissions in Argentina occurring from agriculture-driven deforestation, there is a large area of available land (our study predicts that this is around $122 \%$ of the forest area) so there is a potential to avoid deforestation. Successful interventions such as a tax on soybean exports (Kissinger et al. 2012), which are driving land acquisitions (www.landmatrix.org) have also contributed to reduced expansion of agriculture land. Although our study finds a relatively low yield gap $\left(1.78 \mathrm{t} \mathrm{ha}^{-1}\right)$ there is still room to narrow, so land-sparing could potentially occur from an intervention targeting the yield gap. Governance is medium in Argentina (-0.35) so interventions are likely to be successful, although some capacity building could be integrated into interventions in the short term, since Argentina's R-PP states that insufficient law enforcement is one of the indirect drivers of deforestation (Kissinger et al. 2012).

\subsubsection{Calculating emissions from deforestation}

A number of studies have calculated emissions from recent deforestation. Achard et al. (2014) use the FRA RSS sample data (see Section 3.2.1.1) and find emissions between 2.2

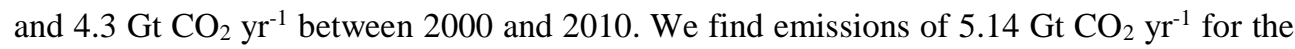
tropics, which are $13 \%$ higher than Achard et al. (2014). For 73 tropical countries (excluding the Caribbean), Harris et al. (2012) finds emissions of 1.9 - $4.73 \mathrm{Gt} \mathrm{CO}_{2} \mathrm{yr}^{-1}$ between 2000 and 2005 from deforestation. Our estimate for the same 73 countries is $4.83 \mathrm{Gt} \mathrm{CO}_{2} \mathrm{yr}^{-1}, 2 \%$ above the upper limit for Harris et al. (2012). Although our results are higher than these estimates, Harris' estimates are typically lower than other recent estimates (Harris, et al. 2012), which supports our findings. In terms of the area of deforestation, Harris et al. (2012) find annual forest loss for 73 tropical countries (excluding the Caribbean) of 36,750 - 143,330 $\mathrm{km}^{2} \mathrm{y}^{-1}$ (with a median of 85,160). This supports our results for the same countries (we estimate $117,486 \mathrm{~km}^{2} \mathrm{y}^{-1}$ total forest loss not only driven by agriculture), which lies within the same range. Estimates of deforestation area from Achard et al. (2014) are not easily comparable to estimates based on country reported data (including our study) and disagree with the FAO FRA data partly due to the definition of forests (Achard et al. 2014). The major difference between estimates stems from the emissions factors rather than the activity data. Since our study uses a comparative approach to assess the need for mitigation on a country level, we consider these data still useful for this purpose. Emissions from deforestation can 


\subsection{Discussion}

also be higher than we predict, as these studies do not consider losses from peat soils, burning of the forest or other GHGs.

\subsubsection{Projecting agriculture-driven deforestation}

Estimates of the mitigation potential of reducing agriculture-driven deforestation are inherently reliant on future estimates of agriculture-driven deforestation. These projections rely on assumptions about the future, and baseline setting which is one of the challenges of REDD+ (Köthke et al. 2014). Historical deforestation rates are commonly used for setting business-as-usual (BAU) baselines for avoided deforestation (Santilli et al. 2005). We therefore selected this approach for our study, however other approaches may lead to more reasonable estimates. For example, adjusting historic baselines based on the forest transition curve (FT) to make projections can be beneficial since otherwise countries at the early stages of the transition will underestimate future BAU deforestation and countries at later stages of the transition will overestimate BAU (Angelsen 2008; Köthke et al. 2014). However, future scenarios should also account for global economic forces and government policies which are not accounted for in the FT, and there are a number of countries which do not fit into the typical FT trajectory, for example Thailand (Meyfroidt \& Lambin 2011). Simulation models are often used to estimate deforestation based on relationships between deforestation and variables such as population, and have been used for a number of applications (Kaimowitz $\&$ Angelsen 1998). Global models are useful for estimating deforestation since they account for leakage across national borders, and partial equilibrium models (e.g. GLOBIOM) are able to model competition for land by accounting for multiple sectors, e.g. agriculture, forestry and bioenergy. However, there is not always a clear relationship between deforestation and the selected explanatory variables, and some aspects of human behaviour such as social and political changes are impossible to predict, consequently leading to projections with high uncertainties (Kaimowitz \& Angelsen 1998; Dalla-Nora et al. 2014). In addition, there is some scepticism on models which are based on assumptions about economic behaviour, and those models which are based on household data are considered most reliable, which are only useful for local level estimates (Kaimowitz \& Angelsen 1998).

\subsubsection{Estimating available land}

Land available for agriculture is one of the indicators for the potential to mitigate agricultural expansion into forests. However, there are many difficulties in quantifying available land (Lambin et al. 2013). There are several limitations to our the approach including: (1) the rainfed potential productivity is considered, which can be exceeded by irrigation, (2) the applied threshold for the minimum potential productivity of $3.5 \mathrm{t} \mathrm{ha}^{-1}$ can be considered overly 
conservative, since many areas are cultivated with lower production levels (Droogers et al. 2001), (3) suitability for agriculture is crop specific, so it is possible that there are some crop types which can potentially produce above $3.5 \mathrm{t} \mathrm{ha}^{-1}$ in the 'very-low productivity' areas, (4) it is a static approach which does not take into account likely impacts of future climate change on crop production (Rosenzweig et al. 2014; Frieler et al. 2015), (5) the land cover classes used in the availability criteria imply availability, but can also include some land already in use (6) we excluded slopes above $15 \%$, which can, however, potentially be cultivated using terracing. The $15 \%$ slope threshold however, is commonly used to identify agricultural suitability at large scale since this is the threshold where the kinetic energy of the runoff increases and outweighs the kinetic energy of the rainfall thus resulting in erosion (Roos 1996). Regarding the implied land availability, we acknowledge that some areas may not be available, for example grazed areas may not be in the agriculture land cover class of the land cover dataset. Promoting agriculture expansion in areas which are used by local communities can lead to negative effects (Mbow 2010). Yet, land availability was used to indicate the amount of available land rather than identifying areas for agricultural development, which requires local evaluation including risk assessments. Despite its limitations, comparisons with other datasets support our approach. Within the tropics we find approximately 8,290,000 $\mathrm{km}^{2}$ of available land (Figure $1 \mathrm{~S}$ in the supplementary materials of the online publication). This is over $11 \%$ of the total terrestrial area. Other studies also suggest that there are large areas of land available globally for example Campbell et al. (2008) finds that over 3.5\% of the land area is suitable for bioenergy production when only considering abandoned agricultural land. Lambin et al. (2013) calculated available land, and we compared three areas for which data are available with our own study, and they are within the same range (Table 3.6). Lambin et al. (2013) used a bottom-up approach to estimate the world's potentially available cropland based on a series of constraints and trade-offs which are considered in different scenarios. A global figure of $13,220,000 \mathrm{~km}^{2}$ was calculated using comparable processes, which is also within the same order of magnitude as our findings (Fader et al. 2013). 
Table 3.6. Available land area (in ' $000 \mathrm{~km}^{2}$ ) for three regions

\begin{tabular}{lllll}
\hline Source & Availability definition & $\begin{array}{l}\text { DR } \\
\text { Congo }\end{array}$ & Indonesia & $\begin{array}{l}\text { Brazilian and } \\
\text { Bolivian } \\
\text { Amazon* }\end{array}$ \\
\hline This study & All available land & 195 & 547 & 383 \\
\cline { 2 - 5 } & $\begin{array}{l}\text { Land cover classes with } \\
\text { potential for agricultural } \\
\text { expansion (1) }\end{array}$ & 854 & 638 & 385 \\
& $\begin{array}{l}\text { Areas excluding those with } \\
\text { major constraints (2) }\end{array}$ & 240 & 75 & 124 \\
\cline { 2 - 5 } \begin{tabular}{l} 
(Lambin et 2013) \\
\cline { 2 - 5 }
\end{tabular} & $\begin{array}{l}\text { Areas excluding those with } \\
\text { trade-offs (3) }\end{array}$ & & 50 & 74 \\
\hline
\end{tabular}

*The Brazilian and Bolivian Amazon region consists of Bolivia, and 5 states in Brazil; Maranhão, Pará, Mato Grosso, Rondônia, and Acre (the Lambin et al. (2013) area is slightly smaller, as it only considers Pará south of the Amazon River, which is the 'Amazon arc of deforestation').

\subsubsection{The land-sparing hypothesis}

To spare land the yield gap needs to be sufficiently decreased or even closed, and available land needs to be successfully used. The extent to which the yield gap can be closed in practice depends on location-specific technological, biophysical and other constraints (Duwayri et al. 2000; Neumann et al. 2010). It is widely recognised that technological advances in agriculture, which improve production can reduce the need to expand agricultural production into forests (Borlaug 2007; Stevenson et al. 2013). Yield gaps vary within countries (Table. $2 \mathrm{~S}$, in the supplementary materials of the online publication), and areas where yield gaps are highest may be targeted for interventions. Scenarios suggest that a $1 \%$ crop yield increase annually would spare 0.76 billion ha of cropland expansion by 2050 (Sands \& Leimbach 2003). Despite increases in fertilizer use, higher yields can reduce emissions, due to a reduced emissions intensity from production (Burney et al. 2010). In order to avoid social and environmental costs of agricultural intensification, including increased emissions, 'climate smart' or 'sustainable intensification' principles can be followed (Foley et al. 2011; Garnett 2012). This theory, however, has been much debated recently, with some research finding that any savings will be offset by changing human diets and increased population (Kastner et al. 2012; Bajzelj et al. 2014).

Few examples are cited in the literature where intensification or utilization of available land has led to land-sparing (Cohn et al. 2011; Minang et al. 2011; Stevenson et al. 2013), perhaps 
since few programmes are developed with this aim. However, in the case of Brazil, Nationally Appropriate Mitigation Actions (NAMAs) to restore grazing land account for 10$12 \%$ (0.1-0.13 $\mathrm{Gt} \mathrm{CO}_{2}$ ) of pledged emission reductions for the year 2020 (Cohn et al. 2011). Despite the potential for emissions reductions from utilizing available land, there will always be emissions created from the utilization of these lands (Searchinger et al. 2015). However, when weighted against potential deforestation emissions, the carbon balance can be tipped in favour of conversion of available lands. In addition, where available lands are degraded (one of the reasons land is not currently utilized), rehabilitating them can increase the carbon storage capacity of soils, so adding to the mitigation potential (Smith et al. 2008).

Even if the yield gap has been closed, and available land utilized, land-sparing must become a reality in order for deforestation to be reduced. Some studies suggest that feedbacks such as increasing land rents from yield improvements will lead to increases in land area dedicated to agriculture (Angelsen 2010). Intensified production has been found more likely than smallholder production to expand into forests (Gutiérrez-Vélez et al. 2011) and freeing grazing lands can lead to more demand for cropland to supply feed for the livestock (Cattaneo 2001). However, we consider the level of governance as a criterion in the selection of areas for interventions which will support the integration of policies to limit agricultural expansion such as LSPs (Rudel et al. 2009; Cohn et al. 2011). Governance indicators, such as rule of law and control of corruption (World Bank 2012) are related to the effective set-up and management of interventions and accompanying policies, and have been used as an indicator of the enabling environment for interventions. The state of Mato Grosso in Brazil is one example where agriculture-driven deforestation has been reduced by the integration of policies including the soybean industry's self-imposed moratorium (2006) on production in deforested areas and pro-active efforts by the local and national governments to control deforestation (DeFries et al. 2013). Although national level governance may be good, central governments may not support community level actions, so a multilevel system is important (Angelsen 2010). NAMAs can also help to achieve targets of agricultural mitigation, can help to reduce leakage risks and foster wider engagement at the country level, and can be combined within REDD+ mechanisms (Kissinger et al. 2012).

\subsection{Conclusions}

This study gives a comprehensive overview of national emissions and mitigation priorities within the forest and agriculture sectors, which can guide decision making and investments at the international level. Specifically, we have demonstrated how available data can be used to identify where emissions from agriculture, forestry and other land use (AFOLU) sector within the IPCC reporting scheme can be best reduced. The inherent link between agriculture and forests highlights need for integrated solutions. Agricultural interventions have been 
incorporated into REDD+ frameworks in some countries, including Indonesia and Brazil (Kissinger et al. 2012). Yet, there is potential for improvement to ensure that where agricultural drivers are present, those are addressed with appropriate interventions within the agricultural sector (Salvini et al. 2014). This task is not without difficulties, since government agencies focusing on agriculture and those focusing on forestry may have differing objectives, and a systematic incorporation of policies is required to consider competing goals. In addition, if interventions are implemented in the agricultural sector to spare forest land, then support from the forestry sector is also necessary to protect existing forests.

Our findings show a mitigation potential of $4.26 \mathrm{Gt}_{\mathrm{CO}_{2}} \mathrm{e}^{-1}$ from agriculture-driven deforestation. Many countries also have a high potential to implement successful interventions in the agricultural sector, as there is a good enabling environment (effective governance or engagement in REDD+) which will support activities. A potential of $1.32 \mathrm{Gt}$ $\mathrm{CO}_{2} \mathrm{y}^{-1}$ can be mitigated in those countries in which more than one third of their emissions stem from agriculture-driven deforestation and which have a good enabling environment (20 countries). These countries are responsible for $31 \%$ of the total emissions from agriculturedriven deforestation in the tropics. They potentially hold the easiest gains and interventions which seek to spare forest land by decreasing the yield gap, or by expanding agriculture into available non-forest lands and these opportunities should be systematically considered. Some of these countries have risks (e.g. Indonesia and DR Congo) associated with potential mitigation interventions and this should be considered as part of the decision making process. A number of countries have a high mitigation potential but indicators for these countries suggest a weak enabling environment (e.g. Angola, Honduras) (Table 3.4). In these cases, long-term support which also seeks to build governance capabilities is required.

Within the agriculture and forestry sectors in particular, there are potential trade-offs (risks to livelihoods and the environment) associated with mitigation interventions. Following the principles of 'sustainable intensification' or 'climate-smart' agriculture can minimize these costs (Foley et al. 2011; Garnett et al. 2013). Interventions which deliver multiple benefits, in terms of yield increases, mitigation and adaptation components can also offer opportunities to support vulnerable communities where risks such as food insecurity or reliance on agriculture for income are present. There is a need to look beyond the broad interventions which are discussed in this paper, and the growing body of evidence on climate-smart agriculture (FAO 2013) is providing examples of best practices in specific locations. Further research is also required to consider other risks, for example to biodiversity, which can be impacted by changes to agricultural systems. This systematic framework can be replicated for other scenarios, or at other scales (for example regional and local) to identify priorities for mitigation across sectors in a transparent manner. 


\section{Acknowledgements}

This research was generously supported by the contributions of the governments of Australia (Grant Agreement \# 46167) and Norway (Grant Agreement \#QZA-10/0468) to the Center for International Forestry Research. This work was carried out as part of the Consultative Group on International Agricultural Research programs on Trees, Forests and Agroforestry (FTA) and Climate Change Agriculture and Food Security (CCAFS). The authors thank Valerio Avitabile and John Stuiver for technical support, and reviewers for their valuable comments on this and a previous version of the manuscript. 


\section{Large scale land acquisitions and REDD+}

This chapter is based on: S Carter, AM Manceur, R Seppelt, K Hermans-Neumann, M Herold, \& L Verchot. 2017. Large scale land acquisitions and REDD+: a synthesis of conflicts and opportunities. Environmental Research Letters 12 (3), 035010.

Supplementary materials to this chapter can be found in the online publication. 


\section{Abstract}

Large scale land acquisitions (LSLA), and Reducing Emissions from Deforestation and forest Degradation (REDD+) are both land based phenomena which when occurring in the same area, can compete with each other for land. A quantitative analysis of country characteristics revealed that land available for agriculture, accessibility, and political stability are key explanatory factors for a country being targeted for LSLA. Surprisingly LSLA occur in countries with lower accessibility. Countries with good land availability, poor accessibility and political stability may become future targets if they do not already have LSLA. Countries which high levels of agriculture-driven deforestation and LSLA, should develop interventions which reduce forest loss driven either directly or indirectly by LSLA as part of their REDD+ strategies. Both host country and investor-side policies have been identified which could be used more widely to reduce conflicts between LSLA and REDD+. Findings from this research highlight the need for and can inform the development of national and international policies on land acquisitions including green acquisitions such as REDD+. Land management must be considered with all its objectives- including food security, biodiversity conservation, and climate change mitigation - in a coherent strategy which engages relevant stakeholders. This is not currently occurring and might be a key ingredient to achieve the targets under the Sustainable Development Goals 2 and 15 and 16 (related to food security and sustainable agriculture and the protection of forests) among others.

\subsection{Introduction}

Land use and land use changes are influenced by global processes including two, which have received recent attention: Large Scale Land Acquisitions (LSLA) and Reducing Emissions from Deforestation and forest Degradation (REDD+). LSLA can be defined as large-scale ( $\geq 200$ ha) land investments which result in the transfer of rights, control or ownership of land (Nolte et al. 2016), although there is ongoing discussion about the definition of LSLA (Edelman et al. 2013). LSLA can provide benefits to local communities (Smalley et al. 2014; Deininger \& Byerlee 2011) and income to host governments who in some cases actively seek investments (Friis \& Reenberg 2010). However, there is a general consensus that LSLA occurring in low-income countries results in negative impacts on food and tenure security, and the livelihoods of local communities (Cotula 2012). REDD+ is a mechanism designed to reduce global greenhouse gasses (GHGs) in the atmosphere, while promoting forest conservation, sustainable management of forests and enhancing carbon stocks (UNFCCC 2014). REDD+ features prominently in the Paris Climate Agreement (UNFCCC 2015b) due 
to the impact of land use change on GHG emissions, with forest loss being major source of GHG emissions in tropical countries (Houghton et al. 2012).

Being a globally limited resource (Foley et al. 2011; Seppelt et al. 2014) competition for land for different land uses occurs and thus links LSLA and REDD+. LSLA has also been identified as a driver of forest loss potentially causing conflicts with REDD+ efforts (Scholes 2012). Yet, most research on LSLA has focussed on the social and political aspects of the phenomena (e.g. De Schutter 2011, Messerli et al. 2013, Scoones et al. 2013a, Borras et al. 2012, Edelman 2013, Edelman et al. 2013), and the impact on forests and on forest protection efforts including REDD+ have not been widely researched to the authors' knowledge.

Most LSLA deals (80\%) are for agriculture (Nolte et al. 2016), with agricultural LSLA being the focus of much research (e.g. De Schutter 2011, Cotula et al. 2011, Mbow 2010). There is an existing body of research on the factors related to agricultural LSLA, with underlying or ultimate drivers on the global scale being world population increases, dietary changes, financial crises (which promotes land as an alternative investment source), and public policies such as European Union biofuel consumption targets and food price increases among others (Friis \& Reenberg 2010; Cotula et al. 2009; Messerli et al. 2013; Edelman et al. 2013; Cotula 2012). Research also exists on the characteristics of areas or countries which are hosts of LSLA and the factors making them attractive to investors. Expanding economic relations between host and investor countries (or economic liberalization of host countries) and support to the private sector through informational, technical and bureaucratic assistance are cited as important. There is no analysis yet however, which identifies the drivers of LSLA for agriculture in a statistically robust and consistent way. This study aims to fill this gap, by providing a comprehensive analysis of country characteristics which may be favourable for LSLA. We use the results to link LSLA with REDD+.

REDD+ has been compared to LSLA and has been labelled one type of "green grabbing" (Fairhead et al. 2012). LSLA and REDD+ can have similar impacts on land tenure, biodiversity and sustainable development (Fairhead et al. 2012; Larson et al. 2013), but REDD+ has been developed with the aim of avoiding some of the negative effects which are typically linked with land acquisitions (Larson et al. 2013), partially through the Cancun safeguards (UNFCCC 2010).

Understanding where LSLA occur is the first objective of this study, and a hypothesis about the predisposing factors characterizing countries which experience LSLA was tested using a data-driven approach. The aims of the study are thus (i) determining the predisposing factors which characterize countries which are objects of LSLA, (ii) identifying countries where forest loss may be driven by LSLA and (iii) exploring the potential to reduce forest loss and conflicts between REDD+ and LSLA. 


\subsection{Conceptual framework characterizing countries which are objects of LSLA}

A deductive approach based on a literature review was used to build the hypothesis that countries that are objects of LSLA will have the following four characteristics:

Potential for returns from investments: LSLA is hypothesized to be more frequent in countries which have land with high potential agricultural productivity and can produce returns on investments of agricultural inputs. Agricultural LSLA are likely to occur in areas with favourable conditions for agriculture which has been demonstrated by growing pressure on the best lands such as those with good soil fertility or irrigation potential (Cotula 2012; Breu et al. 2016). Land value may also influence buyers, with higher valued land attracting investors (probably due to their favourable conditions for agriculture), although cheap lands where returns can be generated also attract investors (Cotula et al. 2009; Cotula 2012). The increase in availability of fertilizers has been cited as a driver of agricultural LSLA (Cotula et al. 2009), since higher yields will result from the investment in fertilizer.

Suitable land: It is assumed that investors focus on countries with large areas of land suitable for agriculture. A wide range of land cover and uses are appropriate for investments, including existing agricultural land (Deininger \& Byerlee 2011; De Schutter 2011; Cotula et al. 2011); both commercial (Cotula 2012) and smallholder (Anseeuw et al. 2012; Fairhead et al. 2012; Edelman et al. 2013; Cotula 2012), and forests (Scholes 2012). Since it is also suggested that most land suitable for LSLA for agriculture is under use or claim already (Cotula et al. 2009) this implies that frontier areas will be sought in future. There is also evidence that marginal lands play a role for new agricultural developments, but that the potential is not fully realized (Nalepa \& Bauer 2012). Proximity to markets is cited as important for investors (Cotula 2012).

Access for investors: It is hypothesized that LSLA are more likely to occur in countries where investors can acquire and develop the land more easily. The legal regimes and national traditions for trade, investment and property (specifically laws and policies applying to land purchasing) will impact the likelihood of LSLA occurring (Edelman et al. 2013). Host country governments make policy reforms specifically to improve the investment climate, including tax breaks to encourage investors, and reforming land regulations (Cotula 2012; Cotula et al. 2009; Deininger \& Byerlee 2011). In contrast to supporting policies, and weak tenure regulations also equate to increased acquisitions (Cotula 2012; Corbera et al. 2011). Other governments restrict investments, for example in the forestry and agricultural sectors, several countries do not allow 100\% foreign ownership (including Philippines, Mexico and 
Thailand which allow a 50\% share, and Armenia, India, Indonesia and Sudan which allow a $50-80 \%$ foreign involvement) (World Bank 2014). Some countries have regulations related to specific crops, for example in Sierra Leone 5 to $20 \%$ of the shares of biofuel investments must be held by Sierra Leoneans (Cotula et al. 2009).

Security of investments: Investors are assumed to develop LSLA in areas where there are low risks to loss of investments through for example conflicts. Political instability is considered a risk for investors in LSLA (Cotula et al. 2009). There also needs to be a minimum regulatory requirement for investments to take place which will ensure respect for private property. The regulatory environment determines how control of resources and stakeholders allows the investor to acquire the land and use it for the desired purpose. This aspect of LSLA is referred to as "control grabbing" (Borras et al. 2012; Messerli et al. 2013). Additionally economic sanctions in the form of trade embargos are often imposed on countries engaged in conflicts, which although are mainly focussed on goods related to conflicts (EC 2016) can affect agricultural activities, making investments insecure. A number of countries included in this study currently have these restrictive measures related to trade (EC 2016).

\subsection{Data and methodology}

\subsubsection{Data on LSLA: the Land Matrix}

Occurrences of LSLA were determined using the Land Matrix, which was designed to introduce transparency and inclusion in decision making in the land acquisition sector (Anseeuw et al. 2012; Nolte et al. 2016). A binary response variable (whether a country is an object of LSLA or not) was used. LSLA were therefore defined according to the definition of the Land Matrix, however only international investments for agricultural purposes (including biofuels and fibre) were included with domestic land acquisitions being excluded. Only "concluded" or "contract signed" deals were included. The countries included in the study were restricted to the scope of the Land Matrix, which is lower-middle income countries. In this study the World Bank (World Bank 2013) list of low to middle income countries was used to identify those countries which had no LSLA. Some inconsistencies appeared in the current list of lower-middle income countries, and those which appeared in the Land Matrix. So countries which appeared in the Land Matrix, but were middle income countries in 2010 (i.e. recently promoted to the high income category according to the World Bank definition) were included (Uruguay, Russia, Lithuania, Chile), leading to a population of 142 countries. This study therefore includes some non-annex 1 countries which were 
excluded for the analysis related to REDD+ and LSLA to avoid misinterpretation of results given the fact that non-annex 1 countries are not eligible for REDD+.

The Land Matrix includes land deals reported by media, official data and research outputs, so methods may be affected and results biased by the intention to produce data for advocacy purposes (Edelman et al. 2013; Scoones, Hall, Borras, et al. 2013). Other potential biases in the Land Matrix are that countries under autocratic rule tend to provide less information and conflict-ridden areas may receive more press attention. Biases in datasets can be dealt with statistically, however validation information on LSLA is required which is not available. Utilizing a binary response variable for LSLA occurrences largely overcomes these biases, since it is unlikely that a country with LSLA would have all LSLA occurrences from the Land Matrix database missing, and if some but not all of the occurrences were missing, the binary response would be correct. Although there is a debate as to the quality of the Land Matrix data, there is also an agreement that these data are valuable for developing the agenda on the topic (Scoones, Hall, Jr, et al. 2013; Rulli \& Odorico 2013). Indeed, several examples exist where the Land Matrix and other similar data have been successfully used to assess LSLA in a number of contexts (Deininger \& Byerlee 2011; Rulli et al. 2012; Anseeuw et al. 2012; Giovannetti \& Ticci 2016; Breu et al. 2016).

\subsubsection{Characterizing countries which are objects of LSLA: indicators}

Indicators were identified (Table 4.1) for each of the four components of the hypothesis regarding the characteristics of countries which are objects of LSLA (Section 4.2). Data sources for which $33 \%$ of countries had no data were omitted (average missing data was $<10 \%$ for all variables).

For the accessibility variable, we use the gridded data set provided by the EU joint research centre (JRC) to estimate the average travel time to major cities ( $>50.000$ inhabitants) per country (Uchida \& Nelson 2008; Václavík et al. 2013). Here accessibility is the travel time to a given location of interest using available transport networks. Transport networks include land based transport; on and off roads and rail networks, and water networks; via navigable rivers and shipping lanes in lakes and oceans. Transport type, potential speeds on different road types, and environmental factors such as land cover and slope are used to calculate the travel speed of the transport network. National boundaries and border crossings are considered, as they can lead to travel delays (Uchida \& Nelson 2008). Thus we characterize each country by the average travel time to major cities. As cities are defined by population, they represent potential markets. 
Table 4.1. Variables used to identify characteristics of countries which explain whether or not they are objects of LSLA (as defined by the Land Matrix)

\begin{tabular}{|c|c|c|}
\hline $\begin{array}{l}\text { Expected indicator for } \\
\text { LSLA occurrence and } \\
\text { explanation }\end{array}$ & Data source and description & $\begin{array}{l}\text { Variable } \\
\text { name }\end{array}$ \\
\hline \multicolumn{3}{|l|}{ Potential for returns } \\
\hline Large yield gaps exist & $\begin{array}{l}\text { Difference between actual yield and } \\
\text { potential yield of major grains } \\
\left(\mathrm{t} \mathrm{ha}^{-1}\right) \text { (Neumann et al., 2010), weighted } \\
\text { based on the area under production } \\
\text { (Monfreda et al., 2008) }\end{array}$ & Yield gap \\
\hline $\begin{array}{l}\text { Agriculture is a successful } \\
\text { sector, and contributes to } \\
\text { the countries' GDP (high } \\
\text { share) }\end{array}$ & $\begin{array}{l}\% \text { of GDP (gross domestic product) from } \\
\text { agriculture (c. year } 2013 \text { or most recent) } \\
\text { (World Bank 2013) }\end{array}$ & $\begin{array}{l}\text { Agricultural } \\
\text { GDP }\end{array}$ \\
\hline $\begin{array}{l}\text { Appropriation of net } \\
\text { primary productivity } \\
(\mathrm{NPP}) \text { by humans is } \\
\text { demonstrated (high value) }\end{array}$ & $\begin{array}{l}\text { Total quantity of NPP appropriated by } \\
\text { humans as vegetables, paper, wood } \\
\text { (including construction and fuel use), meat, } \\
\text { soft fibre, eggs and milk (Imhoff \& } \\
\text { Bounoua 2006; Imhoff et al. 2004) (Pg C) }\end{array}$ & HANPP \\
\hline
\end{tabular}

\begin{tabular}{|c|c|c|}
\hline \multicolumn{3}{|l|}{ Suitable land } \\
\hline $\begin{array}{l}\text { Area of land available for } \\
\text { agricultural use, which is } \\
\text { not protected is large (high } \\
\text { percentage) }\end{array}$ & $\begin{array}{l}\text { Multiple data sources (Table } 4.2) \text { (\% of } \\
\text { country land area) }\end{array}$ & Available land \\
\hline $\begin{array}{l}\text { Accessibility to markets is } \\
\text { high (lower travel time; } \\
\text { low value) }\end{array}$ & $\begin{array}{l}\text { Accessibility, average travel time to city } \\
\text { (minutes) (Uchida \& Nelson 2008) }\end{array}$ & Accessibility \\
\hline \multicolumn{3}{|l|}{ Access for investors } \\
\hline $\begin{array}{l}\text { Favourable conditions for } \\
\text { business (high score on } \\
\text { business index) }\end{array}$ & $\begin{array}{l}\text { Ease of doing business (World Bank 2013), } \\
\text { ordinal data }\end{array}$ & $\begin{array}{l}\text { East of doing } \\
\text { business }\end{array}$ \\
\hline \multirow[t]{2}{*}{$\begin{array}{l}\text { Regulatory quality (high } \\
\text { value) }\end{array}$} & $\begin{array}{l}\text { World Bank governance indicators (World } \\
\text { Bank 2012), ordinal data }\end{array}$ & $\begin{array}{l}\text { Regulatory } \\
\text { quality }\end{array}$ \\
\hline & Table is continued on next page & \\
\hline
\end{tabular}




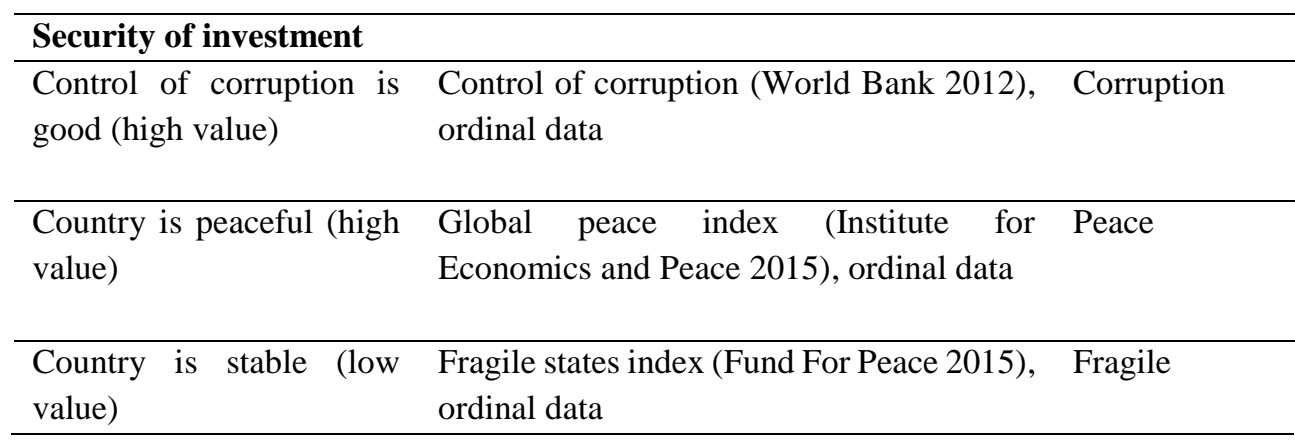

Area of land available for agricultural use was calculated as a proportion of the country land area (Carter et al. 2015) (Table 4.2). Urban areas, as well as bare areas, water bodies, permanent snow and ice, and areas dominated by lichens and mosses, which are likely to have a low biophysical potential for agriculture were excluded. Land with steep slopes, and land with a low potential for agricultural productivity was also excluded, and forests were left in. Information about the selection of these indicators can be found in Carter et al. (2015). Protected areas were excluded since these are typically considered to be unavailable for agriculture (Lambin et al. 2013). Protected areas can reduce deforestation (and therefore may be off-limits for LSLA), however Soares et al. (2010) show that deforestation rates within and outside protected areas may in specific cases not differ. Additionally, in Myanmar, forest reserves have been de-gazetted in order to allow for LSLA (Woods 2015). Another study investigating land for cropland expansion did not consider International Union for Conservation of Nature (IUCN) protected areas categories V and VI (Protected Landscape/ Seascape and Protected area with sustainable use of natural resources) a limit for agricultural expansion as cropland can exist in these areas (Eitelberg et al. 2015). However since details on IUCN categories in the World Database of Protected Areas are incomplete (IUCN UNEPWCMC 2014) all IUCN protected areas were excluded. The inclusion of protected areas therefore in this case gives an indication of barriers for LSLA, but LSLA can also occur where it is not permitted according to an area's protected area status.

Table 4.2. Land available for LSLA - data sources and availability conditions

\begin{tabular}{lll}
\hline $\begin{array}{l}\text { Availability } \\
\text { factor }\end{array}$ & Availability condition & Data source and description \\
\hline Land use / cover & Land is not bare, urban, & $300 \mathrm{~m}$ resolution land cover map based \\
& $\begin{array}{l}\text { water, permanent snow and } \\
\text { ice or currently lichen or a global surface reflectance (SR) } \\
\text { mosses }\end{array}$ & $\begin{array}{l}\text { composite time series, 2013) } \\
\text { (ESA }\end{array}$ \\
\hline
\end{tabular}




\begin{tabular}{|c|c|c|}
\hline $\begin{array}{l}\text { Yield potential } \\
\text { for rainfed } \\
\text { agriculture }\end{array}$ & $\begin{array}{l}\text { Potential crop productivity } \\
>3.5 \text { t ha- } 1\end{array}$ & $\begin{array}{l}10 \text { arc minute climate dataset combined } \\
\text { with soil water storage map and a } \\
\text { dynamic water and crop model } \\
\text { (Droogers et al. 2001) }\end{array}$ \\
\hline $\begin{array}{l}\text { Suitable } \\
\text { topography } \\
\text { agriculture }\end{array}$ & Slopes < $<15 \%$ & $\begin{array}{l}30 \text { arc second aggregate based on } 90 \mathrm{~m} \\
\text { resolution digital terrain map from the } \\
\text { Shuttle Radar Topographic Mission } \\
\text { (SRTM) (Fischer et al. 2008) }\end{array}$ \\
\hline $\begin{array}{l}\text { Protected } \\
\text { status }\end{array}$ & $\begin{array}{l}\text { Land does not have } \\
\text { protected area status }\end{array}$ & $\begin{array}{l}\text { Globally spatially referenced World } \\
\text { Database of Protected Areas (WDPA) } \\
\text { (IUCN UNEP-WCMC 2014) }\end{array}$ \\
\hline
\end{tabular}

\subsubsection{Characterizing countries which are objects of LSLA: classification trees}

Classification trees were used to understand the relationship between the response variable (presence or absence of LSLA) and the explanatory variables (see Table 4.1 and Table 4.2). Classification trees have been used in a variety of situations, and when tested against other comparable methods (clustering or regressions for example) provided useful results (Moreno-Fernández et al. 2015; Shekoofa et al. 2014). In our case, a number of the explanatory variables are highly correlated and show strong non-linear relationships (as would be expected with socio-economic measures at the country level), and have missing data. Classification trees are able to handle such data characteristics. Classification and Regression Trees (C\&RT), involve recursive partitioning to complete a binary tree of homogenous subsets through reducing the impurity in each step. C\&RT uses the Gini impurity to select variables. Trees were pruned by cross-validation to avoid overfitting, the minimum number of cases for each node (parent or child) was set to 5 , and trees were produced with SPSS 22 (IBM 2013).

\subsubsection{The impact of LSLA on REDD+ and forests}

In order to assess the potential for forest loss due to LSLA, two assumptions were considered. Firstly, where agriculture driven deforestation is already high, there is existing demand for farmland so it is likely that any further acquisitions would exacerbate the need for farmland. Secondly, countries which are already objects of LSLA or which have characteristics which are particularly attractive to LSLA investors (findings of the classification tree) can potentially have LSLA driven forest loss. Where both REDD+ and LSLA appear in the same country, potential conflicts occur, so possible mechanisms to avoid this are discussed. 
Assessments of REDD+ drivers and interventions were made, to establish if LSLA was considered a threat to forests and if interventions were in place to address this threat.

Data on agriculture-driven deforestation were obtained from Carter et al. (2015) who combined data on deforestation for the period 2000-2010 with data on the proportion of deforested land which is converted to agriculture. Percent loss of forest area was reported, and countries were divided by tertiles into 3 groups of 41 ; low, medium, and high agriculturedriven deforestation (19 had no data on agriculture-driven deforestation).

In line with Carter et al. (2015), engagement in REDD+ was determined by including engagement in international REDD+ initiatives such as UN-REDD, World Bank Forest Carbon Partnership Facility as well as REDD+ project development and funding acquisition. Countries were classed as being engaged in REDD+ if any of these occurred.

A review of REDD+ documents was carried out to identify if LSLA-related drivers specifically are considered a threat to forests according to national REDD+ preparation documents. For this study, the most recent REDD+ Readiness Preparation Proposals (R-PPs) submitted to the World Bank Forest Carbon Partnership Facility (FCPF) (FCPF 2015) were reviewed to assess if LSLA was specifically considered a driver. Additionally, country reported information on the main drivers of deforestation (direct and indirect) as summarized by Kissinger et al. (2012) were divided into those related to and not related to LSLA (Table 2 in the supplementary materials of the online publication).

Data from Salvini et al. (2014) were used, to identify countries whose REDD+ interventions address LSLA. An analysis of available documents (including R-PPs) was carried out by Salvini et al. (2014) who assessed whether proposed interventions which were designed to reduce deforestation were linked to the drivers which were also identified. Both Kissinger et al. (2012) and Salvini et al. (2014) use official documents which are available and on which REDD+ implementation is based.

\subsection{Results}

\subsubsection{The characteristics of countries which are objects of LSLA}

There were 142 countries in the analysis, 80 (56\%) of which were objects of LSLA and 62 (44\%) were not. The classification tree's main split was based on available land, showing this has the most discriminating role $(\mathrm{p}<0.0001)$ in determining whether or not a country is likely to have LSLA. Countries with relatively small areas of land available $(<18.9 \%$ of the 
country area) are more likely not to have LSLA. If available land area is above this threshold, then an accessibility indicator (mean travel time in the country >192 minutes to a large city or market), determines that countries are likely to have LSLA. For countries with a travel time below this threshold, then fragility is the determinant, and those more fragile $(>72.8-$ described as a 'warning' or 'alert' by the Fragile states index (Fund For Peace 2015)) are likely not to have LSLA. The classification tree has an overall accuracy of $78.9 \%$, an omission error (not identifying a LSLA country) of $13.8 \%$ and commission error (identifying a non-LSLA country as a LSLA country) of $30.6 \%$ for LSLA. 


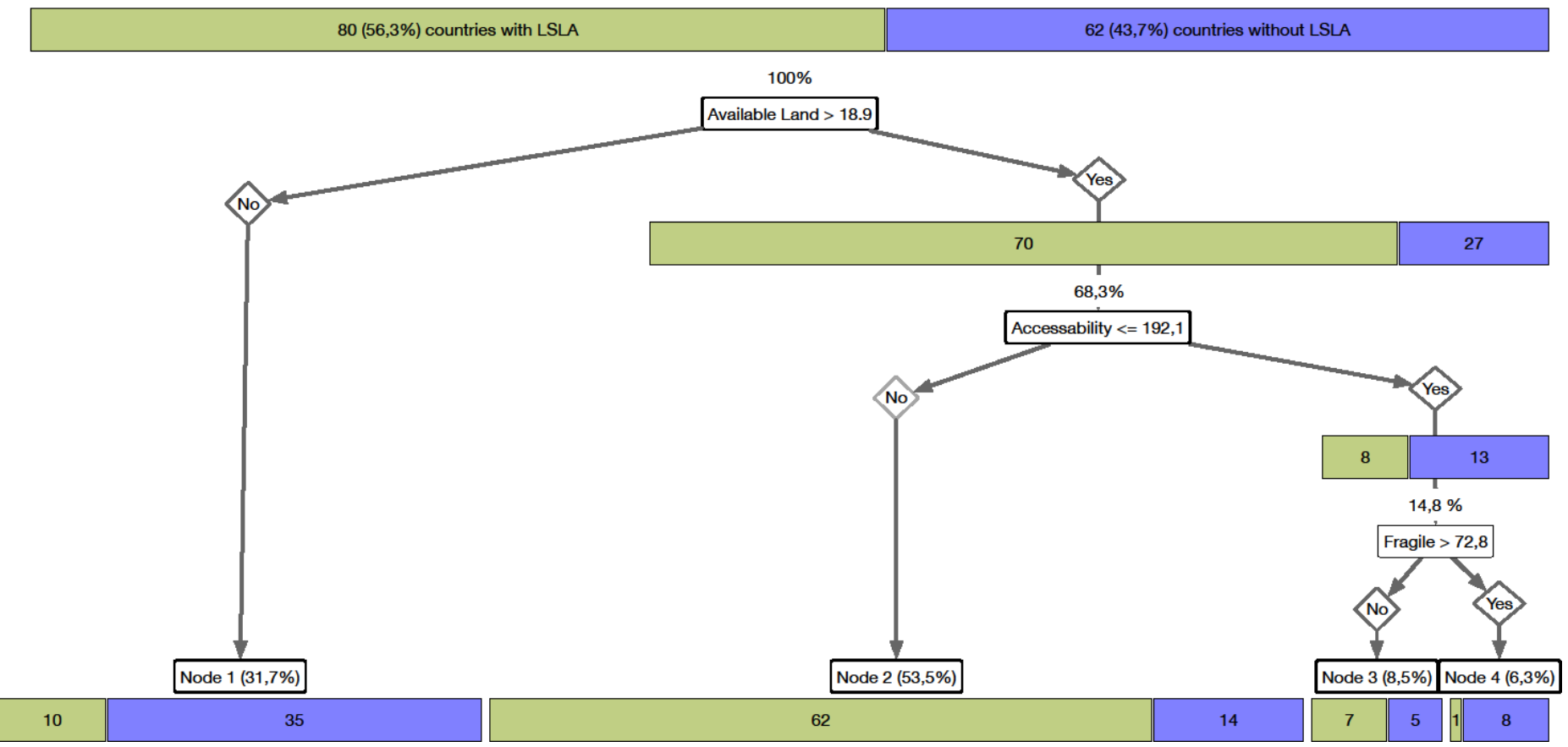

Figure 4.1. Classification tree characterizing countries which are and are not objects of LSLA. The percentage and number (n) of countries belonging to each node are shown, with the condition by which the split is made labelled above each node, and the name of the variable related to that condition is marked at each split. 


\subsubsection{LSLA, forest loss and REDD+}

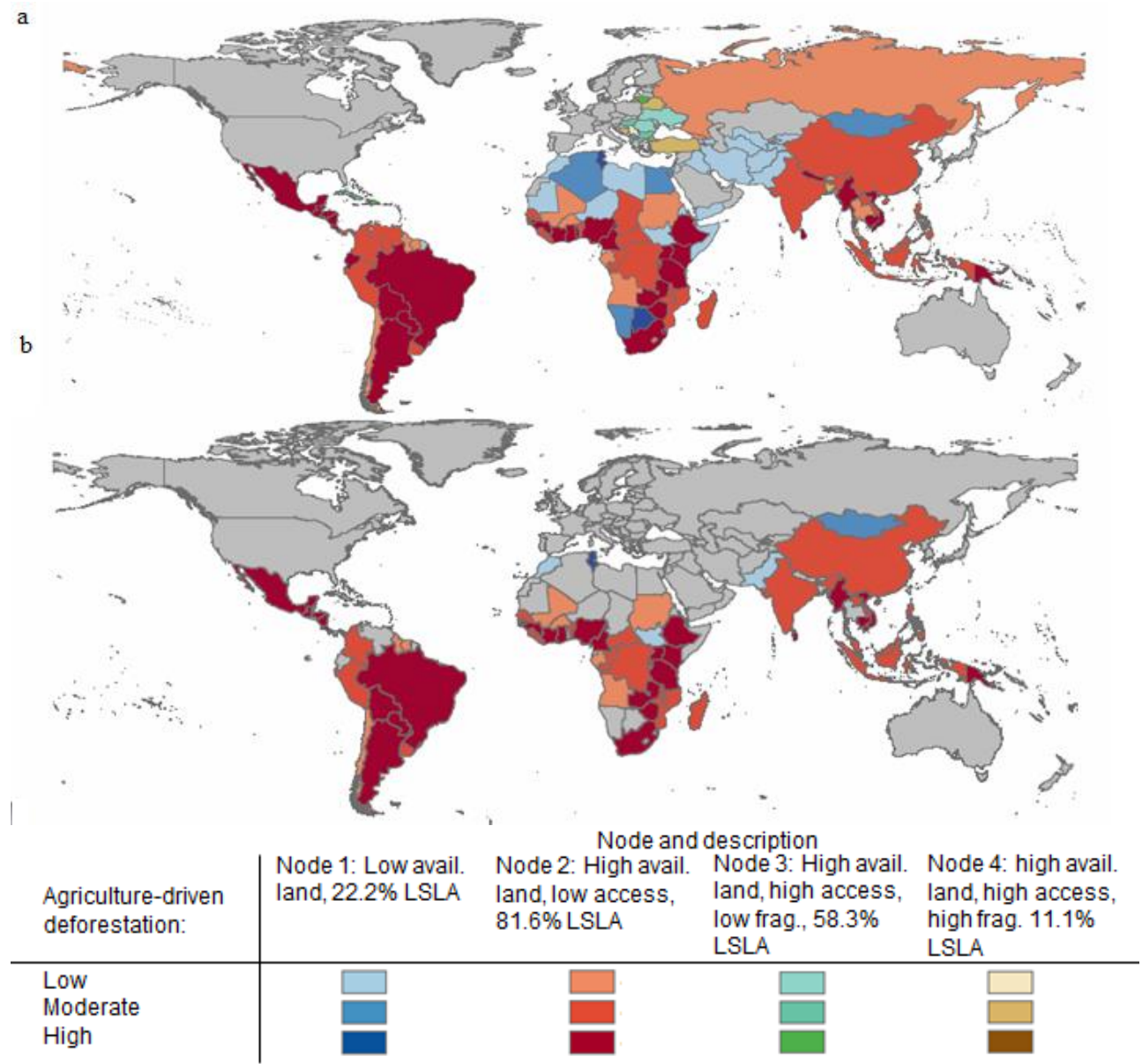

Figure 4.2. Agriculture-driven deforestation (percent forest loss 2000-2010 divided into tertiles) and classification of country with respect to likeliness of LSLA placement in the classification tree (Figure 4.1) for (a) all countries in the study, which also colours those countries which do not report LSLA but show similar characteristics to those with LSLA. (b) only those countries are coloured (in accordance to the classification as described in a), for which LSLA is reported and which participate in REDD+. Nodes are defined in accordance to the results of the classification tree, 1: low available (avail.) land, 2: High available land and low access, 3: high available land, high access, low fragility (frag.), 4: high available land, high access and high fragility. 
Figure 4.2 (see also Table 1 in the supplementary materials of the online publication) groups countries according to the level of agriculture-driven deforestation (percent forest loss, divided into tertiles) and the node in which they end up in the classification tree. Node 1 , in which $22.2 \%$ of the countries have LSLA, includes mainly countries with low agriculturedriven deforestation, and node 2 , where most countries ( $81.6 \%$ of all countries) have LSLA includes countries which are more likely to have high agriculture-driven deforestation.

REDD+ and LSLA can both occur in the same country (Figure 4.2, Table 4.3). Only countries that are eligible for REDD+ (non-annex 1 countries) and are within the scope of the Land Matrix (low and middle income countries) were analysed. Targets of LSLA were 12 times (95\% confidence interval 5 - 32) more likely to be engaged in REDD+ than those who do not have LSLA (P-value of Fisher exact test of association between 132 targets of LSLA and REDD+ <0.001).

Table 4.3. Instances of LSLA recorded in Land Matrix and engagement in REDD+

\begin{tabular}{lll}
\hline Number of countries $^{\mathbf{1}}$ & LSLA & No-LSLA \\
\hline REDD+ & 62 & 17 \\
No-REDD+ & 12 & 41 \\
\hline
\end{tabular}

${ }^{1} 10$ countries included in the Land Matrix were not eligible for REDD+ (i.e. they were UNFCCC Annex 1 countries) so they were not included in this analysis.

Of the countries which are eligible for REDD+, countries in node 2 (around $80 \%$ of which have LSLA) are more likely to be engaged in REDD+ than those in the other nodes in the decision tree (which less have LSLA). Countries in node 2 with high agriculture-driven deforestation tend to be engaged in REDD+ (31 out of 34 countries, all of which are eligible for REDD+), and are spread across Africa, South and Central America and Asia.

In the 30 countries for which REDD+ documents were assessed, agriculture expansion was noted as a major driver of deforestation, with commercial monocultures typical of LSLA being cited as major causes in many countries (Table 2 in the supplementary materials of the online publication). In a number of countries, agricultural LSLA are occurring but the country does not cite commercial agricultural expansion as a driver (Democratic Republic of the Congo, Kenya, Republic of Congo, Zambia) (Kissinger et al. 2012). In these cases it could be that LSLA occur in non-forested land, or more likely that the driver is not recognized. In some countries, LSLA was specifically identified as a direct driver of deforestation (Burkina Faso, Cambodia, Central African Republic, Guatemala) (Kissinger et al. 2012). Indirect drivers also pointed towards LSLA being a threat, with weak governance, poor enforcement of laws, and tenure being cited commonly as drivers (Kissinger et al. 2012). Two of the countries in the study by Kissinger et al.(2012) which did not have LSLA (El Salvador, 
Panama) cited agriculture expansion, and in particular commercial/mechanized agriculture as a main driver of deforestation. In these cases, it could be that domestic LSLA were occurring (which were excluded from the analysis). Of the 27 REDD+ countries investigated which have LSLA, only nine have interventions aiming to reduce deforestation which address the driver. For the four countries that specifically cite LSLA as a driver of deforestation (including Cambodia, Burkina Faso and Central African Republic), only Guatemala has planned interventions which specifically address this and other drivers identified there.

\subsection{Discussion}

\subsubsection{The characteristics of countries which are objects of LSLA}

The review of literature revealed four important requirements for LSLA: potential for returns, available land, access for investment, and security of investment. The results from this analysis confirm several of these requirements. Available land was found to be the main determinant of whether a country will have LSLA. Countries with > 19\% land suitable for agriculture were more likely to have LSLA than countries with less than $19 \%$ available land (21 countries). These countries with less than $19 \%$ available land included those covered by large arid areas which is not suitable for agriculture (for example those with land area within the Sahara desert: Algeria, Eritrea, Egypt, Libya, Niger). For countries with large areas of available land, access to land is also relevant to whether or not they have LSLA. Literature on LSLA suggests that areas with access to markets are more favourable for LSLA, and this may be the case for individual instances of LSLA. Our study found that countries with low access are more likely to have LSLA, which is likely to be partly because our research focuses on deals, which are often large (on average $>330 \mathrm{~km}^{2}$ (The Land Matrix Global Observatory 2013)), and it is likely that large tracts of land cannot be found in countries which have more urban areas for example (where access is high). Countries which have a large areas of suitable land but access of <192 minutes travel time to markets on average in the country, are not interesting to investors if countries fragility is high. This confirms the hypothesis that security of investments is likely to be a consideration for investors. Indicators which identified the 'access for investors' criteria (favourable conditions for business, and regulatory quality), were not found to be related to LSLA according to this methodology. However, an indicator not being recognized in the decision tree does not confirm the absence of a link with LSLA. Other indicators for this criteria 'access for investors' could be tested to confirm the hypothesis posed in this study. 
Countries which exhibit the characteristics which are attractive to investors: land availability, poor accessibility, and political stability may be future targets if they do not already have of LSLA (for example Belize, Ecuador, Nepal and Togo).

There are other characteristics which literature suggested would be linked with LSLA but which were excluded from the analysis because they were not relevant for investors, or data were not available or suitable. For example land prices were found to influence LSLA, with cheap land being preferred by investors as there is potential for capital accumulation, which can mitigate risks in agricultural production (Cotula 2012). However, there is a lack of data on land prices thus it was not included in the analysis. Populated areas can also be attractive to LSLA investors (Messerli et al. 2013), however population density was not included since it is likely to vary widely across countries, with the national average not describing situation for local LSLA investments well (Eckert et al. 2016). Despite these limitations, the deductive approach used to identify factors which attracted investors, allowed the identification of key characteristics of countries which were objects of LSLA. More research carried out at different scales, would allow the identification of more characteristics linked to LSLA (Eckert et al. 2016)

\subsubsection{Impact of LSLA on forests}

This study did not include domestic LSLA, since the aim of the C\&RT analysis was to investigate what characteristics attract foreign LSLA investors to countries. However, domestic LSLA can still threaten forests, so Bangladesh, Niger and Thailand which have only domestic deals should be considered when analysing the impact of LSLA on forests (see Table 1 in the supplementary materials of the online publication).

Countries with LSLA or that have characteristics found in countries with LSLA, often have high agriculture-driven deforestation (Figure 4.2). Although this study cannot confirm a causal relationship (neither direct nor indirect) between LSLA and deforestation, LSLA are often very large, and have been reported to occur in forested areas, and therefore can impact forest cover. According to the Land Matrix, the average size of concluded transnational deals (for any intention) is $364 \mathrm{~km}^{2}$, which is more than the area of annual deforestation in 83 of 125 countries included in this study for which data were available (17 had no data). Many countries also have multiple deals, and considering that the largest agriculture-related reported deal is $14,000 \mathrm{~km}^{2}$ (Republic of Congo), there is potential for large areas of forest loss if forested areas are targeted. On average there are 15 concluded deals in each country, and the countries with the largest number of LSLA are Indonesia (125), Cambodia (104) and Mozambique (79). In these countries increased attention to forest loss associated with LSLA would be beneficial, as a larger area of LSLA may result in a larger chance of forests being 
targeted. The relative size of forest compared to agricultural land is also likely to be important for estimating impacts of LSLA on forests, for example Democratic Republic of the Congo has vast forest areas, and the total area of land deals in this country (according to the Land Matrix database) account for an area of only $1 \%$ of the total forest area. In contrast, in Cambodia, land deals account for an area equivalent of $16 \%$ forest area, $28 \%$ agricultural area, or $41 \%$ of its arable land area (NGOs estimate a higher proportion: between 56 and $63 \%$ of the arable land area (Edelman 2013)). Even if non-forested land in Cambodia is targeted for LSLA, deforestation could occur indirectly where existing activities on the land are displaced into forests.

In some cases LSLA are 'virtual' acquisitions as the conversion to another land use is postponed for long periods, is partially realized, fails to materialize (McCarthy et al. 2012), or acquisitions are speculative and so they involve small and temporary investments (Messerli et al. 2013). These virtual acquisitions may have less of an impact to forests than when conversion to agriculture occurs. However, even if the land is not converted for its intended use, degradation may occur as experienced in Indonesia, where licences and subsidies are given for establishing plantations, but companies instead clear the forest, sell the timber and abandon the land (Romijn et al. 2013). In this case, if land is not subsequently converted to agriculture, it is possible that regrowth of the forest will occur.

\subsubsection{Potential to reduce the impact of LSLA on forests}

To avoid loss of forests from LSLA, the link between the two needs to be understood. Salvini et al. (2014) describe a logical chain for developing interventions to address drivers of deforestation. For interventions to be effective, an understanding of specific drivers should be made and following this, interventions can be designed to address these drivers. REDD+ interventions should then be redesigned following an assessment (monitoring) of the success of the intervention. In in many cases, this link between drivers and interventions is not made in REDD+ plans (Table 2 in the supplementary materials of the online publication). For the countries in which agricultural LSLA are occurring, but in which commercial agricultural expansion is not cited as a driver (Democratic Republic of the Congo, Kenya, Republic of Congo, Zambia) more work can be invested in determining if LSLA is driving deforestation (the first step in the logical chain). The second step is designing the interventions to match the drivers. In the cases of Indonesia, Cambodia and Mozambique (the countries with the highest number of LSLAs according to the Land Matrix), the impacts of commercial agriculture on forests are recognized in the REDD+ documentation, however only in Mozambique were the interventions found to match the drivers of deforestation (Table 2 in the supplementary materials of the online publication). For countries which do not recognize commercial agriculture as a driver of deforestation but that identify LSLA as a driver, indirect 
drivers such as lack of planning and consultation, and lack of secure land tenure are cited. Based on this knowledge, countries can develop interventions which address these indirect drivers, however, developing interventions directly targeting LSLA is recommended to reduce the impact of LSLA on forests.

The fact that some countries do not identify drivers, or do not propose interventions which address these drivers is particularly interesting. Of the 27 countries which were assessed (Table 2 in the supplementary materials of the online publication), all had already produced the R-PP s which forms the basis of their strategy in the FCPF (excluding Zambia which is participating in UN-REDD), so are relatively advanced in terms of REDD+ implementation.

In general, investments in agricultural land (such as through LSLA) are thought to lead to increased returns which incentivise expansion (Angelsen 2008; Deininger \& Byerlee 2011; Pirard \& Belna 2012). Two potential mechanisms exist through which agricultural investments can occur without impacting forests. Firstly, existing agricultural land can be acquired and production maintained or increased to avoid the displacement of agricultural activities to other areas (Valin et al. 2013; Ausubel et al. 2013). The Land sparing concept (or segregation) suggests that increasing the output on agricultural land reduces the need to increase agricultural areas (Kastner et al. 2012; Stevenson et al. 2013). Specifically, technology-induced intensification is supposed to be land saving at the global level (Byerlee et al. 2014) but could potentially have negative effects on productivity (Seppelt et al. 2016). Secondly, available or degraded land can be used for LSLA, again avoiding the need to acquire forested areas (Carter et al. 2015). Global maps of unused or low carbon land have been produced (Dinerstein et al. 2015), but national or regional maps are needed to suggest hot spots and cold spots of LSLA and deforestation coincidence. However there is some debate on whether there is land unused, or idle available (which is non-forested), and also whether current maps are useful for identifying it, as discussed by Nalepa and Bauer (2012) on the use of remote sensing tools to identify marginal land. There are several examples of initiatives which aim to restore degraded land, for example 'Initiative 20x20' which aims to restore 20 million hectares of degraded land in Latin America and the Caribbean by 2020 (World Resources Institute 2016). However, these initiatives themselves need to be implemented with care, as they be classed as "green grabbing" and may involve elements found in LSLA; large areas, and a change in land rights being obvious ones.

\subsubsection{Planning for LSLA and REDD+}

Since there are a number of countries which have both REDD+ and LSLA, there is an opportunity for lessons learned in REDD+ to be transferred into the policies relating to LSLA. In the case of Liberia, the R-PP aims to avoid REDD+ becoming a LSLA. Much 
research is focussed on the impacts of LSLA on smallholders, which mainly stem from loss of land (Anseeuw et al. 2012; Cotula 2012; Fairhead et al. 2012; Edelman et al. 2013; Oberlack et al. 2016). Community participation is one key approach to mitigate this (Oberlack et al. 2016). The 'Cancun safeguards for policy approaches and positive incentives on issues relating to REDD+ (UNFCCC 2010) include several actions mostly relating to rights of local communities and other stakeholders, which could be modified for the context of LSLA and directly integrated into national regulations. Consultations for REDD+ require the engagement of relevant stakeholders, and an iterative consultation process that includes a complaint management process; a structure which would also be suited to the LSLA context. This has in some cases led to better tenure security (Larson et al. 2013), which could also be beneficial for investors in LSLA. Similar recommendations can also be found for instance in Cotula et al. (2009).

In practice, that there is a potential for interventions in the supply chains of agricultural products (for example those produced in LSLA) which aim to reduce deforestation, to be implemented alongside REDD+ to produce low emissions rural development (Nepstad et al. 2013). Green public procurement policies (for example the Roundtable for Sustainable Palm Oil (RSPO 2016) and Round Table on Responsible Soy (RTRS 2016)) could also make agricultural production more sustainable and aligned to climate change objectives. Zerodeforestation is commonly understood as commitments from the private sector to eliminate deforestation from their supply chain (Meyer \& Miller 2015), and when applied to LSLA can avoid forest loss. Since investors of LSLA in this study are international and due to the scale of investments, it is likely that some are exporting products. Concern from countries and consumers in importing countries about environmental issues could lead to uptake of green procurement policies in LSLA.

One barrier to success is policy coherence which is typically difficult to achieve, and conflicting policies (for example those favouring LSLS and those favouring REDD+) can hinder sustainable land use (Minang et al. 2015).

LSLA and REDD+ show two distinct patterns with respect to the governance of the global land system. While the first is driven by tele-connected global agricultural markets, the latter is a legal framework introduced to mitigate climate change. This study demonstrates how these processes co-occur in different countries where competition for land can potentially lead to conflicts. As such, LSLA should be specifically discussed in platforms where interventions to reduce deforestation are being planned. Our analysis suggests that land management must be considered with all its objectives such as food security, biodiversity conservation, climate change mitigation in a coherent strategy which engages relevant stakeholders. This is not currently occurring and might be a key ingredient for the implementation of activities to achieve the targets under the Sustainable Development Goals 
2, 15 and 16 (related to food security and sustainable agriculture and the protection of forests) among others.

\section{Acknowledgements}

We acknowledge funding from the Germany Federal Ministry of Education and Research (GLUES, 01LL0901A, R.S.), and the International Climate Initiative (IKI) of the German Federal Ministry for the Environment, Nature Conservation, Building and Nuclear Safety (BMUB), NORAD (Grant Agreement \# QZA-016/0110 nr 1500551), and AusAID (Grant Agreement \# 63560) within CIFOR's Global Comparative Study on REDD+. This research contributes to the Global Land Project (www.globallandproject.org) and was carried out as part of the CGIAR Research Program on Forests, Trees, and Agroforestry. We thank the reviewers for their helpful comments which strengthened the manuscript. 


\section{Climate smart agriculture and REDD+}

This chapter is based on: S Carter, B Arts, KE Giller, C Soto Golcher, K Kok, J de Koning, M van Noordwijk, P Reidsma, MC. Rufino, G Salvini, L Verchot, E Wollenberg, and M Herold. Climate-smart land use requires local solutions, transdisciplinary research, policy coherence, and transparency. Carbon Management Accepted, on condition of minor revisions. 


\section{Abstract}

Successfully meeting the mitigation and adaptation targets of the Paris Climate Agreement (PA) will depend on strengthening the ties between forests and agriculture. Climate-smart land use can be achieved by integrating climate-smart agriculture (CSA) and REDD+. The focus on agriculture for food security within a changing climate, and on forests for climate change mitigation and adaptation can be achieved simultaneously with a transformational change in the land-use sector. Striving for both independently will lead to competition for land, inefficiencies in monitoring, and conflicting agendas. Practical solutions exist for specific contexts that can lead to increased agricultural output and forest protection. Landscape-level emissions accounting can be used to identify these practices. Transdisciplinary research agendas can identify and prioritize solutions and targets for integrated mitigation and adaptation interventions. Policy coherence must be achieved at a number of levels, from international to local to avoid conflicting incentives. Transparency must lastly be integrated, through collaborative design of projects, and open data and methods. Climate-smart land use requires all these elements, and will increase the likelihood of successful REDD+ and CSA interventions. This will support the PA as well as other initiatives as part of the Sustainable Development Goals.

\subsection{Introduction}

The ambitious goals set at the 21st conference of parties (COP) of the UN Framework Convention on Climate Change (UNFCCC) in Paris have since been discussed in Bonn and Marrakesh. The Road Map for Global Climate Action, notes a long-term move in focus from mitigation action towards adaptation (Tubiana \& El Haite 2016), which will also be reflected in funding allocation (UNFCCC 2016a). The Marrakesh Action proclamation promises actions in the agriculture sector, primarily ensuring food security and enhancing the ability to deal with climate change impacts on agriculture (UNFCCC 2016b). There was further progress on agriculture in Bonn, the links between agriculture and climate change was included as a discussion point, with options such as increasing soil carbon mentioned (UNFCCC 2017). At the same time, the Paris Climate Agreement (PA) features forest-based mitigation as a key mitigation strategy as well as working to secure food production. This presents a potential conflict between forests and agriculture.

The land use sector is unique in its large potential for negative emissions, besides climate engineering options such as carbon capture and storage (see van Vuuren et al. 2015), and therefore must be fully utilized. The focus on food security and food production in the PA 
must leverage the potential synergies between adaptation and mitigation, which will support forest protection (Duguma et al. 2014). A crucial point of entry relates to linking existing concepts that address climate change mitigation and adaptation in the land-use sector, such as Climate-Smart Agriculture (CSA) and REDD+. CSA aims to tackle three main objectives: sustainably increasing agricultural productivity and incomes; adapting and building resilience to climate change; and reducing and/or removing greenhouse gas emissions, where possible (FAO 2013). REDD+, a forest-based mitigation mechanism, aims to reduce emissions from deforestation and forest degradation and to conserve forests and enhance forest carbon stocks by reducing pressure from drivers of deforestation, and managing forests sustainably. The agricultural drivers of deforestation, and their links to food security should also be well understood. Commercial agriculture, which is often the result of large-scale land acquisitions, can have a large impact on forests (Carter et al. 2017), and can lead to food insecurity for smallholders (Cotula 2012). Smallholder farming in contrast has a large role to play in terms of food security (FAO 2014c). These key differences must be addressed when planning interventions.

The primacy of food production is clear in global strategies, not only in the PA (and the main text of the UNFCCC) but also in the Sustainable Development Goals (UN 2016). With increasing global populations, this focus is crucial, as population increases are not matched food production increases (Alexandratos \& Bruinsma 2012), and in Africa, population growth is expected to be the dominant driver of food insecurity above climate change (Hall et al. 2017). As such, the focus of CSA leans towards food security and adaptation, with mitigation being pursued only 'where possible'; a shift from earlier definitions in which it was described as a mandatory component (FAO 2010a). In addition, the mitigation potential of agriculture and forests varies greatly from country to country (Carter et al. 2015), as well as the motivation within a country to focus on one or the other of the aims (Richards et al. 2015). A major challenge in reconciling the two is the different accounting bases for food production relative to consumer demand, and area-based carbon balance in land use. For this reason, in this paper we focus on the forest sparing potential of interventions in the agricultural sector which seek to provide food security benefits.

The starting point for our analysis is the need to reconcile competing claims on land for climate mitigation (including forest protection and biofuel production) and for food production. Since deforestation is closely linked with agriculture (Hosonuma et al. 2012; De Sy et al. 2015), REDD+ will fail if agriculture expansion into forests persists (Kissinger et al. 2012; Locatelli et al. 2015). A review of REDD+ readiness documents reveals that most forest-related policies tend to overlook agricultural drivers of deforestation (Salvini et al. 2014). Initiatives that increase production on existing agricultural land can in a planned economy reduce the need to expand agriculture into, for example, high carbon landscapes (forests, woodlands, wetlands). In a market economy, however, the land sparing effects of 
intensification might only be achieved if it induces commodity prices to drop to a level that expansion and less-intensive production become uneconomic uses of land and labour, otherwise increasing profits from yield improvements can lead to increased land acquisition for agriculture. This can however be avoided, if agricultural intensification is coupled with forest protection mechanisms (for example policies or interventions which directly address the agriculture drivers) to ensure that forest-sparing actually occurs (Mandemaker et al. 2011; Strassburg et al. 2013; Carter et al. 2015; Kastner et al. 2012; Rudel et al. 2009). While REDD+ may operate with area-based ('simple') scaling rules, global markets for agricultural commodities imply more complex scale relationships for CSA, and hence for the way REDD+ and CSA are related to each other (Minang et al. 2015). These feedbacks at different scales call for an exploration of how REDD+ and CSA could be linked, and what the mutual synergies and trade-offs might be. We propose an approach in which not all agricultural expansion is avoided, but in which emissions from agriculture-driven deforestation are minimized, and food security is protected.

Support to develop solutions which reduce deforestation may be found in the emerging science on the dependence of hydroclimates on vegetative cover (Ellison et al. 2017), which highlights the links CSA and REDD+ further. For example, those interventions which secure food production and those to protect forests can be mutually beneficial: forests provide numerous ecosystem services that can increase the adaptive capacity of agriculture which reduces vulnerability to climate change (Vignola et al. 2009; Ellison et al. 2017). Forestgenerated humidity, soil stability and soil fertility maintenance are services which are crucial for agriculture, but also support communities by providing drinking water and reducing risks such as landslides and flooding. Additionally, forest products provide safety nets for local communities when agricultural yields decline because of climate change impacts (Turner et al. 2009), further supporting the goal of securing food production (Alkama \& Cescatti 2016; van Noordwijk et al. 2014).

\subsection{A roadmap for transformational change}

Currently, there is a lack of coherent policies and conflicting incentives in the agriculture and forest sectors, implying that emissions reductions can only be realised through a deep transformational change. Transformational change, is a move away from the business as usual and is likely to include a shift in practices, a change in commodities, innovative policies, and/or financing actions (Lipper et al. 2014). We envisage that changes can be applied incrementally or stepwise, however, major changes across sectors and at all levels will be required (Foley et al. 2011; Lipper et al. 2014). 
To address the challenge of competition for land, while promoting forest-based mitigation efforts without compromising food production, we propose an area-based integration of REDD+ and CSA at intermediate (e.g. local government or 'jurisdictional') scales, to enhance synergies and reduce trade-offs. We argue that the costs of not integrating will lead to competition for land and other resources, inefficiencies in monitoring, and conflicting agendas which leads to less success in reducing forest loss and in protecting food security. An integrated approach requires:

1. Practical local solutions which integrate CSA and REDD+ and reduce emissions at the landscape scale,

2. Transdisciplinary research approaches and priorities, in the agricultural, forest, social sciences and non-scientific communities,

3. Policy coherence at (inter)national and local levels,

4. Transparency in reporting and engagement.

\subsection{Practical local solutions}

The definition of what is and what is not CSA is important if economic incentives and policy recognition matter. We propose that practices should only be classed as CSA when they, in addition to enhancing food security and increasing resilience, achieve reductions in greenhouse gas emissions (mitigation) at the landscape level including importantly the lifecycle of the product, and avoid expansion of agriculture into forests, which should be avoided where possible. Sa et al. (2017) used a similar definition for activities which mitigate climate change and advance food security in South America. They stated these activities must have "low carbon dioxide $\left(\mathrm{CO}_{2}\right)$ emissions from land use (LU) and land use change (LUC) in response to agricultural best management practices" (Sa et al. 2017). Only activities which met these criteria, were considered suitable by the authors to contribute to the Low Carbon Agriculture (LCA) strategy as part of Brazil's programme on low carbon agriculture (Climate Action 2012). The activities identified were diverse, and included restoration of degraded pasture, biological $\mathrm{N}$ fixation and plantations of commercial forests. In all the scenarios assessed by the study, food production increased. In order for this to occur, the expansion of agricultural land was required. In these cases, emissions from the expansion event should be estimated and used to guide decision making as to whether and where agriculture should expand.

Calculating the emissions intensity of crops is a useful tool to understand the impact of production and also to set targets for mitigation (Carlson et al. 2016). Different outcomes in terms of the best options for mitigation can be found by using different accounting methods (van Noordwijk et al. 2016), so using a number of approaches and comparing results can be useful for decision makers. The 'carbon debt' when establishing oil palm plantations in 
Indonesia has been discussed by van Noordwijk et al. (Figure 5.1) (van Noordwijk et al. 2016). In this case an optimal fertilizer level is determined by the production levels at which net emission savings per unit of biofuel are maximized. These figures are then compared to the carbon debt of clearing land - including draining of peatlands, and the loss of forests. The carbon debt and emissions from fertilizer were the dominant factors in the whole life cycle assessment - showing how important the impacts on the forest sector are for mitigation efforts in agriculture. Palm oil produced on peat soils, and in some cases mineral soils was found not to meet the current EU emissions threshold for biofuel production, which requires at least $35 \%$ emissions savings compared to fossil fuels.

\begin{tabular}{|c|c|c|c|}
\hline $\begin{array}{l}\frac{\text { Unit of }}{\text { analysis / }} \\
\text { stakeholders }\end{array}$ & $\begin{array}{l}\text { Emissions component } \\
\text { A. Länd cover change: } \\
\text { biomass stock change }\end{array}$ & $\begin{array}{l}\underline{\text { Units }} \\
\Delta \mathrm{C}, \mathrm{t} \mathrm{ha}^{-1}\end{array}$ & $\begin{array}{c}\text { Productivity } \\
\text { (unprocessed) }= \\
\text { tFFB ha-1 } \mathrm{yr}^{-1}\end{array}$ \\
\hline $\begin{array}{l}\text { Pixel/plot } \\
\text { Foresters }\end{array}$ & $\begin{array}{l}\text { from original vegetation } \\
\text { biomass to oil palm } \\
\text { plantation }\end{array}$ & $\begin{array}{c}\mathrm{tCO}_{2} \mathrm{e} \\
\mathrm{ha}^{-1} \mathrm{yr}^{-1}\end{array}$ & $\begin{array}{c}\downarrow \\
\text { Productivity } \\
\text { (processed) }=\end{array}$ \\
\hline $\begin{array}{l}\text { Industry } \\
\text { Farmers }\end{array}$ & $\begin{array}{l}\text { B. Production of inputs: } \\
\mathrm{CO}_{2} \text { emissions from } \\
\text { fertilizer production }\end{array}$ & $\begin{array}{c}\mathrm{tCO}_{2} \mathrm{e} \\
\mathrm{ha}^{-1} \mathrm{yr}^{-1}\end{array}$ & $\begin{array}{c}\frac{\text { tCPO ha-1 } \mathrm{yr}^{-1}}{\downarrow} \\
\text { Footprint }=\end{array}$ \\
\hline Life cycle of & $\begin{array}{l}\text { C. Recurrent land use } \\
\text { emissions: } \\
\mathrm{N}_{2} \mathrm{O} \text { from fertilizer, } \mathrm{CO}_{2}\end{array}$ & $\mathrm{tCO}_{2} \mathrm{e}$ & $\begin{array}{c}(\mathrm{A}+\mathrm{B}+\mathrm{C}) / \\
\text { productivity } \\
\text { (processed) } \\
\mathrm{tCO}_{2} \mathrm{e} / \mathrm{tCPO}^{-1}\end{array}$ \\
\hline $\begin{array}{l}\text { plantation } \\
\text { Farmers }\end{array}$ & $\begin{array}{l}\text { (including peat), } \mathrm{CH}_{4} \\
\text { from soil management } \\
\text { D. Processing and }\end{array}$ & & $\begin{array}{l}\downarrow \\
\text { FF equivalent }= \\
\text { Footprint } / \mathrm{t} \text { FF }\end{array}$ \\
\hline $\begin{array}{l}\text { Product } \\
\text { Private sector }\end{array}$ & $\begin{array}{l}\text { transport: } \mathrm{CH}_{4} \text { from } \\
\text { palm oil processing and } \\
\mathrm{CO}_{2} \text { from fossil fuel use }\end{array}$ & $\begin{array}{c}\mathrm{tCO}_{2} \mathrm{e} \\
\mathrm{ha}^{-1} \mathrm{yr}^{-1}\end{array}$ & Emission saving \% = \\
\hline $\begin{array}{l}\text { Energy sector } \\
\text { Private sector }\end{array}$ & $\begin{array}{l}\text { E. Comparator: fossil fuel } \\
\text { emissions for equivalent } \\
\text { end-user utility }\end{array}$ & t FF & $\begin{array}{c}\text { 100*(1-footprint/ } \\
\text { FF equivalent) }\end{array}$ \\
\hline
\end{tabular}

Figure 5.1. Information flow in an assessment of the emission footprint per unit palm oil, and subsequent step to estimate the percentage emission saving in biofuel use (adapted from van Noordwijk et al. (2016). FFB = fresh fruit bunches, $\mathrm{CPO}=$ crude palm oil.

In van Noordwijk et al. (van Noordwijk et al. 2016), an optimum fertilizer application rate can be identified for a given relationship between fertilizer and yield. Attention to other management choices can, however, shift the relationship between fertilizer and yield, as 
current fertilizer use on smallholder oil palm farms can be excessive and inefficient (Soliman et al. 2016).

Similarly, Sa et al. (Sa et al. 2017) assessed emissions associated with land use change over time using the concept of ecosystem $\mathrm{C}$ pay-back time (ECPT). ECPT considers how long the annual savings from the Low Carbon Agriculture (LCA) activities (in comparison with nonLCA) can repay the debt of conversion (for example clearing the forest in the conversion to agriculture). ECPT, expressed in years, represents the time that the intervention has to be effective in order to offset the land use and land use change emissions from the intervention. Implementing activities in areas with the lowest ECPT is a way of minimizing the impact, and the restoration of degraded pastures was found to be one of the most advantageous scenarios, although it still had an ECPT of 56 to 188 years (Sa et al. 2017). In the case of Sa et al. restoration of pastures was achieved by application of fertilizers, lime and gypsum, (accounting for associated emissions related to their application, as well as altering species composition and introducing forage management to increase the carrying capacity. The restoration of grazing land has also been implemented as a National Appropriate Mitigation Action (NAMA), and has been estimated to fulfil $10-12 \%$ of pledged emission reductions for the year 2020, due to land spared from deforestation (Cohn et al. 2011). We suggest that restoration of pastures can be a promising tool to reduce agricultural expansion into forests, and should be considered as a priority mitigation action in the agriculture sector. However in many cases, degraded land has marginal potential for production, even after costly rehabilitation. Lal (Lal 2016) suggested that agriculturally marginal and degraded soils should be avoided for this purpose (and could be set-aside for nature), and that lands with potential for higher yields could be restored, for example those in areas of sub-Saharan Africa and South Asia where there is potential for tripling or quadrupling of yields. Over 1.3 billion people however, use degraded agricultural land, particularly in the drylands (UNCCD 2017), and in general larger soil $\mathrm{C}$ sequestration rates can be achieved from interventions to increase $\mathrm{C}$ sequestration in degraded soils than from other soils (Minasny et al. 2017). There are a number of GHG mitigating practices which can be implemented to restore degraded and marginal land, such as the use of cover crops, avoiding overgrazing, using crop residues and organic composts and agroforestry, however employing these is not always straightforward (Paustian et al. 2016). The conditions under which yields in sub-Saharan Africa and South Asia could be increased while sparing land should be investigated, utilizing the existing body of evidence on successful CSA interventions (FAO 2013) (see for example also (Sa et al. 2017; van Noordwijk et al. 2016; Soliman et al. 2016; Lal 2016)) . The dichotomy between forest and agriculture itself may prevent the emergence of optimal solutions, as for example in a landscape where fodder for dairy cows can be derived from any part of the landscape (Lusiana et al. 2012).

The sink capacity of forests can provide a large and cost effective contribution towards climate change mitigation (Richter \& Houghton 2014). However, agricultural systems can 
also provide mitigation benefits, as well as contributing to forest sparing. In fact, a recent global study of trees in agricultural lands suggested a considerable carbon stock that has so far been ignored in the accounting (Zomer et al. 2016). Agroforestry and soils represent a sink potential and biogas digesters a promising mitigation potential, and measures related to these potentials have been implemented without compromising agricultural production (Wilkes et al. 2013). Agroforestry has one of the highest land-based potentials to sequester carbon (Mbow et al. 2014; Rosenstock et al. 2014; Locatelli et al. 2015), and provides the adaptation benefits aimed at by CSA. It is however also reversible, so land can be converted back to tree-less agriculture should local priorities change. Reducing emissions from soils storage is possible through a number of management interventions such as increasing inputs which contain $\mathrm{C}$, avoiding over fertilization of crops, and altering irrigation and tillage regimes (Minasny et al. 2017). This has received recent attention for example through the Soils for Food Security and Climate 4\%o Initiative (4 per 1000 Initiative 2016; Lal 2016). Knowledge gaps exist however, in for example soil $\mathrm{C}$ sequestration processes, turnover, and stabilization (Paustian et al. 2016), and potential trade-offs between soil C sequestration and $\mathrm{N}_{2} \mathrm{O}$ emissions (Bos et al. 2017), making it controversial not least because it is easily reversible. There is currently also an active debate on the potential of the 4 per mille initiative, and whether the claims (of offsetting 30\% of global GHG emissions (Minasny et al. 2017)) are feasible. Although the difficulties of engaging large numbers of people who are using agricultural lands around the world, and the technical challenges in monitoring and verifying results are discussed (Minasny et al. 2017), other points such as the feasibility of including currently unmanaged rangelands, time to reach carbon equilibrium, and depth at which soils can be managed are still being debated (de Vries (2018), among others). However, identifying areas which have the potential to increase soil $\mathrm{C}$ stocks at a rate of $4 \%$ o could contribute to climate mitigation efforts, and soils remain an important consideration in the context of this paper, in their role in forest-sparing and food security.

Although interventions exist which not only deliver increased production within a changing climate (food security), but that also avoid that land-use change (particularly from forests or other high carbon landscapes), robust and inclusive methods to identify which ones can provide the largest mitigation benefits must be used.

\subsection{Transdisciplinary research approaches and priorities}

Transdisciplinary research is vital to set priorities for climate change actions in the land use sector. Research should recognize the varied interests of each actor by answering questions and delivering results which the stakeholders find useful (Giller et al. 2015). Approaches should account for the disconnect between the timescales at which various actors operate for example climate science considers longer timescales than those at which farmers, and at 
which foresters make decisions. Using backcasting to develop transition pathways is one way to evaluate options to achieve multiple sustainability objectives (e.g. van Vuuren et al. (2015)). In addition, models and tools should be able to assess the outcomes of various interventions related to adaptation, mitigation, and food production (Valin et al. 2013; Havlík et al. 2014; Descheemaeker et al. 2016). Trade-offs for stakeholders are inevitable, which need to be evaluated (for example in the context of the landscape approach). Smallholder farmers are often key stakeholders who should be consulted, and who will then assess whether they are willing to engage in such interventions. Engel and Muller (2016) discuss the potential for incorporating CSA into a payments for ecosystem services (PES) context (for example REDD+), and highlight the potential for PES to address some reasons why farmers do not adopt CSA. A PES approach was found deal with issues such as an unwillingness to wait for medium or long-term productivity and an aversion to risk, as shortterm costs are often required (Engel \& Muller 2016). Other barriers identified included lack of information, and insecure tenure and weak property rights. These issues can both be addressed by incorporating CSA into the framework of REDD+ projects. Securing tenure and community engagement are key processes for REDD+ implementation.

Landscape approaches could provide a platform for assessing the benefits and challenges of integrating mitigation and adaptation (Turnhout et al. 2016; Reidsma et al. 2015; Minang et al. 2015) (also for emissions accounting as discussed previously). To involve and improve communication between stakeholders and researchers in the landscape, methods using both quantitative and qualitative data can be used (for example role playing games (Salvini et al. 2016; Villamor \& van Noordwijk 2011), and innovative participatory scenario planning (Diniz et al. 2015)). Increasing availability of remote sensing data, emerging technologies and community based monitoring can be the focus of research streams aiming to monitor results from both CSA and REDD+ together (de Sassi et al. 2015; Pratihast et al. 2013). Measuring the impacts of ongoing initiatives is key to understand how to implement a landscape approach.

To have the greatest impact, interventions in the agricultural sector which promote forest land-sparing should be implemented first in areas where most agriculture-driven deforestation, and emissions from agriculture are occurring (Bastos Lima et al. 2015). These were identified at the national level by Carter et al. (Carter et al. 2015). Emission hotspots have been identified on a much higher spatial resolution by Roman-Cuesta et al. (2016), through a collaborative effort from the forest and agricultural communities. Hotspots covering $25 \%$ of the tropical area are responsible for $70 \%$ of the tropical AFOLU (Agriculture, Forestry and Other Land Use) emissions. All continents have hotspots and they cover a variety of biomes across the tropics - so these make promising locations for interventions (Roman-Cuesta et al. 2016). Typically emissions in hotspots are dominated by forest emissions (69\%; e.g. fire, deforestation and wood harvesting), highlighting the 
important role of forests in mitigation, although livestock and paddy rice also produce high emissions (Figure 5.2).
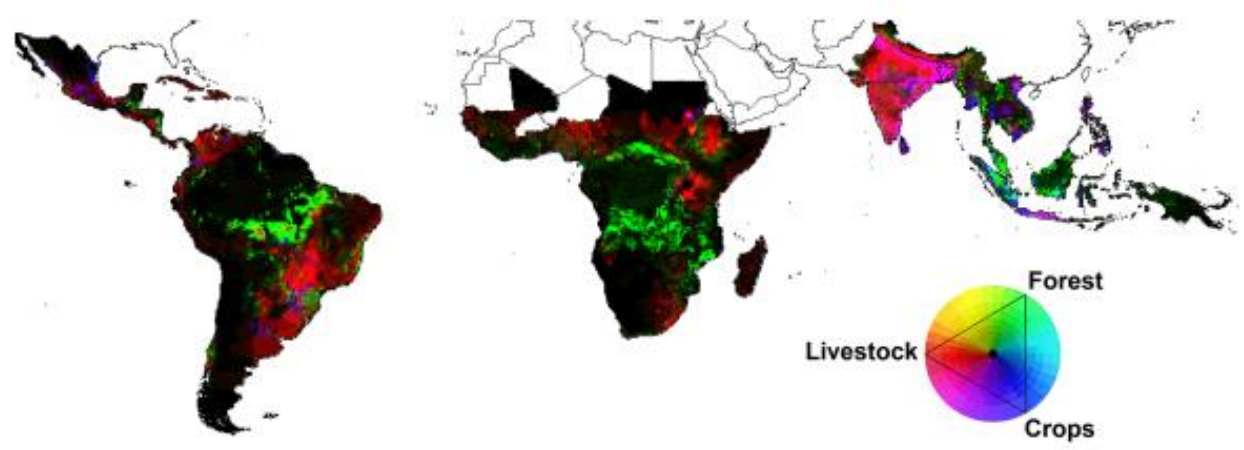

Figure 5.2. Contribution of the leading emission sources (grouped into forests, crops, and livestock) \% per pixel $\left(0.5^{\circ}\right), 2000-2005$. Forest emission sources include fire, deforestation, and wood harvesting. Crop emissions include paddy rice, cropland soil, and croplands over drained histosols. Livestock includes enteric fermentation and manure management emissions. Colours represent the strength of the emissions for the three sources (e.g. fuchsia in Asia represents equal emissions from livestock (red) and crops (blue). Dark represent areas of low emissions. Adapted from Roman-Cuesta et al. 2016 (2016).

One important point for research priorities from the example from Roman-Cuesta et al. (Roman-Cuesta et al. 2016) is that hotspot regions have the highest uncertainties. These are up to $30 \%$ of the mean AFOLU emissions, so research needs to focus on reducing uncertainties for emissions estimates (Roman-Cuesta et al. 2016). This is because uncertainty in these estimates leads to uncertain potential benefits from interventions. Forests have the highest uncertainties associated with their emissions, with their uncertainties accounting for $98 \%$ of the AFOLU emission uncertainty. This is due to the combined effect of uncertain areas and uncertain carbon densities, so future research could focus on quantifying these variables (Roman-Cuesta et al. 2016). The contribution of forests as a carbon sink therefore requires further research, as the impact of the recovery of carbon stocks after wood harvesting and fire could be better understood (Roman-Cuesta et al. 2016).

Once locations for mitigation initiatives have been identified, the impact of the initiatives must be monitored. Measuring and evaluating mitigation options for smallholder farmers (who occupy most land holdings in developing countries) is difficult due to lack of available emissions factors and the diversity of smallholder farming systems (e.g. (Descheemaeker et al. 2016)). The needs of the organization who is measuring also differ in terms of accuracy required, budget, and scale of measurements, so one monitoring, reporting and verification 
system will not suit all scenarios. However, protocols have been developed which offer options for measuring performance according not only to mitigation and adaptation goals, but also to food security and local livelihoods, and which can be adjusted to suit the needs of the project developer (Rosenstock et al. 2013). Research could focus on testing and improving such approaches, as well as incorporating monitoring of forests and agricultural interventions using the same system.

\subsection{Policy coherence}

At the international level, agriculture and forests are often addressed through their own international platforms such as the Committee on Food Security for agriculture and the UNFF (United Nations Forum on Forests) for forests, and even through different UNFCCC SBSTA (UN Framework Convention on Climate Change Subsidiary Body for Scientific and Technological Advice) negotiation tracks. There has been a call for a SBSTA negotiation track on agriculture (Chandra et al. 2016; Dinesh et al. 2016), but a better option might be to establish a SBSTA negotiation track which could accommodate landscape issues (including forests and agriculture) in one body.

At the national level, strong policy coherence is important (Mandemaker et al. 2011), and conflicting incentives (subsidies, and tax breaks for example) should be removed and tradeoffs addressed to create a supportive environment for both adaptation and mitigation in the land-use sector. Utilizing the institutional structures of REDD+ (specifically in its national policies which have been relatively rapidly developed (Den Besten et al. 2014)) and integrating CSA, should be explored as priorities, particularly where there are clear links between the two (for example high-yield palm oil in Peru (Gutiérrez-Vélez et al. 2011)). Inspiration might be found in India's agroforestry policy adopted in 2014, which opted for an 'agriculture plus forestry' concept in a one level playing field: any policy applied to one, should be applied to the other, relative to measurable performance. In this case, specific funds were allocated for the harmonization of the approaches (Singh et al. 2016).

The Nationally Determined Contributions (NDCs) implemented under the UNFCCC relate to different components of the land sector, and could be a starting point for an integrated national approach. In fact agriculture and forestry are already prominent components of many NDCs with most parties using forest management and reforestation in their mitigation measures (Richards et al. 2015), so including or linking agricultural NDCs to forest mitigation and adaptation could be further developed in future. Indeed, forest based mitigation could provide a quarter of emission reductions planned in several NDC's (Grassi et al. 2017). 
As the demand for agricultural products is responsible for much deforestation (DeFries et al. 2010), the role of the private sector (including international markets) is important in connecting REDD+ and CSA. Private sector commitments include green public procurement policies, for example the Roundtable for Sustainable Palm Oil and Round Table on Responsible Soy. One promising example from the private sector is the zero-deforestation commitments that many companies are adopting, even though the choice of net or gross zerodeforestation creates space for a disparity of outcomes (Brown \& Zarin 2013). Despite these policies being adopted by some companies, a report from Forest 500 reveals that there are still many companies with weak or no policies on deforestation (Global Canopy Programme 2016).

How to link commitments from the private sector to REDD+ is a key question. Research shows that there is a potential for agricultural value chains to be further integrated into REDD+ and CSA strategies (Nepstad et al. 2013). Examples include 'jurisdictional approaches to zero deforestation commitments' (JA-ZDCs) which allow policies such as REDD+ to be linked with private sector interventions which also seek to reduce deforestation. Zero deforestation policies and REDD+ already exist in parallel, so this option allows their numerous synergies (in terms of social and environmental goals), to be brought together (Stickler et al. 2012). These approaches encompass a number of stakeholders and spheres in which they operate, including jurisdictions of governments (national or subnational), private sector actors, and also a landscape perspective (WWF 2016) (Figure 5.3). Notable examples include the Forest, Farms and Finance initiative, which aims to link interventions which aim to increase agricultural productivity and improve smallholder livelihoods to interventions which reduce deforestation (Earth Innovation Institute 2016a). Monitoring of these integrated approaches may also be more efficient. The Earth Innovation Institute has proposed a Territorial Performance System, which includes integrated incentives, an online monitoring system and multi stakeholder governance. Other jurisdictional approaches to zero deforestation commitments have been led by the private sector, including Marks and Spencer, and Unilever who pledged to preferentially source production from jurisdictions which adhere to a number of criteria including that the jurisdiction has a strategy for reducing emissions from deforestation (Consumer Goods Forum 2015). Success of integrated approaches has been seen in the Brazilian Amazon for example, where deforestation has been halted due to a combination of efforts from both the private sector, jurisdictional government and voluntary efforts in the landscapes (Earth Innovation Institute 2016b). 


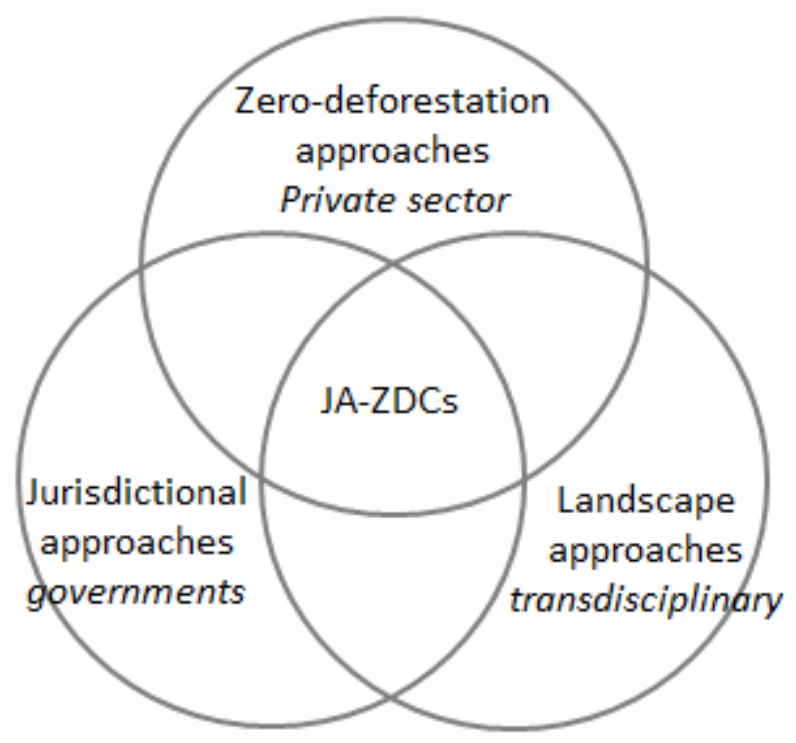

Figure 5.3. Intersection of three strategies to reduce deforestation. Adapted from (WWF 2016).

In addition to supply-side policies, policies or efforts to address demand for different types of food are needed. Demand-side measures have been suggested to have a greater mitigation potential (1.5-15.6 Gt $\mathrm{CO}_{2}$-eq. $\mathrm{yr}^{-1}$ ) than supply-side measures (1.5-4.3 Gt CO2-eq. $\left.\mathrm{yr}^{-1}\right)$ (Smith et al. 2013). They are however difficult to achieve and require great societal change and commitment. One example requiring social commitment is diet change. Since there is a strong relationship between income and meat intake, future increases in meat consumption are expected. Limiting animal protein intake can save land (Van Kernebeek et al. 2016; Erb et al. 2016). Examples of mechanisms which can achieve societal change are Voluntary Sustainability Standards (VSS) that inform consumers about the sustainability of goods (Derkx \& Glasbergen 2014). Examples are FSC (timber), MSC (fish) and UTZ (coffee). Although they originate from private and civic sectors that cooperate 'to green' global value chains, governments can - and do in various cases - actively endorse these through their own policies (the Netherlands being an example). An integrated framework for analysing where and how standards and certification emerge and further evolve in the case of tropical timber, coffee, cacao, palm oil and rubber is provided by Mithöfer et al. (2016). Voluntary standards with very high social and environmental requirements provide information to consumers. However, they represent a small segment of the market, so product wide commitments even with lower requirements could also lead to a larger impact. The Carbon Disclosure Project is 
a platform where companies can voluntarily report their environmental impacts, and most of the largest companies in the world participate (CDP 2017). Like voluntary standards, this information allows investors and consumers to make informed choices, however, the system remains voluntary. Mandatory reporting could provide more comprehensive information on emissions and carbon management practices, although reporting of practices to reduce emissions does not necessarily lead to a reductions in emissions (Doda et al. 2016). Our recommendation is that any future reporting should indicate the emissions reductions made by the company as well as reporting on forest impacts, both direct and indirect from the supply chain.

\subsection{Transparency}

Transparency should be understood as catalyst for action by providing open and consistent data, definitions, assumptions and methodologies for an assessment of the credibility and reliability of land use sector mitigation and adaptation activities in both developing, and developed countries. Enhancing transparency is now a fundamental step to make the bottomup nature of the Paris Agreement work in practice, and increases accountability for the various stakeholders involved (De Sy et al. 2016). This development is supported by an increasing set of free and open data and methods, for example through Global Forest Watch (World Resources Institute 2017), OpenForis (FAO 2017b) and GODAN (Janssen et al. 2017). On the national level, enhancing transparency for emissions accounting, including estimates for mitigation action impacts (for example NDCs) (Grassi et al. 2017) is already one of the reporting criteria for the IPCC GHG inventories (transparency, accuracy, completeness, comparability, consistency) (UNFCCC 2003). Such national reporting will be increasingly compared to independent data sources as part of the technical reviews and UNFCCC global stocktakes. National and other independent data sources should become available for local stakeholders to underpin their mitigation and adaptation activities. This should target non-state actors in particular such as land owners, farmers, local communities and the private sector to stimulate them to participate in and achieve more climate-smart land use decisions and actions. Transparency should be multi-dimensional, interactive and covering all stakeholders, thus being a pathway to engagement. Open and transparent sharing of information are essential for collaborative design and interactive processes for involving of communities, i.e. through for example the participatory methods described by Salvini et al. (2016). This has been shown to reduce the risk of failure in mitigation activities, i.e. in the case of the voluntary carbon market that led to a decrease in credit prices (Gupta \& Mason 2016). Thus, transparency should become a key element to planning, implementation and reporting of activities with particular need to address the following issues: 
1. Provide data, case studies and guidance to assist national-level processes and UNFCCC-coordinated technical assessment processes and upcoming global stock-take(s); 2. Underpin multi-stakeholder processes for streamlining pathways to achieve land use sector mitigation and adaptation on the national (i.e. NDCs) and landscape scales;

3. Facilitate participatory monitoring for land use mitigation activities tracking and impact assessment involving the private sector engaged in zero-deforestation, civil society and government agencies.

\subsection{Conclusions}

New local integrated solutions, transdisciplinary research approaches and priorities, policy coherence, and transparency can all be independently sought and achieved, but transformational change will only happen when they are pursued simultaneously. We recommend that this transformational change includes several components. Firstly that landscape level accounting is used to assess the mitigation potential for interventions in the agricultural sector, which not only deliver increased production within a changing climate (food security), but that also avoid that land-use change (particularly from forests or other high carbon landscapes) where possible. Secondly, interventions in 'hotspot' regions, where the most emissions are occurring are given priority. In order to limit global average temperature increases to $1.5^{\circ} \mathrm{C}$, attention should be first given to those emissions hotspots, and all aspects of the land sector - particularly the potential of the agriculture and forest sectors should be utilized. Research should focus on decreasing uncertainties in emissions estimates in the land sector, so that more accurate mitigation potentials can be calculated. Thirdly, policies at all levels must be coherent, and must support both mitigation and adaptation. At the international level, landscape issues should be discussed together. At the national level, institutional structures from REDD+ can be used to support CSA interventions, and these can also integrate private sector actors, such as through JA-ZDC. Demand-side measures are also and can be achieved further through voluntary private-sector standards for example. Fourthly, transparency can be used to build trust, and to encourage the engagement of stakeholders. Support from the international community, including scientists, through the development of open data and tools can ensure that these initiatives are successfully implemented. This transformational change will also support other platforms, for example Sustainable Development Goals 2, 13 and 15 in particular which focus on hunger, climate change and sustainable management of natural resources. 


\section{Acknowledgements}

This research is part of CIFOR's Global Comparative Study on REDD+ (www.cifor.org/gcs). The funding partners that have supported this research include the Norwegian Agency for Development Cooperation (Norad) [Grant no. QZA-16/0110 No. 1500551] and the International Climate Initiative (IKI) of the German Federal Ministry for the Environment, Nature Conservation, Building and Nuclear Safety (BMUB) [Grant no. KI II 7 - 42206-6/75], and the CGIAR Research Program on Forests, Trees and Agroforestry (CRP-FTA), and Climate Change Agriculture and Food Security (CCAFS) with financial support from the CGIAR Fund Donors. 
6 Synthesis 


\subsection{Main findings}

First the main findings of each research question will be summarized, then the results and relevance of this thesis in a wider research context will be discussed. Recommendations for further work are also proposed.

A) What are the emissions and their uncertainties of agriculture-driven deforestation in the tropics?

Emissions from agriculture-driven deforestation between 1990 and 2015 varied from $1511 \pm 174 \mathrm{Mt} \mathrm{CO}_{2} \mathrm{yr}^{-1}$ between 1990 and 2000, to $1792 \pm 133 \mathrm{Mt} \mathrm{CO}_{2} \mathrm{yr}^{-1}$ between 2005 and 2010 (chapter 2, this thesis). Emissions differed country by country, and Brazil had the largest emissions, which peaked in 2000-2005, also the peak years for emissions in Latin America. Africa emerged as the next biggest potential source of emissions from agriculture-driven deforestation, because emissions there have increased continuously since 1990 . The countries in the Congo Basin and in East Africa all had their highest emissions in the 2010-2015 period. In all countries, agriculture is the major driver of deforestation, with 'the rest of Latin America' being the region where it drives deforestation the most (94\%), and Indonesia being the region where it drives it the least (52\%).

Also in chapter 2, we found that overall uncertainties for emissions from agriculture-driven deforestation in the tropics are $\pm 62.4 \%$ (average for 1990-2015) per country (Figure 2.6). Uncertainties differed widely from country to country, from $\pm 24.9 \%$ to $\pm 283.1 \%$ for the $95 \%$ confidence interval. Uncertainties are lower when aggregated at the regional level, and at this level, in Asia they are largest $( \pm 22.5 \%)$, and in Latin America they are smallest $( \pm 15.9 \%)$. Estimates for the whole of the tropics had uncertainties of $\pm 11.4 \%$. Uncertainties resulted from the use of sample-based estimates (sample size, and variability between sample units), adjustments for thematic mismatches (definitions), data quality, and the use of data from other time periods as substitutes when there was a lack of data. In general, for estimates of emissions from deforestation, the area of deforestation is the most uncertain component, but for estimates of emissions from agriculture-driven deforestation, the fraction of deforestation which is driven by agriculture is the largest contributor of the uncertainty. Thus, in order to improve the certainty of results, more and better data are needed for these two components.

The agriculture sector itself was found to be a key source of emissions (i.e. emissions from existing agricultural land). This was explored in chapter 3, where it was found that in some countries, annual emissions from the agriculture sector were higher than emissions from agriculture-driven deforestation. Three broad categories defining the sources of agricultural 
emissions were used to show where largest mitigation potential lies for each country in the tropics. The categories are (1) countries where $>66 \%$ of total emissions (emissions from agriculture-driven deforestation + emissions from agriculture) are from agriculture-driven deforestation, (2) those where $>66 \%$ of total emissions were from agriculture, and (3) the rest. Those countries with highest emissions from agriculture-driven deforestation (and therefore low emissions from agriculture) (1) include DR Congo, Papua New Guinea, Cameroon, Peru, Bolivia, Venezuela, Myanmar, Tanzania, Mexico and Brazil. Argentina, China, Pakistan and India had very low agriculture-driven deforestation related emissions in comparison to their agriculture emissions (2). Countries with a mixture (3) included Ethiopia, Vietnam and Indonesia (Figure 3.4 and Table 3.4).

Our research shows that although estimates of emissions from agriculture-driven deforestation can be produced, providing consistent estimates across longer time periods (for example 25 years between 1990 and 2015) is difficult, and produces uncertain results. Emissions from agriculture-driven deforestation calculated in chapter $3\left(4260 \mathrm{Mt} \mathrm{CO}_{2} \mathrm{yr}^{-1}\right.$ ) are higher than those in chapter 2, which is due to different methods, datasets, and timeframes. Comparing the data used for chapters 3 and 2 reveals where some of the difference in the results comes from. More countries have higher estimates for forest area loss in chapter 2 than chapter 3, which will be partially due to the use new area data (for example including Kim et al. 2015), and due to also the different methods used to harmonize the datasets. On the emissions factors used, in chapter 2, we assume that a proportion of the biomass remains or regrows (which is particularly relevant in the case of tree crops), whereas in chapter 3 the removal of all biomass alone is included in calculations. This means that results will be lower in chapter 2 and this is where the majority of the difference between the two chapters comes from. Additionally, the biases in the biomass data (Avitabile et al. 2016; Saatchi et al. 2011; Baccini et al. 2012), were removed, and only Avitabile was used in chapter 3 . For the proportion of deforestation which is driven by agriculture, the estimates are higher for more countries in chapter 3 than chapter 2, which would not contribute to the overall pattern of lower estimates found in chapter 2. The number of countries included in the studies also differs (97 in chapter 3, and 91 in chapter 2). As such the results cannot be directly compared. I propose the use of the more recent results in chapter 2 over the older results from chapter 3 . This is because chapter 2 uses updated data and methods, the data also cover a longer time frame, and also contain information on the certainty of the results. However, results in both chapter 2 and 3 are compared to other datasets, and are considered to be robust (sections 2.4 and 3.4.2). In chapter 3, the aim was to establish a decision tree to identify the countries which had the largest potential for forest land-sparing interventions. If any of the input datasets were replaced (not only the emissions from agriculture-driven deforestation), the results would differ. The value of the paper is the approach which was developed to guide decision making on this topic, and data in the decision tree can be replaced as new data emerges. 
Both the methods in chapter 2 and chapter 3 involve the use of a number of input datasets which are used to calculate emissions from agriculture-driven deforestation. This is essential because not all input datasets covered the entire time period of interest, so different datasets had to be used for different time periods in each country. The selection of datasets also differed from country to country in chapter 2 , as the most certain datasets were prioritized. This mixture of data meant that datasets had to be harmonized, and finding suitable data to harmonize the datasets was difficult. Data on the certainty of the input datasets was lacking which meant that these had to be estimated in order to be able to prioritize the datasets, and in order to produce uncertainty estimates for the emissions values.

B) In which countries can forest-land sparing interventions be best introduced to mitigate these emissions?

Both chapter 3 and 4 address this research question using a similar approach. First, we considered the threat of, or actual emissions from agriculture, and in chapter 3, emissions are also categorized by the dominant source (either existing agricultural land, or agriculturedriven deforestation). In chapter 4 , the presence of LSLA which is considered to be a threat to forests was incorporated. The mitigation potential through forest-sparing interventions is then evaluated. Two options were considered, firstly intensifying agricultural production on existing land, and secondly expanding agriculture into other available land areas, rather than into forests. Finally any barriers (for example poor governance) which hinder land-sparing interventions, or synergies (for example engagement in REDD+) which will support interventions were considered. From these steps, priority countries could be identified.

A total theoretical $4260 \mathrm{Mt} \mathrm{CO}_{2} \mathrm{yr}^{-1}$ of emissions from agriculture-driven deforestation was found in chapter 3 . When a decision tree which incorporates several social, economic, and biophysical factors is implemented, six priority countries emerge (Panama, Paraguay, Ecuador, Mexico, Malaysia and Peru), which have the largest potential mitigation opportunities for reducing agriculture-driven deforestation emissions. Although Africa emerges as a significant source of future emissions in chapter 2, and has a typically high yield gap, which is used as an indicator of forest-sparing potential in chapter 3, the low governance, and high food insecurity mean that none of the six priority countries are African countries. If the risk to food security is not included in the analysis, 20 priority countries are identified with a potential of $1.3 \mathrm{Gt} \mathrm{CO}_{2} \mathrm{y}^{-1}$. A similar mitigation potential of $1 \mathrm{Gt} \mathrm{CO}_{2} \mathrm{y}^{-1}$ was found for emissions from existing agricultural land in 12 countries which currently have large emissions (>1.68 $\mathrm{t} \mathrm{CO}_{2} \mathrm{e} \mathrm{ha}^{-1}$ ). Supporting countries that already have good governance or engagement in REDD+ to mitigate emissions was discussed, as engagement in REDD+ demonstrates that they have experience and support to implement mitigation interventions. Countries which have low governance scores (based on World Bank 2012), and no 
engagement in, and therefore support for, REDD+ implementation would be candidates for increased longer term support for the mitigation of agriculture-driven deforestation; these include Honduras, Liberia, Nicaragua, Venezuela and Zimbabwe.

Chapter 4 focuses on LSLA, and identifies countries that are potential candidates for interventions which will reduce LSLA-driven deforestation. The chapter incorporates a literature review to identify several characteristics which are typical of those countries with LSLA. These are: the potential for returns on investments, suitable land for agriculture, access for investors, and security of investments. An analysis of these characteristics in countries with and without LSLA was carried out using a classification tree (Figure 4.1). We found that the availability of land suitable for agriculture is the dominant characteristic of countries with LSLA. Countries with $<18.9 \%$ of their land area available and suitable are likely not to have LSLA. If available land is above this threshold, then those countries where land is not accessible (based on average travel time to cities within the country) are more likely to have LSLA. The classification tree then splits those countries further, and the more fragile countries (according to Fragile states index (Fund For Peace 2015)) are not likely to have LSLA. The classification had an overall accuracy of $78.9 \%$. Countries with high accessibility are less likely to have LSLA, which we conclude is because these countries are unlikely to have large areas of land available, and large amounts of land are required for LSLA. On average acquisitions in the Land Matrix database of LSLA are $>330 \mathrm{~km}^{2}$. Security of investments was also found to be important for investors, as countries which have available land and are fragile are less likely to have investments than those who are not fragile. Countries which fulfil these criteria include four countries (Belize, Ecuador, Nepal and Togo), which currently do not have LSLA (as reported in the Land Matrix database). We propose that these countries are likely candidates for future LSLAs, and therefore likely cases for future agriculture-driven deforestation, and these countries should be prioritized for initiatives which can reduce the likelihood of LSLA-driven deforestation. Those countries with an already high level of agriculture-driven deforestation were also identified as priority countries for action. Other key targets for interventions to reduce the impact of LSLA on forests are countries with a large number of deals, such as Cambodia. Cambodia has 104 deals in the Land Matrix database, and a relatively small forest area. The deals listed in the Land Matrix, would cover an equivalent of $16 \%$ of the forest area, and $28 \%$ of the agricultural land area, so this would mean that the deals are likely to either directly or indirectly drive deforestation. Little research has been done on the impact of LSLA on forests and REDD+ interventions, and this research found that countries with LSLA are also more likely to be engaged in REDD+ confirming that the two processes are occurring within the same country. Actions which directly address LSLA should be considered in these countries. 
C) How can interventions in both the forest and agricultural sectors be better integrated to achieve emissions reductions?

In order for significant (i.e. as per the Paris Climate Agreement) emissions reductions to be achieved, a transformational change in the land use sector is required. Because of the close links between agriculture and forests (chapter 1, chapter 5), we argue in chapter 5 that addressing both together is required, otherwise neither objectives of emissions reductions or food security will be achieved. Although transformational change across the land use sectors is likely to be difficult, support for such changes may be found by leveraging the synergies between adaptation and mitigation. For example, forests provide services which enable agriculture to adapt to climate change, such as soil stability and fertility maintenance, and providing humidity due to their influence on water cycles (Ellison et al. 2017).

In Chapter 4 we assess interventions to reduce deforestation and conclude that the link between forest loss and different agricultural activities should be better understood, so that interventions can be designed to address each specific deforestation driver directly. In a number of countries, agricultural LSLA are occurring (which are likely to lead to agriculturedriven deforestation), and commercial agriculture is not cited as a driver in their REDD+ documentation. Some indirect drivers related to LSLA are identified, such as weak governance and poor enforcement of law and tenure rights, and some interventions to target these drivers have been implemented by some countries. However, LSLA is almost always not specifically mentioned as a driver of deforestation, even in countries with many instances of LSLA. Some host and investor-side policies which can target LSLA, with the aim of reducing deforestation are highlighted (Section 4.5.4). The indirect drivers such as weak tenure rights can be addressed by the host country.

Chapter 5 looked at broad types of interventions which may be considered to spare forest land from agricultural expansion. In summary, a number of different actions need to be considered in order to achieve transformative change. The incorporation of multiple interventions on both the agriculture and forest is required to ensure that both agricultural production is supported, and at the same time, forests are protected. Climate Smart Agriculture (CSA) approaches should be considered as they are designed to enhance food security, mitigate climate change and increase the resilience of agriculture to climate variability. CSA can therefore promote intensification, where more food is produced from existing agricultural land, which avoids the need for expansion of agriculture. We argue, therefore, that CSA interventions, which lead to expansion of agriculture into forests, should be avoided where possible, and should not be considered as climate smart. Policy coherence is a major challenge with policies favoring both conversion of forest to agriculture and protection of forest occurring in the same area. Transdisciplinary approaches are required to consider both policies and activities in the agriculture and forest sectors together. The 
landscape approach is a commonly used platform and can be used to consider both the challenges of ensuring food security and protecting forests. Accounting methods which can take into account the indirect emissions related to agriculture, including agriculture-driven deforestation need to be used in order for the best outcome for emissions to be selected. A number of approaches for carbon accounting at the landscape level are highlighted (Section 5.3), such as the concept of calculating the carbon debt from land cleared and incorporating this into life cycle assessments.

Chapter 4 identified the opportunity for measures used in REDD+ to be used in LSLA policies. For example, safeguarding has been a key area of REDD+, and consultations of local communities and stakeholders are required during REDD+ design, and this consultative process could also be used in the case of LSLA. In contrast, countries that are implementing REDD+ can also learn lessons from the negative impacts which are reportedly associated with LSLA, since REDD+ and LSLA share a number of characteristics, such as the transfer of rights to land. These points are closely related to the need for transparency, and this is a key requirement for future mitigation strategies. Transparency in data related to planning, reporting and implementation is required in order to increase accountability to stakeholders, and is already a key part of REDD+.

\subsection{Outlook and recommendations}

\subsubsection{Comparing direct and indirect agricultural emissions, their mitigation potential and contribution to global emissions reductions}

Emissions from agriculture can be divided into direct emissions (those that occur on agricultural land), and indirect emissions. In this chapter, we refer to indirect agriculture emissions as those from agriculture-driven deforestation. Other studies refer to indirect land use change which is a consequence of agriculture, and from which emissions also result. For example biofuel production leading to displacement of agriculture which then drives deforestation elsewhere (Gallagher 2008) and cattle ranching leading to increased soy production which has emissions and can lead to deforestation in another location (Arima et al. 2011). This thesis focused on agriculture-driven deforestation emissions which we refer to as indirect emissions. In the context of the Brazilian Amazon (Arima et al. 2011) both deforestation driven by pasture or soy production would be considered indirect emissions, and in the context of biofuels (Gallagher 2008), and biofuels, both deforestation from biofuels or displaced agriculture which occur in the same country would be included in our study as indirect emissions. Direct emissions from agricultural land were also included in the analysis in chapter 3. Emissions from agriculture-driven deforestation result from the loss of above- 
and below-ground forest biomass. However, in addition to those emissions, which are usually allocated in the year in which the deforestation took place, the annual direct emissions from the agriculture which occurs on the land every year after the deforestation event could also be attributed to the deforestation event. Calculating the cumulative emissions which occur on deforested land from agriculture activities could be investigated as a future research question. Incorporating emissions from activities which lead to the deforestation event (i.e. activities that first lead to degradation, for example fuelwood and charcoal making) would add further detail in the total emissions that are related to the conversion of land from forest to agriculture. Empirical studies implemented at the local level would be required to explore this in detail, and to provide an insight into the regional and local differences.

The work in this thesis on indirect agriculture emissions has contributed to the work by Wollenberg et al. (2016), who calculated the contribution of agriculture to the goals of the Paris Agreement of limiting the increase in the global average temperature to well below 2 ${ }^{\circ} \mathrm{C}$ above preindustrial levels. This work looks at direct and indirect emissions from agriculture, but the focus is on the direct emissions from agriculture. In Wollenberg et al. (2016) we used the methods described in chapter 3 of this thesis, to provide an estimate of indirect emissions from agriculture at the global level (Table 6.1). The technical mitigation potential of $75 \%$ of the physical potential was derived from the Eliasch Review, which stated that REDD could potentially reduce deforestation by up to $75 \%$ in 2030 (Eliasch 2008). Three global mitigation potentials are presented and differences between estimates by WURCIFOR (in Wollenberg et al. (2016)) and Havlík et al. (2014) are due to differing carbon prices, definitions of agriculture-driven deforestation (for example, whether tree crops are considered agriculture or forests), and assumptions of projected trends, which in the case of the WUR-CIFOR estimate are considered to be stable. These details are discussed in Wollenberg et al. (2016).

Table 6.1. Mitigation possible by 2030 from reduced agriculture-driven deforestation (in Wollenberg et al. 2016).

\begin{tabular}{|c|c|c|c|}
\hline \multirow[t]{2}{*}{ Data source } & \multirow{2}{*}{$\begin{array}{l}2030 \text { Reference } \\
\text { level }\end{array}$} & \multicolumn{2}{|c|}{$\begin{array}{l}\text { Mitigation, as a reduction } \\
\text { of } 2030 \text { emissions }\end{array}$} \\
\hline & & Percent & $\mathrm{Gt} \mathrm{CO}_{2} \mathrm{e} \mathrm{yr}^{-1}$ \\
\hline WUR-CIFOR & 5.75 & $75 \%$ & 4.31 \\
\hline $\begin{array}{l}\text { Havlík et al., 2014/IIASA-ILRI- } \\
\text { CSIRO at } 20 \text { USD per t CO2e }\end{array}$ & 3.03 & $56 \%$ & 1.71 \\
\hline $\begin{array}{l}\text { Havlík et al., 2014/IIASA-ILRI- } \\
\text { CSIRO at } 100 \text { USD per t CO2e }\end{array}$ & 3.03 & $67 \%$ & 2.02 \\
\hline
\end{tabular}


Wollenberg et al. (2016) use a number of scenarios and indicate a preliminary goal for the

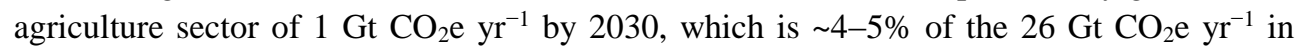
mitigation needed across all sectors in 2030 needed to achieve the $2{ }^{\circ} \mathrm{C}$ limit. Table 6.2 shows the relative importance of emissions from deforestation and agriculture-driven deforestation, and their mitigation potentials globally and in the tropics.

Table 6.2. Direct and indirect (agriculture-driven deforestation only) emissions from agriculture. These are not intended to be used for direct comparison, but to give an indication of the general patterns. Time periods, and countries included vary, as well as assumptions and emissions sources included. The source should be consulted for information.

\begin{tabular}{|c|c|c|c|}
\hline & Agriculture sector & Global & Tropics \\
\hline \multirow[t]{4}{*}{$\begin{array}{l}\mathrm{Gt} \mathrm{CO}_{2} \mathrm{e} \\
\mathrm{yr}^{-1}\end{array}$} & Direct emissions (A) & $\begin{array}{l}\text { 5.0-5.8 (2000-2010) } \\
\text { (Smith et al. 2014) }\end{array}$ & $\begin{array}{l}3.28 \\
\text { (Chapter 3, this thesis, } \\
\text { 2000-2010) }\end{array}$ \\
\hline & $\begin{array}{l}\text { Potential for } \\
\text { mitigation of direct } \\
\text { emissions (B) }\end{array}$ & $\begin{array}{l}0.21-0.4 \text { by } 2030 \\
\text { (Wollenberg et al. } \\
2016 \text { ) }\end{array}$ & $\begin{array}{l}0.14-0.22 \\
*\end{array}$ \\
\hline & Indirect emissions (C) & $\begin{array}{l}3.03-5.75(2030 \\
\text { reference level) } \\
\text { (Wollenberg et al. } \\
2016)\end{array}$ & $\begin{array}{l}1.66-1.93 \\
\text { (Chapter 2, this thesis, } \\
\text { 2005-2010) }\end{array}$ \\
\hline & $\begin{array}{l}\text { Potential for } \\
\text { mitigation of indirect } \\
\text { emissions (D) }\end{array}$ & $\begin{array}{l}1.71-4.03 \text { by } 2030 \\
\text { (Wollenberg et al. } \\
2016 \text { ) }\end{array}$ & $\begin{array}{l}0.94-1.16 \\
* *\end{array}$ \\
\hline
\end{tabular}

*Calculated as (B Global / A Global) x A Tropics. ** Calculated as (D Global / C Global) x $\mathrm{C}$ Tropics. The same fractions relating to the emissions and mitigation potential of global emissions are used to calculate the mitigation potential from the emissions in the tropics. This approach therefore assumes that the same proportion of total emissions can be mitigated in the tropics as at the global scale.

Although numbers cannot be directly compared due to different timeframes and assumptions, this comparison is considered useful to give an indication of the relative contribution of direct and indirect emissions and the potential for their mitigation on the two scales. The global figures for direct and indirect emissions are in line with Tubiello et al. (2013), who use

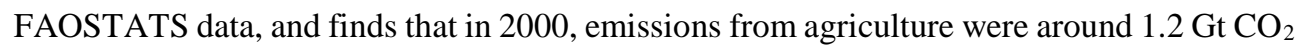
$\mathrm{yr}^{-1}$ larger than those from net deforestation. In Tubiello et al. (2013), emissions from agriculture include those from organic soils, and emissions from soils (including peats) are not included in deforestation emissions, which may explain some of the difference. Despite direct emissions being larger, a higher mitigation potential is found for indirect emissions 
(Table 6.2). Although different approaches were used to estimate the mitigation potential of direct and indirect emissions, these findings agree with other studies who highlight the large potential of avoided deforestation for emissions reductions. What is also important to note, is that Wollenberg only assessed interventions to address direct emissions which would not compromise food production, and found that this $1 \mathrm{Gt} \mathrm{CO}_{2} \mathrm{e}$ goal is not likely to be met. The mitigation of indirect-agriculture emissions should therefore also be explored, but also with the aim of not compromising food production. The abatement potential for LULUCF has been predicted to be very large and low cost, and could even reduce total emissions to negative $0.7 \mathrm{Gt} \mathrm{CO}_{2} \mathrm{e} \mathrm{yr}^{-1}$ by 2030 due to the creation of sinks (McKinsey and Company 2009). Within LULUCF, reduced deforestation from smallholder agricultural conversion, and pastureland conversion are the most cost effective mitigation approaches (around 2 EUR $\mathrm{t} \mathrm{CO}_{2}^{-1}$ ), which is below the average price of transactions on the voluntary carbon market in 2016 (Hamrick \& Gallant 2017). Reduced intensive agriculture conversion is the most

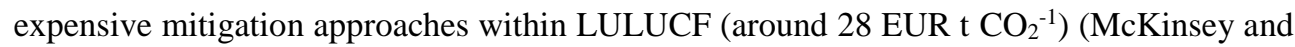
Company 2009). The feasibility of avoiding deforestation is also discussed by Zarin et al. (2016), who find similar emissions of $2.270 \mathrm{Gt} \mathrm{CO}_{2} \mathrm{yr}^{-1}$ from gross tropical deforestation to those in Chapter 2 of our study (Table 6.2). Zarin et al. (2016) conclude that by 2020, 50\% of these emissions could be reduced.

The mitigation potentials presented in chapter 3 of this thesis represent the emissions that are produced by the countries specified, which is essentially the maximum potential for the mitigation of emissions. It is unlikely that this maximum potential will be reached, as there are barriers to implementation, such as lack of finance and capacity to implement activities (this is discussed further in section 6.2.3, and by McKinsey and Company (2009)). Additionally, emissions from the initiatives themselves need to be deducted from the mitigation total. More efficient mitigation opportunities may also be found in other sectors. For example emerging technologies such as carbon capture and storage could have a large potential in the ever growing energy sector (Boysen et al. 2017), although costs remain high (McKinsey and Company 2009). Switching from incandescent to LED lights is the most cost effective option across all sectors (around -80 EUR t $\mathrm{CO}_{2}^{-1}$ ). Between 2000 and 2010, 75\% of the total global emissions increase was from the energy and industrial sectors, and a large proportion $(59 \%)$ of this took place in the upper-middle income countries (which were not within the scope of this thesis) (Edenhofer et al. 2014). Therefore it is also important to focus on these other sectors and regions which might deliver large mitigation benefits. However, links between the land and energy sector should be considered, as bioenergy production for example requires land, which leads to further competition for land (see also section 6.2.4). 


\subsubsection{Co-benefits or adverse side effects of forest land sparing interventions}

In terms of total anthropogenic emissions, the Agriculture, Forestry and Other Land Use (AFOLU) sector accounts greater proportion of the national emissions budgets in low income countries than in high income countries (Edenhofer et al. 2014). Mitigation options therefore have a relatively large role to play in the AFOLU sector in food insecure countries, which are also typically low income countries. Food security may be negatively impacted by mitigation initiatives, particularly forest land-sparing initiatives, due to reduced access to land, a shift in commodities, and changes to agricultural practices which impact food production and prices (Frank et al. 2017). Threats are not equally distributed across the tropics (chapters 3 and 4 of this thesis), and Frank et al. (2017) suggests that land-rich countries such as Brazil could reduce emissions with only a marginal effect on food availability, however China and India for example, would experience substantial losses. The advantages of a country-by country analysis, as used throughout this thesis are clear when linking mitigation initiatives to threats. Land sparing interventions, such as intensification can also threaten biodiversity. The use of pesticides for example, which are used in some intensification scenarios, has been linked to reduced bird diversity (Green et al. 2005). Information on specific species, and the influence of intensification on their density is required to select the optimal intensity level, (Green et al. 2005), from which the optimal land-sparing potential could be calculated, thus careful analysis of these threats is required before intensification is proposed.

Several options for increasing food production while maintaining biodiversity and supporting communities are discussed in literature, many of which are considered Climate Smart Agriculture (CSA) practices. CSA has the potential to mitigate emissions from existing land, where emissions can be reduced and production increased so that forest-land sparing can occur through reducing agriculture-driven deforestation. Utilizing non-forested available land is also a forest land-sparing intervention which is discussed in this thesis, and CSA practices can also be used in the management of this non-forested available land. Currently, over 1.3 billion people are trapped on degrading agricultural land (UNCCD 2017), so there is a potential that rehabilitating degraded land can support these communities as well as reducing emissions from that land, and sparing forests. Although food security benefits may be assumed from increasing land under agriculture, a move from forested systems to agrarian systems were found to not necessarily benefit people (Sunderland et al. 2017). An abundance of literature on LSLA (also see chapter 4 of this thesis) suggests that negative impacts to food security are likely outcomes from commercial land conversions. Additionally, the diversity of agricultural and nutrient productivity diminishes as farm size increases, and small farms have more local importance for food production, particularly in sub-Saharan Africa and south 
and southeast Asia (Herrero et al. 2017). Thus, food availability is only one element of food security. Implementing initiatives using the landscape approach is discussed in this thesis, and can help to ensure that land rehabilitation for example, delivers food security benefits to communities. Although there is currently a debate as to what the landscape approach is (Erbaugh \& Agrawal 2017), in this thesis, we refer to it as a philosophy by which to manage land, which encompasses the set of 10 principles for multifunctional land use, as set out by Sayer et al. (2013). The principals are particularly relevant to our work, since they mainly seek to reduce competition between productive land uses (such as agriculture), and environmental goals (such as carbon storage). Several useful themes emerge, such as community involvement in planning and monitoring, consideration of multiple scales for impacts and feedbacks, and managing tradeoffs for multiple functions.

The focus of our study on tropical developing countries also presents an opportunity to finance mitigation projects through mechanisms such as REDD+. One source of finance is the voluntary carbon market, which has seen a decrease in volumes traded in recent years. REDD+ has however remained a large component of the voluntary carbon market, and forestry (including REDD+) and land use offsets represent $>12 \%$ of the market volume. There is also a potential that company commitments, such as zero deforestation commodities could lead to increased demand for these offsets, as there is a potential for the two to be incorporated (Hamrick \& Gallant 2017). The ratification of the Paris Climate Agreement also means an increased likelihood for compliance finance to become available for mitigation projects, so several promising financing streams are likely to be available in the future. REDD+ has so far been funded by a number of streams including Official Development Assistance (ODA) as well as results based payments (Neeff et al. 2014), so it is likely that future financing will also come from diverse sources. More discussion on the cost effectiveness of REDD+ and other carbon mitigation options can be found in section 6.2.1.

\subsubsection{The capacity to monitor success}

One of the barriers to success for reducing agriculture-driven deforestation is a lack of capacity of countries to successfully implement activities. Our work is on the national level, and research on the capacity of countries to monitor REDD+, gives an insight into the current state of their capacity to implement mitigation initiatives, including the forest-sparing initiatives discussed in this thesis. Currently, a number of countries have a low capacity to measure, monitor and report on REDD+, particularly in Africa (Romijn et al. 2012). Although capacities have been increasing, a capacity gap remains in many countries (Romijn et al. 2015). External factors have been identified to have impacted capacity including slowness of international REDD+ policy formulation, and the unclear path of development of the forest carbon market (Joseph et al. 2013), which has probably stalled interventions in 
the past. Although there have been advances in capacity, a number of countries still face technical challenges, where further specific guidance and support is required. Countries dealing with seasonal variation for example must take this into account in the analysis of remote sensing data (Hamunyela et al. 2016). Deforestation monitoring in countries with humid forests can be difficult due to persistent cloud cover which reduces optical data availability. Data gaps of more than one year can, for example, occur in the commonly used Landsat dataset (Hansen et al. 2016; Potapov et al. 2012; Sannier et al. 2014). Solutions are available, but they can require complex methods, and incorporation of radar data (Reiche et al. 2017; Vollrath et al. 2016). Despite some countries having technical capacity for MRV, they may not have structures (for example administration and good governance) which will support the implementation of these MRV processes (Ochieng et al. 2016; Tulyasuwan et al. 2012). A lack of financing was also identified as hindering REDD+ MRV reporting (Tulyasuwan et al. 2012). It is likely that some interventions will be at the project rather than national level, for example CSA initiatives discussed in this thesis, and a gap in readiness has also been identified at that level (Joseph et al. 2013). Countries can develop their capacities through both CSA and REDD+ related activities, and as discussed in chapter 5, there is a potential for existing structures which have been supported through REDD+ engagement to be used in the context of CSA, thus capacity support can come from various initiatives. The Sustainable Development Goals (SDGs) (UN 2016) also highlight the need to focus on capacity building, and include a call to "Enhance international support for implementing effective and targeted capacity-building in developing countries to support national plans to implement all the Sustainable Development Goals, including through North-South, SouthSouth and triangular cooperation" (target 17.9). In the context of this thesis, target 12.a also aims to "Support developing countries to strengthen their scientific and technological capacity to move towards more sustainable patterns of consumption and production", so there is a potential for improvements in capacity to be seen, as these goals are addressed.

\subsubsection{Competition for land and the SDGs}

Competition for land as discussed in this thesis in the context of food production and forest protection, is also seen in the Sustainable Development Goals (SDGs)F. There are 17 goals with 232 associated targets covering social, economic and environmental fields (UN 2016). Several of the SDGs are potentially in conflict, for example, SDG 13 (Climate action) and SDG 15 (Life on land) may conflict with SDG 2 (Zero hunger). Obersteiner et al. (2016) explore this issue and predict that if the goals are dealt with individually, then problem shifting will occur, and that success in one sector, will result in failure in another. A siloed approach in which actions to address each SDG individually are determined without integration of other policies, will potentially lead to the SDGs not being met by 2030. Several options are presented by Obersteiner et al. (2016) through which conflicts might be avoided, 
for example 'hotspot' strategies have been proposed, which focus conservation efforts on small areas (i.e. $2 \%$ of the land area). These small areas are carefully selected in order to reduce the likelihood of mass extinctions for example, while allowing expansion of agricultural land in other areas. Not all the goals are as susceptible to tradeoffs as others, and tradeoffs are minimized when focus is put on SDG 12, which is Responsible Consumption and Production (Obersteiner et al. 2016). Targets set out for this goal includes minimizing food loss (target 12.3), which can directly contribute to forest land-sparing.

A number of indicators have been set out for each target (UN 2017), and a review of a selection of goals, targets and indictors uncovers some of the potential conflicts which will arise (Table 6.3). For example, SDG 2 sets out to end hunger, and target 2.3 aims to double agricultural productivity. This target (2.3) seeks equal access to land for communities, which may lead to agriculture-driven deforestation. Most of the indicators measure progress in absolute terms, rather than in terms of productivity per area, so intensification is not specifically sought in this goal. Target $2 \mathrm{a}$ and $2 \mathrm{~b}$ are particularly relevant as can promote LSLA, from which many conflicts can arise (see chapter 4). Deforestation is likely to be driven by the investments for agriculture, and investments in rural infrastructure (target $2 b$ ), are likely to lead the way to further deforestation (for example Kleinschroth and Healey 2017). SDG 7 (Energy for all) and its target 7.2 on renewable energy, has the potential to negatively impact both food production and forest protection. At the same time, SDG 15 (Life on land) has several targets which are measured by indicators which relate to conserving forest areas, thus conflicting with the renewable energy goal and the goal to end hunger. The conclusions made in this thesis regarding minimizing conflicts between land uses should therefore be applied to the SDGs. 
Table 6.3. Selected goals, targets and indicators from the Sustainable Development Goals (UN 2017) which highlight some of the potential conflicts (other conflicts may occur between other goals, but a selection was made in the interest of conciseness)

\begin{tabular}{|c|c|c|}
\hline Goals & Targets & Indicators \\
\hline \begin{tabular}{lr}
\multicolumn{2}{c}{ Goal 2. End hunger, } \\
achieve & food \\
security & and \\
improved & nutrition \\
and & promote \\
sustainable & \\
agriculture &
\end{tabular} & 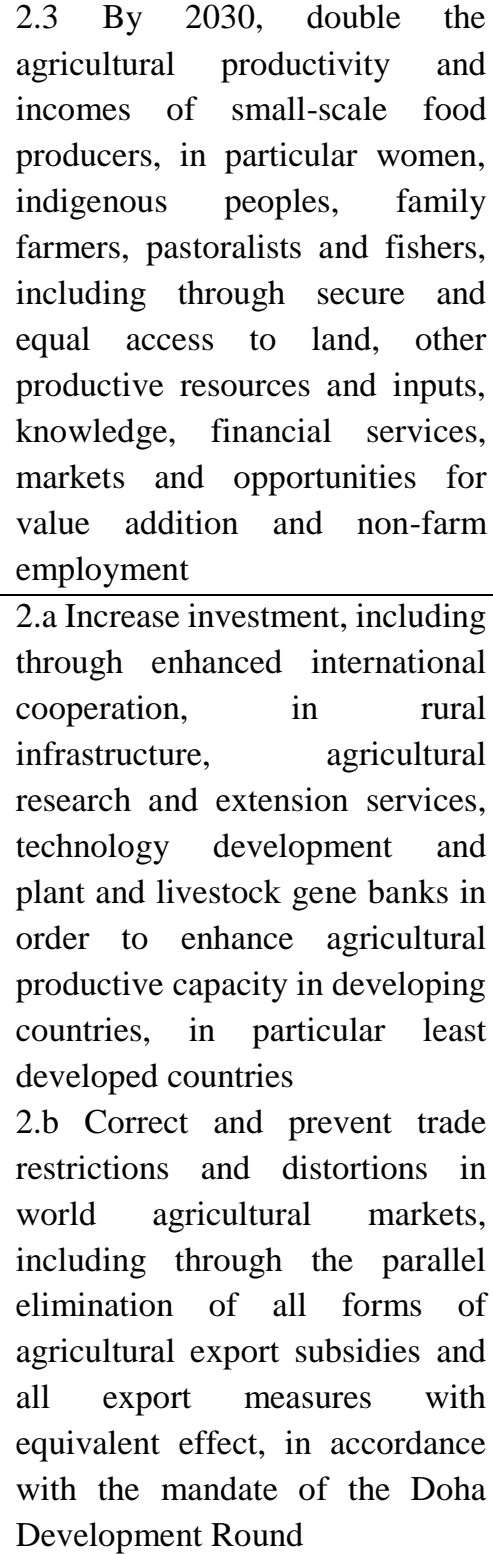 & $\begin{array}{l}\text { 2.a.1 The agriculture } \\
\text { orientation index for } \\
\text { government expenditures } \\
\text { 2.a.2 Total official flows } \\
\text { (official development } \\
\text { assistance plus other official } \\
\text { flows) to the agriculture } \\
\text { sector Agricultural export } \\
\text { 2.b.1 } \\
\text { subsidies }\end{array}$ \\
\hline
\end{tabular}




\begin{tabular}{|c|c|c|}
\hline $\begin{array}{l}\text { Goal } 7 . \text { Ensure } \\
\text { access to affordable, } \\
\text { reliable, sustainable } \\
\text { and modern energy } \\
\text { for all }\end{array}$ & $\begin{array}{l}7.2 \text { By 2030, increase } \\
\text { substantially the share of } \\
\text { renewable energy in the global } \\
\text { energy mix }\end{array}$ & $\begin{array}{l}\text { 7.2.1 Renewable energy share } \\
\text { in the total final energy } \\
\text { consumption }\end{array}$ \\
\hline \multirow{3}{*}{$\begin{array}{l}\text { Goal 15. Protect, } \\
\text { restore and promote } \\
\text { sustainable use of } \\
\text { terrestrial } \\
\text { ecosystems, } \\
\text { sustainably manage } \\
\text { forests, combat } \\
\text { desertification, and } \\
\text { halt and reverse land } \\
\text { degradation and halt } \\
\text { biodiversity loss }\end{array}$} & $\begin{array}{l}15.1 \text { By 2020, ensure the } \\
\text { conservation, restoration and } \\
\text { sustainable use of terrestrial and } \\
\text { inland freshwater ecosystems and } \\
\text { their services, in particular } \\
\text { forests, wetlands, mountains and } \\
\text { drylands, in line with obligations } \\
\text { under international agreements }\end{array}$ & $\begin{array}{l}\text { 15.1.1 Forest area as a } \\
\text { proportion of total land area } \\
15.1 .2 \text { Proportion of } \\
\text { important sites for terrestrial } \\
\text { and freshwater biodiversity } \\
\text { that are covered by protected } \\
\text { areas, by ecosystem type }\end{array}$ \\
\hline & $\begin{array}{l}15.2 \text { By } 2020 \text {, promote the } \\
\text { implementation of sustainable } \\
\text { management of all types of } \\
\text { forests, halt deforestation, restore } \\
\text { degraded forests and substantially } \\
\text { increase afforestation and } \\
\text { reforestation globally }\end{array}$ & $\begin{array}{lr}15.2 .1 \quad \text { Progress } & \text { towards } \\
\text { sustainable } & \text { forest } \\
\text { management } & \end{array}$ \\
\hline & $\begin{array}{l}15.3 \text { By 2030, combat } \\
\text { desertification, restore degraded } \\
\text { land and soil, including land } \\
\text { affected by desertification, } \\
\text { drought and floods, and strive to } \\
\text { achieve a land degradation- } \\
\text { neutral world }\end{array}$ & $\begin{array}{l}\text { 15.3.1 Proportion of land that } \\
\text { is degraded over total land } \\
\text { area }\end{array}$ \\
\hline
\end{tabular}

\subsubsection{Future data needs}

One of the major challenges highlighted in this thesis, is the production of better data on emissions from agriculture-driven deforestation. A number of recent remote sensing advances including new data streams and processing methodologies, have led to better emissions estimates (Section 1.3). However, in the AFOLU sector, data remain poor, and "positive and negative emission changes are reported across different databases and uncertainties in the data are high" (Edenhofer et al. 2014). The new data on emissions from agriculture-driven deforestation presented in chapter 2, are the first of their kind, and provide the best understanding of the current status for emissions from this sector to the authors' 
knowledge. However, these emissions estimates are uncertain, and do not provide enough information for all requirements. For example, basing future projections on these data are difficult, and although we can anticipate for example that Africa will be the next hotspot for these emissions, the extent to which this will happen is largely unknown. Some unknowns relate to our knowledge on the proportion of deforestation driven by agriculture. In Africa, it is lower than in other regions (62\%), so if this were to increase, it could lead to an increase in emissions if action to avoid this was not taken. In addition, the data on area of deforestation is limited and uncertain. We used a combination of up to four datasets over four time periods, but only in one time period (2000-2005) are all the datasets potentially available, and in some countries, only two datasets are available for this time period. Emissions factors could also be improved, although the new $30 \mathrm{~m}$ above ground carbon density data by Baccini et al. (Zarin et al. 2016; Baccini 2017) is likely to be an important dataset for future analyses. In general, new more certain data are also required on the sub-national level to allow different scales of analysis to take place (rather than national only, as presented in this thesis).

A key characteristic of new data should be transparency (as discussed in section 5.6). This applies to all aspects of the data, including reporting its origins, assumptions, limitations, methodologies and associated uncertainties. The need to take into account all the sources of uncertainty and the necessity of suitable data to calculate these uncertainties is highlighted in chapter 2. Where data are used in relation to company or government commitments, or for country reporting, it is essential to have transparency for accountability. One example is the reporting of emissions from trade flows for agricultural commodity chains. The lack of transparency in these often complex supply chains is one of the obstacles to progress in reducing emissions for example through zero-deforestation commitments (Godar et al. 2016). Although there is a balance between the level of detail and complexity of supply chain mapping, increasing the spatial detail can help to provide more accurate results. Where risk of, for example, deforestation varies from region to region, more spatial detail about the supply chain means that this risk can be more accurately calculated. Selecting the best spatial detail for reporting, will help to remove the doubts which remain over the feasibility of these commitments, while keeping implementation practical (Godar et al. 2016). One aspect of the supply chain, is the acquisition of farmland, and in the case of LSLA (see chapter 4) transparent data at the right spatial detail can be used to identify conversions of forest land due to LSLA.

New data on emissions from forest degradation and soils is required to better understand the links between agriculture and forests. For example, 69\% of gross emissions from forests were found to relate to forest degradation, or in other words losses of carbon from standing forests (Baccini et al. 2017). Understanding forest degradation should therefore be given more priority in research and also policy, and it is relevant to this thesis, as agricultural activities such as grazing in forests can lead to forest degradation. Additionally, sequestration of carbon 
in soils, or avoiding losses of soil carbon is one potentially important mitigation mechanism, and benefit of forest protection. Better data are required on soil carbon sequestration potentials and mechanisms, as these data are typically uncertain (for example: Lal 2004). Although soil carbon is not specifically mentioned in the SDGs, the restoration of degraded land is the focus of target 15.3 (Table 6.3). There has been a focus on the land restoration potential in Africa in recent times, for example the ambitious Africa Forest Landscape Restoration Initiative (AFR100) which seeks to restore 100 million hectares of land by 2030 (NEPAD 2017). Alongside forest land restoration, restoration of agriculture land can not only promote soil carbon sequestration, but can also address food security (Gnacadja \& Wiese 2016), and spare forests.

In summary, there is an urgent need to reduce emissions related to agriculture and deforestation. In order to do this effectively, more certain data must become available, upon which mitigation decisions can be based. There is an increasing sense of urgency, as efforts to decrease emissions worldwide face difficulties (Anon 2017; Ripple et al. 2017). Prioritizing mitigation in the forest and agriculture sectors will harness its large potential for emissions reductions, and also the opportunity for positive co-benefits, including increasing food security. 


\section{References}

4 per 1000 Initiative, 2016. 4\%o Initiative: soils for food security and climate. Available at: http://4p1000.org/ [Accessed March 23, 2016].

Achard, F. et al., 2014. Determination of tropical deforestation rates and related carbon losses from 1990 to 2010. Global Change Biology, 20, pp.2540-2554.

Agrawal, A., Nepstad, D. \& Chhatre, A., 2011. Reducing Emissions from Deforestation and Forest Degradation. Annual Review of Environment and Resources, 36(1), pp.373396.

Alexandratos, N. \& Bruinsma, J., 2012. World Agriculture Towards 2030 / 2050 The 2012 Revision, ESA Working Paper 12-03, FAO Rome, Italy.

Alkama, R. \& Cescatti, A., 2016. Biophysical climate impacts of recent changes in global forest cover. Science, 351(6273), pp.600-604.

Angelsen, A. et al., 2012. Analysing REDD+: Challenges and choices, Bogor, Indonesia: CIFOR.

Angelsen, A., 2008. Moving Ahead with REDD Issues, Options and Implications A. Angelsen, ed., Bogor, Indonesia: Center for International Forestry Research (CIFOR). Angelsen, A., 2010. Policies for reduced deforestation and their impact on agricultural production. Proceedings of the National Academy of Sciences of the United States of America, 107(46), pp.19639-19644.

Angelsen, A. \& Kaimowitz, D., 2001. Agricultural Technologies and Tropical Deforestation A. Angelsen \& D. Kaimowitz, eds., Wallingford, UK: CABI.

Anon, 2017. Bonn chance. Nature, 551(November), pp.413-414.

Anseeuw, W. et al., 2012. Transnational Land Deals for Agriculture in the Global South Analytical Report based on the Land Matrix Database,

Arima, E.Y. et al., 2011. Statistical confirmation of indirect land use change in the Brazilian Amazon. Environmental Research Letters, 6(2), p.24010.

Ausubel, J., Wernick, I. \& Waggoner, P., 2013. Peak Farmland and the Prospect for Land Sparing. Population and Development Review, 38, pp.221-242.

Avitabile, V. et al., 2011. Mapping biomass with remote sensing: a comparison of methods for the case study of Uganda. Carbon Balance and Management, 6(7), pp.1-14.

Avitabile, V. et al., 2016. An integrated pan-tropical biomass map using multiple reference datasets. Global Change Biology, 22, pp.1406-1420.

Baccini, A., 2017. Aboveground live woody biomass density. Available at: http://data.globalforestwatch.org/datasets/8f93a6f94a414f9588ce4657a39c59ff_1 [Accessed October 13, 2017]. 
Baccini, A. et al., 2012. Estimated carbon dioxide emissions from tropical deforestation improved by carbon-density maps. Nature Climate Change, 2(3), pp.182-185.

Baccini, A. et al., 2017. Tropical forests are a net carbon source based on aboveground measurements of gain and loss. Science, 358(6360), pp.230-234.

Baede, A., van der Linden, P. \& Verbruggen, A., 2007. Annex to IPCC Fourth Assessment Report, Geneva, Switzerland.

Bajzelj, B. et al., 2014. Importance of food-demand management for climate mitigation. Nature Climate Change, 4(October), pp.924-929.

Barnes, R.F.W., 1990. Deforestation trends in tropical Africa. African Journal of Ecology, 28, pp.161-173.

Bastin, J. et al., 2017. The extent of forest in dryland biomes. Science, 356(6338), pp.635638.

Bastos Lima, M.G. et al., 2015. Contribution of Forests and Land Use to Closing the Gigatonne Emissions Gap by 2020. WWF-WUR policy brief 2, WWF, Gland, Switzerland.

Bauhus, J., Meer, P.J. van der \& Kanninen, M., 2010. Plantation forests: global perspectives, London, Washington, DC: Earthscan.

Den Besten, J.W., Arts, B. \& Verkooijen, P., 2014. The evolution of REDD+: An analysis of discursive-institutional dynamics. Environmental Science and Policy, 35, pp.40-48.

Borlaug, N., 2007. Feeding a Hungry World. Science, 318(5849), p.359.

Borras, S. et al., 2012. Land grabbing and global capitalist accumulation: key features in Latin America. Canadian Journal of Development Studies/Revue canadienne d'études du développement, 33(4), pp.402-416.

Bos, J.F.F.P. et al., 2017. Trade-offs in soil fertility management on arable farms. Agricultural Systems, 157, pp.292-302.

Boysen, L.R. et al., 2017. The limits to global-warming mitigation by terrestrial carbon removal. Earth's Future, 5, pp.463-474.

Breu, T. et al., 2016. Large-Scale Land Acquisition and Its Effects on the Water Balance in Investor and Host Countries. Plos One, 11(3), pp.1-18.

Brown, S. \& Zarin, D., 2013. What Does Zero Deforestation Mean? Science, 342(6160), pp.805-807.

Burney, J.A., Davis, S.J. \& Lobell, D.B., 2010. Greenhouse gas mitigation by agricultural intensification. Proceedings of the National Academy of Sciences of the United States of America, 107(26), pp.12052-12057.

Byerlee, D., Stevenson, J. \& Villoria, N., 2014. Does intensification slow crop land expansion or encourage deforestation? Global Food Security, 3(2), pp.92-98.

Campbell, J.E. et al., 2008. The global potential of bioenergy on abandoned agriculture lands. Environmental science \& technology, 42(15), pp.5791-5794. 
Canadell, J.G. et al., 2010. Interactions of the carbon cycle, human activity, and the climate system: a research portfolio. Current Opinion in Environmental Sustainability, 2, pp.301-311.

Cardona, O. et al., 2012. Determinants of Risk : Exposure and Vulnerability. In Managing the Risks of Extreme Events and Disasters to Advance Climate Change Adaptation A Special Report of Working Groups I and II of the Intergovernmental Panel on Climate Change (IPCC). Cambridge, UK: Cambridge University Press, pp. 65-108.

Carlson, K.M. et al., 2016. Greenhouse gas emissions intensity of global croplands. Nature Climate Change, 7(January), pp.63-68.

Carter, S. et al., 2015. Mitigation of agricultural emissions in the tropics: comparing forest land-sparing options at the national level. Biogeosciences, 12(15), pp.4809-4825.

Carter, S. et al., 2017. Large scale land acquisitions and REDD+: a synthesis of conflicts and opportunities. Environmental Research Letters, 12(3), p.35010.

Cassman, K.G., 1999. Ecological intensification of cereal production systems: yield potential, soil quality, and precision agriculture. Proceedings of the National Academy of Sciences of the United States of America, 96(11), pp.5952-5959.

Cattaneo, A., 2001. A general equilibrium analysis of technology, migration and deforestation in the Brazilian Amazon. In A. Angelsen \& D. Kaimowitz, eds. Agricultural Technologies and Tropical Deforestation. Wallingford, UK: CABI, pp. 69-90.

CDP, 2017. Carbon Disclosure Project. Available at: www.cdp.net [Accessed March 6, 2017].

Chandra, A. et al., 2016. Resolving the UNFCCC divide on climate-smart agriculture. Carbon Management, 7(5-6), pp.295-299.

Climate Action, 2012. Brazil's programme on low carbon agriculture. Available at: http://www.climateactionprogramme.org/news/brazils_low_carbon_agriculture_progr amme [Accessed January 20, 2017].

Cohn, A. et al., 2011. The Viability of Cattle Ranching Intensification in Brazil as a Strategy to Spare Land and Mitigate Greenhouse Gas Emissions, CGIAR Research Program on Climate Change, Agriculture and Food Security (CCAFS) working paper 11. Copenhagen, Denmark (2011).

Consumer Goods Forum, 2015. Acting individually: production protection. Available at: http://tfa2020.org/wp-content/uploads/2015/12/01122015-_Produce-Protect-CGFstatement.pdf [Accessed June 15, 2017].

Corbera, E. et al., 2011. Rights to land, forests and carbon in REDD+: Insights from Mexico, Brazil and Costa Rica. Forests, 2(1), pp.301-342.

Cotula, L. et al., 2009. Land grab or development opportunity? agricultural investment and international land deals in Africa., 36(8), p.130.

Cotula, L. et al., 2011. Agricultural investment and international land deals: evidence from a multi-country study in Africa. Food Security, 3(S1), pp.99-113. 
Cotula, L., 2012. The international political economy of the global land rush: A critical appraisal of trends, scale, geography and drivers. Journal of Peasant Studies, 39(3-4), pp.649-680.

Creed, A., Strassburg, B. \& Latawiec, A., 2010. Agricultural Expansion and REDD+: An Assessment of the Risks and Considerations to inform REDD+ and Land Use Policy Design, Washington, DC.

Dalla-Nora, E.L. et al., 2014. Why have land use change models for the Amazon failed to capture the amount of deforestation over the last decade? Land Use Policy, 39, pp.403-411.

DeFries, R. et al., 2013. Export-oriented deforestation in Mato Grosso: harbinger or exception for other tropical forests? Philosophical transactions of the Royal Society of London. Series B, Biological sciences, 368(1619), p.20120173.

DeFries, R.S. et al., 2010. Deforestation driven by urban population growth and agricultural trade in the twenty-first century. Nature Geoscience, 3(3), pp.178-181.

Deininger, K. \& Byerlee, D., 2011. Rising Global Interest in Farmland: Can it yield sustainable and equitable benefits?, World Bank, Washington, DC.

Derkx, B. \& Glasbergen, P., 2014. Elaborating global private meta-governance: An inventory in the realm of voluntary sustainability standards. Global Environmental Change, 27(1), pp.41-50.

Descheemaeker, K. et al., 2016. Climate change adaptation and mitigation in smallholder crop-livestock systems in sub-Saharan Africa: a call for integrated impact assessments. Regional Environmental Change, 16, p.2331.

DiMiceli, C. et al., 2011. Vegetation Continuous Fields MOD44B, 20011 Percent Tree Cover, Collection 5. The University of Maryland, USA.

Dinerstein, E. et al., 2015. Guiding Agricultural Expansion to Spare Tropical Forests. Conservation Letters, 8(4), pp.262-271.

Dinesh, D. et al., 2016. Options for agriculture at Marrakech climate talks: messages for SBSTA 45 agriculture negotiators. CCAFS Report 16.

Diniz, F.H. et al., 2015. Mapping future changes in livelihood security and environmental sustainability based on perceptions of small farmers in the Brazilian Amazon. Ecology and Society, 20(2), p.art26.

Doda, B. et al., 2016. Are Corporate Carbon Management Practices Reducing Corporate Carbon Emissions? Corporate Social Responsibility and Environmental Management, 23(5), pp.257-270.

Droogers, P., Seckler, D. \& Makin, I., 2001. Estimating the Potential of Rain-fed Agriculture, Colombo, Sri Lanka.

Duguma, L.A., Minang, P.A. \& Van Noordwijk, M., 2014. Climate change mitigation and adaptation in the land use sector: From complementarity to synergy. Environmental Management, 54(3), pp.420-432. 
Duwayri, M., Tran, D. Van \& Nguyen, V.N., 2000. Reflections on yield gaps in rice production: how to narrow the gaps. In M. K. Papademetriou, F. J. Dent, \& E. M. Herath, eds. Bridging the Rice Yield Gap in the Asia-Pacitic Region. Rome, Italy: FAO Regional office for Asia and the Pacific, p. 61.

Earth Innovation Institute, 2016a. Forests, Farms \& Finance Initiative. Available at: http://earthinnovation.org/our-work/global/forests-farms-finance-initiative/ [Accessed January 3, 2016].

Earth Innovation Institute, 2016b. Making Corporate Deforestation Pledges Work. earthinnovation.org

EC, 2016. European Union Restrictive measures (sanctions) in force. European Commission Service for Foreign Policy Instruments, p.111.

Eckert, S., Giger, M. \& Messerli, P., 2016. Contextualizing local-scale point sample data using global-scale spatial datasets: Lessons learnt from the analysis of large-scale land acquisitions. Applied Geography, 68, pp.84-94.

Edelman, M., 2013. Messy hectares: questions about the epistemology of land grabbing data. The Journal of Peasant Studies, 40(February), pp.485-501.

Edelman, M., Oya, C. \& Borras, S.M., 2013. Global Land Grabs: historical processes, theoretical and methodological implications and current trajectories. Third World Quarterly, 34(9), pp.1517-1531.

Edenhofer, O. et al., 2014. Technical Summary. In O. Edenhofer et al., eds. Climate Change 2014: Mitigation of Climate Change. Contribution of Working Group III to the Fifth Assessment Report of the Intergovernmental Panel on Climate Chang. Cambridge, UK and New York, USA: Cambridge University Press.

Eitelberg, D. a., van Vliet, J. \& Verburg, P.H., 2015. A review of global potentially available cropland estimates and their consequences for model-based assessments. Global Change Biology, 21, pp.1236-1248.

Eliasch, J., 2008. Eliasch Review - Climate change: Financing global forests, UK Office of Climate Change, London, UK.

Ellison, D. et al., 2017. Trees, forests and water: Cool insights for a hot world. Global Environmental Change, 43, pp.51-61.

Engel, S. \& Muller, A., 2016. Payments for environmental services to promote " climatesmart agriculture "? Potential and challenges. Agricultural Economics, 47, pp.173184.

Erb, K.-H. et al., 2016. Exploring the biophysical option space for feeding the world without deforestation. Nature communications, 7, pp.1-7.

Erbaugh, J. \& Agrawal, A., 2017. Clarifying the landscape approach: A Letter to the Editor on "Integrated landscape approaches to managing social and environmental issues in the tropics." Global Change Biology, 23(11), pp.4453-4454.

ESA, 2013. Land Cover State 2010 (2008-2012) 300m v1.1, Paris, France. 
Fader, M. et al., 2013. Spatial decoupling of agricultural production and consumption: quantifying dependences of countries on food imports due to domestic land and water constraints. Environmental Research Letters, 8(1), p.14046.

Fairhead, J., Leach, M. \& Scoones, I., 2012. Green Grabbing: a new appropriation of nature? The Journal of Peasant Studies, 39(No. 2 April), pp.237-261.

FAO, 2003. Trade Reforms and Food Security: Conceptualizing the Linkages. Commodicy Policy and Projections Service, Commodities and Trade Division. Rome, Italy.

FAO, 2010a. Climate-Smart Agriculture: Agriculture: Policies, Practices and Financing for Food Security, Adaptation and Mitigation. Rome, Italy.

FAO, 2010b. Global Forest Resources Assessment: Main report, FAO Forestry Paper 163, Rome, Italy.

FAO, 2013. Climate-Smart Agriculture Sourcebook. Rome, Italy.

FAO, 2014a. FAOSTAT glossary. Available at: http://faostat.fao.org/site/375/default.aspx [Accessed March 18, 2015].

FAO, 2014b. Food and Agriculture Organisation of the United Nations statisitical database. Available at: http://faostat3.fao.org/home/index.html.

FAO, 2014c. The State of Food and Agriculture: Innovation in family farming. Rome, Italy FAO, 2015a. Fra 2015 Terms and Definitions, Rome, Italy.

FAO, 2015b. Global Forest Resources Assessment 2015. FAO Forestry Paper No. 1.

Available at: http://www.fao.org/forestry/fra/fra2015/en/ [Accessed September 1, 2015].

FAO, 2015c. Global Forest Resources Assessment 2015: Desk reference.

FAO, 2015d. Guide for country reporting for FRA 2015, Rome, Italy.

FAO, 2017a. FAOSTAT Statistics Database. Available at: www.fao.org/faostat/.

FAO, 2017b. OpenForis. Available at: http://www.openforis.org/ [Accessed March 10, 2017].

FAO, 2017c. SEPAL: System for earth observations, data access, processing $\&$ analysis for land monitoring. Available at: https://sepal.io/ [Accessed August 16, 2017].

FAO, 2017d. The Global Forest Resources Assessments (FRA). Available at: http://www.fao.org/forest-resources-assessment/en/ [Accessed June 21, 2017].

FAO \& JRC, 2012. Global forest land-use change 1990-2005, Rome, Italy.

FCPF, 2015. Most Recent R-PP Submissions by Countries to the World Bank Forest Carbon Partnership Facility (FCPF). Available at: http://www.forestcarbonpartnership.org/redd-countries-1.

FCPF, 2013. The Forest Carbon Partnership Facility. Available at: http://www.forestcarbonpartnership.org/redd-countries.

Fischer, G. et al., 2008. GAEZ v3.0, IASA, Laxenburg, Austria and FAO, Rome, Italy.

Foley, J.A. et al., 2011. Solutions for a cultivated planet. Nature, 478(20 October), pp.337342. 
Frank, S. et al., 2017. Reducing greenhouse gas emissions in agriculture without compromising food security? Environmental Research Letters, 12(10), p.105004.

Frieler, K. et al., 2015. A framework for the cross-sectoral integration of multi-model impact projections: land use decisions under climate impacts uncertainties. Earth System Dynamics, 6(2), pp.447-460.

Friis, C. \& Reenberg, A., 2010. Land grab in Africa Emerging land system drivers, Global Land Project International Project Office, Copenhagen, Denmark.

Fund For Peace, 2015. Fragile States Index. Fragile States Index. Available at: http://fsi.fundforpeace.org/.

Gallagher, E., 2008. The Gallagher Review of the indirect effects of biofuels production, The Renewable Fuels Agency, East Sussex. p.90.

Garnett, T., 2012. Climate change and agriculture: Can market governance mechanisms reduce emissions from the food system fairly and effectively?, London: International Institute for Environment and Development.

Garnett, T. et al., 2013. Sustainable Intensification in Agriculture: Premises and Policies. Science, 341(6141), pp.33-34.

Gibbs, H.K. et al., 2010. Tropical forests were the primary sources of new agricultural land in the 1980s and 1990s. Proceedings of the National Academy of Sciences of the United States of America, 107(38), pp.16732-16737.

Giller, K.E. et al., 2015. Beyond conservation agriculture. Frontiers in Plant Science, 6(October), p.Art 870.

Giovannetti, G. \& Ticci, E., 2016. Determinants of biofuel-oriented land acquisitions in Sub-Saharan Africa. Renewable and Sustainable Energy Reviews, 54, pp.678-687.

Global Canopy Programme, 2016. Sleeping giants of deforestation: the companies, countries and financial institutions with the power to save forests. The 2016 Forest 500 results and analysis. Oxford, UK, p.12.

Gnacadja, L. \& Wiese, L., 2016. Land Degradation Neutrality: Will Africa Achieve It? Institutional Solutions to Land Degradation and Restoration in Africa. In R. Lal et al., eds. Climate Change and Multi-Dimensional Sustainability in African Agriculture: Climate Change and Sustainability in Agriculture. Cham: Springer International Publishing, pp. 61-95.

Godar, J. et al., 2016. Balancing detail and scale in assessing transparency to improve the governance of agricultural commodity supply chains Balancing detail and scale in assessing transparency to improve the governance of agricultural commodity supply chains. Environmental Research Letters, 11(3), p.35015.

Godfray, H.C.J. et al., 2010. Food security: the challenge of feeding 9 billion people. Science, 327(5967), pp.812-818.

Goetz, S.J. et al., 2015. Measurement and monitoring needs, capabilities and potential for addressing reduced emissions from deforestation and forest degradation under REDD+. Environmental Research Letters, 10(12), p.123001. 
GOFC-GOLD, 2016. A sourcebook of methods and procedures for monitoring and reporting anthropogenic greenhouse gas emissions and removals associated with deforestation, gains and losses of carbon stocks in forests remaining forests, and forestation Report version. Wageningen University, Netherlands. COP22-1.

Goodman, L.A., 1962. The Variance of the Product of K Random Variables. Journal of the American Statistical Association, 57(297), pp.54-60.

Gordon, L.J. et al., 2017. Rewiring food systems to enhance human health and biosphere stewardship. Enviromental Research Letters, 12(100201), pp.1-12.

Gorelick, N. et al., 2017. Google Earth Engine: Planetary-scale geospatial analysis for everyone. Remote Sensing of Environment, In Press.

Grace, J., Mitchard, E. \& Gloor, E., 2014. Perturbations in the carbon budget of the tropics. Global Change Biology, 20, pp.3238-3255.

Grainger, A., 2008. Difficulties in tracking the long-term global trend in tropical forest area. Proceedings of the National Academy of Sciences of the United States of America, 105(2), pp.818-823.

Grassi, G. et al., 2017. The key role of forests in meeting climate targets requires science for credible mitigation. Nature Climate Change, 7(February), pp.220-225.

Green, R.E. et al., 2005. Farming and the Fate of Wild Nature. Science, 307(5709), pp.550556.

Grieg-Gran, M., 2010. Beyond forestry: why agriculture is key to the success of REDD+, International Institute for Environment and Development (IIED). London, UK.

Gupta, A. \& Mason, M., 2016. Disclosing or obscuring? The politics of transparency in global climate governance. Current Opinion in Environmental Sustainability, 18, pp.82-90.

Gutiérrez-Vélez, V.H. et al., 2011. High-yield oil palm expansion spares land at the expense of forests in the Peruvian Amazon. Environmental Research Letters, 6(4), p.44029.

Hall, C. et al., 2017. The impact of population growth and climate change on food security in Africa : looking ahead to 2050 The impact of population growth and climate change on food security in Africa : looking ahead to 2050. International Journal of Agricultural Sustainability, 15(2), pp.124-135.

Hamrick, K. \& Gallant, M., 2017. Unlocking Potential: State of the Voluntary Carbon Markets 2017. Forest Trends' Ecosystem Marketplace. Washington, DC.

Hamunyela, E., Verbesselt, J. \& Herold, M., 2016. Using spatial context to improve early detection of deforestation from Landsat time series. Remote Sensing of Environment, 172(January), pp.126-138.

Hansen, M.C. et al., 2013. High-Resolution Global Maps of 21st-Century Forest Cover Change. Science, 342(6160), pp.850-853.

Hansen, M.C. et al., 2014. Response to Comment on " High-resolution global maps of 21stcentury forest cover change." Science, 344(6187), p.981. 
Hansen, M.C. et al., 2016. Humid tropical forest disturbance alerts using Landsat data. Environmental Research Letters, 11(3), p.34008.

Harris, N.L., Brown, S., Hagen, S.C., et al., 2012. Baseline map of carbon emissions from deforestation in tropical regions. Science, 336(6088), pp.1573-1576.

Harris, N.L., Brown, S., Hagen, S., et al., 2012b. Progress toward a consensus on carbon emissions from tropical deforestation, Winrock International \& Woods Hole Research Center.

Havlík, P. et al., 2014. Climate change mitigation through livestock system transitions. Proceedings of the National Academy of Sciences of the United States of America, 111(10), pp.3709-3714.

Heinimann, A. et al., 2017. A global view of shifting cultivation: Recent, current, and future extent. PLoS ONE, 12(9), p.e0184479.

Hergoualc'h, K. \& Verchot, L. V., 2013. Greenhouse gas emission factors for land use and land-use change in Southeast Asian peatlands. Mitigation and Adaptation Strategies for Global Change, 19(6), pp.789-807.

Herrero, M. et al., 2017. Farming and the geography of nutrient production for human use : a transdisciplinary analysis. Lancet Planet Health, 1, pp.e33-e42.

Heuvelink, G.B.M., 2005. Propagation of error in spatial modelling with GIS. In P. A. Longley et al., eds. Geographical Information Systems. Principles, Techniques, Management and Applications. New Jersey, USA: Wiley, pp. 207-217.

Hosonuma, N. et al., 2012. An assessment of deforestation and forest degradation drivers in developing countries. Environmental Research Letters, 7(4), p.44009.

Houghton, R.A. et al., 2012. Carbon emissions from land use and land-cover change. Biogeosciences, 9(12), pp.5125-5142.

IBM, 2013. IBM SPSS Decision Trees 21,

Ickowitz, A. et al., 2015. Agriculture and deforestation in the Democratic Republic of the Congo: A synthesis of the current state of knowledge. CIFOR Occasional Paper 119, Bogor, Indonesia.

Imhoff, M.L. et al., 2004. HANPP Collection: Human Appropriation of Net Primary Productivity (HANPP) by Country and Product. NASA Socioeconomic Data and Applications Center (SEDAC). Available at: http://dx.doi.org/10.7927/H48G8HMK [Accessed January 1, 2015].

Imhoff, M.L. \& Bounoua, L., 2006. Exploring Global Patterns of Net Primary Production Carbon Supply and Demand Using Satellite Observations and Statistical Data. Journal of Geophysical Research, 111, p.D22S12.

Institute for Economics and Peace, 2015. Global Peace Index 2015: Quantifying Peace and its Benefits. p. 120.

IPCC, 2006. 2006 IPCC Guidelines for National Greenhouse Gas Inventories H. S. Eggleston et al., eds., Japan: National Greenhouse Gas Inventories Programme, IGES. 
IPCC, 2013. Summary for Policymakers. In: Climate Change 2013: The Physical Science Basis. Contribution of Working Group I to the Fifth Assessment Report of the Intergovernmental Panel on Climate Change T. F. Stocker et al., eds., Cambridge, United Kingdom and New York, NY, USA: Cambridge University Press.

van Ittersum, M.K. et al., 2013. Yield gap analysis with local to global relevance-A review. Field Crops Research, 143, pp.4-7.

IUCN UNEP-WCMC, 2014. The World Database on Protected Areas (WDPA). Available at: www.protectedplanet.net.

Janssen, S.J.C. et al., 2017. Towards a new generation of agricultural system data, models and knowledge products: Information and communication technology. Agricultural Systems, 155, pp.200-212.

Joseph, S. et al., 2013. REDD+ readiness: early insights on monitoring, reporting and verification systems of project developers. Environmental Research Letters, 8(3), p.34038.

Kaimowitz, D. \& Angelsen, A., 1998. Economic Models of Tropical Deforestation A Review, CIFOR, Bogor, Indonesia.

Kastner, T. et al., 2012. Global changes in diets and the consequences for land requirements for food. Proceedings of the National Academy of Sciences of the United States of America, 109(18), pp.6868-6872.

Keenan, R.J. et al., 2015. Dynamics of global forest area: Results from the FAO Global Forest Resources Assessment 2015. Forest Ecology and Management, 352, pp.9-20.

Van Kernebeek, H.R.J. et al., 2016. Saving land to feed a growing population: consequences for consumption of crop and livestock products. International Journal of Life Cycle Assessment, 21(5), pp.677-687.

Kim, D.-H. et al., 2014. Global, Landsat-based forest-cover change from 1990 to 2000. Remote Sensing of Environment, 155, pp.178-193.

Kim, D.-H., Sexton, J.O. \& Townshend, J.R., 2015. Accelerated Deforestation in the Humid Tropics from the 1990s to the 2000s. Geophysical Research Letters, 42, pp.3495-3501.

Kissinger, G., Herold, M. \& De Sy, V., 2012. Drivers of Deforestation and Forest Degradation: A Synthesis Report for REDD+ Policymakers. Lexeme Consulting, Vancouver, Canada.

Kleinschroth, F. \& Healey, J.R., 2017. Impacts of logging roads on tropical forests. Biotropica, 49(5), pp.620-635.

Köthke, M., Schröppel, B. \& Elsasser, P., 2014. National REDD + reference levels deduced from the global deforestation curve. Forest Policy and Economics, 43, pp.18-28.

Lal, R., 2004. Soil carbon sequestration to mitigate climate change. Geoderma, 123(1-2), pp.1-22.

Lal, R., 2016. Feeding 11 billion on 0.5 billion hectare of area under cereal crops. Food and Energy Security, 5(4), pp.239-251. 
Lambin, E.F. et al., 2013. Estimating the world's potentially available cropland using a bottom-up approach. Global Environmental Change, 23(5), pp.892-901.

Larson, A.M. et al., 2013. Land tenure and REDD+: The good, the bad and the ugly. Global Environmental Change, 23(3), pp.678-689.

Leblois, A. et al., 2017. What has Driven Deforestation in Developing Countries Since the 2000s? Evidence from New Remote-Sensing Data. World Development, 92(April), pp.82-102.

Lipper, L. et al., 2014. Climate-smart agriculture for food security. Nature Climate Change, 4(December), pp.1068-1072.

Locatelli, B. et al., 2015. Integrating climate change mitigation and adaptation in agriculture and forestry: opportunities and trade-offs. Wiley Interdisciplinary Reviews: Climate Change, 6(November/December), pp.585-598.

Lusiana, B., van Noordwijk, M. \& Cadisch, G., 2012. Land sparing or sharing? Exploring livestock fodder options in combination with land use zoning and consequences for livelihoods and net carbon stocks using the FALLOW model. Agriculture, Ecosystems and Environment, 159, pp.145-160.

Mandemaker, M., Bakker, M. \& Stoorvogel, J., 2011. The role of governance in agricultural expansion and intensification: A global study of arable agriculture. Ecology and Society, 16(2), p.art8.

Mbow, C. et al., 2014. Achieving mitigation and adaptation to climate change through sustainable agroforestry practices in africa. Current Opinion in Environmental Sustainability, 6(1), pp.8-14.

Mbow, C., 2010. Africa's risky gamble. Global Change, June(75), pp.20-23.

Mbow, C., 2014. Examining the deforestation paradox for climate change mitigation in Africa. Available at: http://cdkn.org/2014/09/examining-deforestation-mitigation-inafrica [Accessed July 15, 2015].

McCarthy, J.F., Vel, J. a. C. \& Afiff, S., 2012. Trajectories of land acquisition and enclosure: development schemes, virtual land grabs, and green acquisitions in Indonesia's Outer Islands. Journal of Peasant Studies, 39(2), pp.521-549.

McKinsey and Company, 2009. Pathways to a low-carbon economy: version 2 of the global greenhouse gas abatement cost curve. p.190.

Mertz, O.L.E. \& Mertens, C.F., 2017. Land Sparing and Land Sharing Policies in Developing Countries - Drivers and Linkages to Scientific Debates. World Development, 98, pp.523-535.

Messerli, P. et al., 2013. From "land grabbing" to sustainable investments in land: potential contributions by land change science. Current Opinion in Environmental Sustainability, 5(5), pp.528-534.

Meyer, C. \& Miller, D., 2015. Zero Deforestation Zones: The Case for Linking Deforestation-Free Supply Chain Initiatives and Jurisdictional REDD+. Journal of Sustainable Forestry, 34(6-7), pp.559-580. 
Meyfroidt, P. \& Lambin, E.F., 2011. Global Forest Transition: Prospects for an End to Deforestation. Annual Review of Environment and Resources, 36(1), pp.343-371.

Minang, P. et al., 2011. Agroforestry in REDD+: Opportunities and Challenges., Nairobi, Kenya.

Minang, P.A. et al., 2015. Climate-Smart Landscapes: Multifunctionality in Practice P. A. Minang et al., eds., Nairobi, Kenya (2015): World Agrforestry Centre (ICRAF).

Minasny, B. et al., 2017. Soil carbon 4 per mille. Geoderma, 292, pp.59-86.

Mitchard, E.T.A. et al., 2013. Uncertainty in the spatial distribution of tropical forest biomass: a comparison of pan-tropical maps. Carbon balance and management, 8(10), pp.1-13.

Mithöfer, D. et al., 2016. Certify and shift blame, or resolve issues? Environmentally and socially responsible global trade and production of timber and tree crop commodities. Journal of Biodiversity Science, Ecosystem Services \& Management., 13(1), pp.7295.

Mokany, K., Raison, R.J. \& Prokushkin, A.S., 2006. Critical analysis of root : shoot ratios in terrestrial biomes. Global Change Biology, 12(1), pp.84-96.

Monfreda, C., Ramankutty, N. \& Foley, J.A., 2008. Farming the planet: 2. Geographic distribution of crop areas, yields, physiological types, and net primary production in the year 2000. Global Biogeochemical Cycles, 22(1), pp.1-19.

Moreno-Fernández, D. et al., 2015. Alternative approaches to assessing the natural regeneration of Scots pine in a Mediterranean forest. Annals of Forest Science, 72(5), pp.569-583.

Nalepa, R.A. \& Bauer, D.M., 2012. Marginal lands: the role of remote sensing in constructing landscapes for agrofuel development. Journal of Peasant Studies, 39(February 2015), pp.403-422.

Neeff, T., Göhler, D. \& Ascui, F., 2014. Finding a path for REDD + between ODA and the CDM Finding a path for REDD + between ODA and the CDM. Climate Policy, 14(2), pp.149-166.

NEPAD, 2017. AFR100. Available at: http://www.afr100.org/ [Accessed October 18, 2017].

Nepstad, D. et al., 2013. More food, more forests, fewer emissions, better livelihoods: linking REDD+, sustainable supply chains and domestic policy in Brazil, Indonesia and Colombia. Carbon Management, 4(6), pp.639-658.

Neumann, K. et al., 2010. The yield gap of global grain production: A spatial analysis. Agricultural Systems, 103(5), pp.316-326.

Nolte, K., Chamberlain, W. \& Giger, M., 2016. International Land Deals for Agriculture Fresh insights from the Land Matrix : Analytical Report II, Centre for Development and Environment, University of Bern; Centre de coopération internationale en recherche agronomique pour le développement; German Institute of Global and Area Studies; University of Pretoria. Bern, Montpellier, Hamburg, Pretoria. 
van Noordwijk, M. et al., 2014. Agroforestry solutions for buffering climate variability and adapting to change. In Climate change Impact and Adaptation in Agricultural Systems. Wallingford, UK: CAB-International, pp. 216-232.

van Noordwijk, M., Khasanah, N. \& Dewi, S., 2016. Can intensification reduce emission intensity of biofuel through optimized fertilizer use? Theory and the case of oil palm in Indonesia. GCB Bioenergy, 9, pp.940-952.

Oberlack, C. et al., 2016. Sustainable livelihoods in the global land rush? Archetypes of livelihood vulnerability and sustainability potentials. Global Environmental Change, 41, pp.153-171.

Obersteiner, M. et al., 2016. Assessing the land resource - food price nexus of the Sustainable Development Goals. Science Advances, 2(9), p.e1501499.

Ochieng, R.M. et al., 2016. Institutional effectiveness of REDD + MRV: Countries progress in implementing technical guidelines and good governance requirements. Environmental Science and Policy, 61, pp.42-52.

Olofsson, P. et al., 2013. Making better use of accuracy data in land change studies: Estimating accuracy and area and quantifying uncertainty using stratified estimation. Remote Sensing of Environment, 129(February), pp.122-131.

Olson, D.M. et al., 2001. Terrestrial ecoregions of the world: a new map of life on Earth. Bioscience, 51(11), pp.933-938.

Paustian, K. et al., 2016. Climate-smart soils. Nature, 532(7597), pp.49-57.

Pelletier, J., Busch, J. \& Potvin, C., 2015. Addressing uncertainty upstream or downstream of accounting for emissions reductions from deforestation and forest degradation. Climatic Change, 130, pp.635-648.

Peskett, L. \& Todd, K., 2013. Putting REDD+ Safeguards and Safeguard Information Systems Into Practice, UN-REDD Programme Pokicy brief, Geneva, Switzerland.

Pirard, R. \& Belna, K., 2012. Agriculture and Deforestation: Is REDD+ Rooted In Evidence? Forest Policy and Economics, 21, pp.62-70.

Potapov, P. V. et al., 2012. Quantifying forest cover loss in Democratic Republic of the Congo, 2000-2010, with Landsat ETM+ data. Remote Sensing of Environment, 122(July), pp.106-116.

Pratihast, A. et al., 2013. Linking community-based and national REDD+ monitoring: a review of the potential. Carbon Management, 4(1), pp.91-104.

Le Quéré, C. et al., 2015. Global Carbon Budget 2015. Earth System Science Data, 7(2), pp.349-396.

Reed, J. et al., 2016. Integrated landscape approaches to managing social and environmental issues in the tropics: learning from the past to guide the future. Global Change Biology, 22, pp.2540-2554.

Reiche, J. et al., 2017. Improving near-real time deforestation monitoring in tropical dry forests by combining dense Sentinel-1 time series with Landsat and ALOS-2 PALSAR-2. Remote Sensing of Environment, In Press. 
Reidsma, P. et al., 2015. Sustainable agricultural development in a rural area in the Netherlands? Assessing impacts of climate and socio-economic change at farm and landscape level. Agricultural Systems, 141, pp.160-173.

Richards, M. et al., 2015. How countries plan to address agricultural adaptation and mitigation. An analysis of Intended Nationally Determined Contributions.

Richter, D. deB \& Houghton, R.A., 2014. Gross CO2 fluxes from land-use change: implications for reducing global emissions and increasing sinks. Carbon Management, 2(1), pp.41-47.

Ripple, W.J. et al., 2017. World Scientists' Warning to Humanity: A Second Notice. BioScience, In Press.

Roman-Cuesta, R.M. et al., 2016. Hotspots of gross emissions from the land use sector: Patterns, uncertainties, and leading emission sources for the period 2000-2005 in the tropics. Biogeosciences, 13(14), pp.4253-4269.

Romijn, E. et al., 2012. Assessing capacities of non-Annex I countries for national forest monitoring in the context of REDD+. Environmental Science \& Policy, 19-20(MayJune 2012), pp.33-48.

Romijn, E. et al., 2013. Exploring different forest definitions and their impact on developing REDD+ reference emission levels: A case study for Indonesia. Environmental Science \& Policy, 33, pp.246-259.

Romijn, E. et al., 2015. Assessing change in national forest monitoring capacities of 99 tropical countries. Forest Ecology and Management, 352, pp.109-123.

Roos, E., 1996. Land husbandry Components and strategy, FAO Soils Bulletin 70. Rome, Italy.

Rosenstock, T.S. et al., 2013. Toward a protocol for quantifying the greenhouse gas balance and identifying mitigation options in smallholder farming systems. Environmental Research Letters, 8(2), p.21003.

Rosenstock, T.S. et al., 2014. Agroforestry with N2-fixing trees: Sustainable development's friend or foe? Current Opinion in Environmental Sustainability, 6(February), pp.1521.

Rosenzweig, C. et al., 2014. Assessing agricultural risks of climate change in the $21 \mathrm{st}$ century in a global gridded crop model intercomparison. Proceedings of the National Academy of Sciences of the United States of America, 111(9), pp.3268-73.

RSPO, 2016. Roundtable for Sustainable Palm Oil (RSPO). Available at: http://www.rspo.org/ [Accessed August 3, 2016].

RTRS, 2016. Round Table on Responsible Soy (RTRS). Available at: http://www.responsiblesoy.org/ [Accessed August 3, 2016].

Rudel, T.K. et al., 2009. Agricultural intensification and changes in cultivated areas, 19702005. Proceedings of the National Academy of Sciences of the United States of America, 106(49), pp.20675-20680. 
Rulli, C.M., Saviori, A. \& Odorico, P.D., 2012. Global land and water grabbing. Proceedings of the National Academy of Sciences of the United States of America, 110(3), pp.892-897.

Rulli, M.C. \& Odorico, P.D., 2013. The science of evidence: the value of global studies on land rush. The Journal of Peasant Studies, 40(0), pp.907-909.

Sa, J.C. d M. et al., 2017. Low-carbon agriculture in South America to mitigate global climate change and advance food security. Environment International, 98, pp.102112.

Saatchi, S.S. et al., 2011. Benchmark map of forest carbon stocks in tropical regions across three continents. Proceedings of the National Academy of Sciences of the United States of America, 108(24), pp.9899-9904.

Salvini, G. et al., 2014. How countries link REDD+ interventions to drivers in their readiness plans: implications for monitoring systems. Environmental Research Letters, $9(7)$, p.74004.

Salvini, G. et al., 2016. REDD+ and climate smart agriculture in landscapes: A case study in Vietnam using companion modeling. Journal of Environmental Management, 172, pp.58-70.

Sands, R.D. \& Leimbach, M., 2003. Modeling Agriculture and Land Use in an Integrated Framework. Climatic Change, 56, pp.185-210.

Sannier, C. et al., 2014. Using the regression estimator with Landsat data to estimate proportion forest cover and net proportion deforestation in Gabon. Remote Sensing of Environment, 151(August), pp.138-148.

Santilli, M. et al., 2005. Tropical Deforestation and the Kyoto Protocol. Climatic Change, 71(3), pp.267-276.

Sanz-Sanchez, M., Herold, M. \& Penman, J., 2013. REDD+ related forest monitoring remains a key issue: a report following the recent $\mathrm{UN}$ climate conference in Doha. Carbon Management, 4(2), pp.125-127.

de Sassi, C. et al., 2015. Towards integrated monitoring of REDD+. Current Opinion in Environmental Sustainability, 14, pp.93-100.

Sayer, J. et al., 2013. Ten principles for a landscape approach to reconciling agriculture, conservation, and other competing land uses. Proceedings of the National Academy of Sciences of the United States of America, 110(21), pp.8349-8356.

Schepaschenko, D. et al., 2017. Comment on "The extent of forest in dryland biomes." Science, 358(6362), pp.34-36.

Schmitz, C. et al., 2014. Land-use change trajectories up to 2050: insights from a global agro-economic model comparison. Agricultural Economics, 45(1), pp.69-84.

Scholes, M., 2012. After Durban: New issues on the table. Environmental Development, 1(1), pp.124-125.

De Schutter, O., 2011. How not to think of land-grabbing: three critiques of large-scale investments in farmland. Journal of Peasant Studies, 38(2), pp.249-279. 
Scoones, I., Hall, R., Jr, S.M.B., et al., 2013. The politics of evidence: A response to Rulli and D'Odorico. The Journal of Peasant Studies, 40(5), pp.911-912.

Scoones, I., Hall, R., Borras, S.M., et al., 2013. The politics of evidence: methodologies for understanding the global land rush. Journal of Peasant Studies, 40(3), pp.469-483.

Searchinger, T.D. et al., 2015. High carbon and biodiversity costs from converting Africa's wet savannahs to cropland. Nature Climate Change, 5(May), pp.481-486.

Seppelt, R. et al., 2014. Synchronized peak-rate years of global resources use. Ecology and Society, 19(4), p.50.

Seppelt, R. et al., 2016. Harmonizing Biodiversity Conservation and Productivity in the Context of Increasing Demands on Landscapes. BioScience, 66(10), pp.890-896.

Shekoofa, A. et al., 2014. Determining the Most Important Physiological and Agronomic Traits Contributing to Maize Grain Yield through Machine Learning Algorithms: A New Avenue in Intelligent Agriculture. PLoS ONE, 9(5), p.e97288.

Singh, V.P. et al., 2016. The national agroforestry policy of India: experiential learning in development and delivery phases, Working Paper No. 240, New Delhi (India): World Agroforestry Centre (ICRAF).

Smalley, R., Sulle, E. \& Malale, L., 2014. The role of the state and foreign capital in agricultural commercialisation: The case of sugarcane outgrowers in Kilombero District. Future Agricultures Working Paper 106, Tanzania, Brighton, UK.

Smith, P. et al., 2008. Greenhouse gas mitigation in agriculture. Philosophical transactions of the Royal Society of London. Series B, Biological sciences, 363(1492), pp.789813.

Smith, P. et al., 2010. Competition for land. Philosophical transactions of the Royal Society of London. Series B, Biological sciences, 365(1554), pp.2941-57.

Smith, P. et al., 2013. How much land-based greenhouse gas mitigation can be achieved without compromising food security and environmental goals? Global change biology, 19(8), pp.2285-2302.

Smith, P. et al., 2014. Agriculture, Forestry and Other Land Use (AFOLU). In O. Edenhofer et al., eds. Climate Change 2014: Mitigation of Climate Change, Contribution of Working Group III to the Fifth Assessment Report of the Intergovernmental Panel on Climate Change. Cambridge, United Kingdom and New York, USA.

Soares, B. et al., 2010. Role of Brazilian Amazon protected areas in climate change mitigation. Proceedings of the National Academy of Sciences of the United States of America, 107(24), pp.10821-10826.

Soliman, T. et al., 2016. Closing oil palm yield gaps among Indonesian smallholders through industry schemes, pruning, weeding and improved seeds. Royal Society Open Science, 3, pp.1-9.

Stern, N., 2006. Stern Review on the Economics of Climate Change, London, UK. 
Stevenson, J.R. et al., 2013. Green Revolution research saved an estimated 18 to 27 million hectares from being brought into agricultural production. Proceedings of the National Academy of Sciences of the United States of America, 110(21), pp.8363-9368.

Stickler, C., Bezerra, T. \& Nepstad, D., 2012. Global Rules for Sustainable Farming: A comparison of social and environmental safeguards for REDD+ and Principles \& Criteria for Commodity Roundtables. The RT-REDD Consortium, p.14.

Strassburg, B. et al., 2008. An Empirically-Derived Mechanism of Combined Incentives to Reduce Emissions from Deforestation, Centre for Social and Economic Research on the Global Environment (CSERGE). Working Paper ECM-08-01 Norwich, UK.

Strassburg, B.B.N. et al., 2013. Biophysical suitability, economic pressure and land-cover change: a global probabilistic approach and insights for REDD+. Sustainability Science, 9(2), pp.129-141.

Sunderland, T. et al., 2017. A methodological approach for assessing cross-site landscape change: Understanding socio-ecological systems. Forest Policy and Economics, 84(November), pp.83-91.

De Sy, V., 2016. Remote sensing of land use and carbon losses following tropical deforestation. Wageningen University.

De Sy, V. et al., 2012. Synergies of multiple remote sensing data sources for REDD+ monitoring. Current Opinion in Environmental Sustainability, 4(6), pp.696-706.

De Sy, V. et al., 2015. Land use patterns and related carbon losses following deforestation in South America. Environmental Research Letters, 10(12), p.124004.

De Sy, V. et al., 2016. Enhancing transparency in the land-use sector: Exploring the role of independent monitoring approaches, Bogor, Indonesia: CIFOR Infobrief no. 156.

Taylor, J.R., 1997. An Introduction to Error Analysis: The Study of Uncertainties in Physical Measurements 2nd ed., Sausalito, California, USA: University Science Books.

The Land Matrix Global Observatory, 2013. Land Matrix. Available at: http://www.landmatrix.org/.

Tropek, R. et al., 2014. Comment on "High-resolution global maps of 21st-century forest cover change.” Science, 344(6187), p.981.

Tubiana, L. \& El Haite, H., 2016. Road map for global climate action. Available at: http://newsroom.unfccc.int/media/658505/high-level-champions-climate-actionroadmap.pdf [Accessed June 15, 2017].

Tubiello, F.N. et al., 2013. The FAOSTAT database of greenhouse gas emissions from agriculture. Environmental Research Letters, 8(1), p.15009.

Tubiello, F.N. et al., 2015. The Contribution of Agriculture, Forestry and other Land Use activities to Global Warming, 1990-2012. Global Change Biology, 21(7), pp.26552660 . 
Tulyasuwan, N. et al., 2012. Issues and challenges for the national system for greenhouse gas inventory in the context of REDD+. Greenhouse Gas Measurement and Management, 2(2-3), pp.73-83.

Turner, W., Oppenheimer, M. \& Wilcove, D., 2009. A force to fight global warming. Nature, 462, pp.278-279.

Turnhout, E. et al., 2016. Envisioning REDD+ in a post-Paris era: between evolving expectations and current practice. Wiley Interdisciplinary Reviews: Climate Change, 8(1), pp.1-13.

Tyukavina, A. et al., 2015. Aboveground carbon loss in natural and managed tropical forests from 2000 to 2012. Environmental Research Letters, 10(7), p.74002.

Uchida, H. \& Nelson, A., 2008. Agglomeration Index : Towards a New Measure of Urban, World Development Report: Reshaping Economic Geography, World Bank. Washington, DC.

UN, 2016. UN Sustainable Development Goals. Available at: https://sustainabledevelopment.un.org/?menu=1300 [Accessed December 22, 2016]. UN, 2017. Revised list of global Sustainable Development Goal indicators. Report of the Inter-Agency and Expert Group on Sustainable Development Goal Indicators (E/CN.3/2017/2), Annex III. , (March), pp.1-26.

UN-REDD, 2013. United Nations collaborative initiative on Reducing Emissions from Deforestation and forest Degradation (REDD) in developing countries. Available at: http://www.un-redd.org/Partner_Countries/tabid/102663/Default.aspx.

UNCCD, 2017. The Global Land Outlook. Secretariat of the United Nations Convention to Combat Desertification. Bonn, Germany.

UNFCCC, 2003. Report of the Conference of the Parties on Its Eighth Session: 17/CP.8, New Delhi, India.

UNFCCC, 2010. The Cancun agreements: Outcome of the work of the Ad Hoc Working Group on long-term Cooperative Action under the Convention. decision 1/CP 16, fCCC/CP/2010/7/add.1., Cancun, Mexico.

UNFCCC, 2013. UNFCCC REDD+. Available at: http://unfccc.int/methods/redd/items/7377.php.

UNFCCC, 2014. UNFCCC: Full text of the convention. Available at: http://unfccc.int/essential_background/convention/background/items/1353.php.

UNFCCC, 2015a. List of Non-Annex I Parties to the Convention. Available at: http://unfccc.int/parties_and_observers/parties/non_annex_i/items/2833.php [Accessed January 1, 2015].

UNFCCC, 2015b. The Paris Agreement FCCC/CP/2015/L.9/Rev.1, Paris, France. UNFCCC, 2016a. Long-term climate finance, Agenda item 10(a), Proposal by the President, Draft decision -/CP.22. Marrakesh, Morocco 
UNFCCC, 2016b. Marrakech action proclamation for our climate and sustainable development. Available at:

https://unfccc.int/files/meetings/marrakech_nov_2016/application/pdf/marrakech_acti on_proclamation.pdf [Accessed June 16, 2017].

UNFCCC, 2017. Advance unedited version. Decision -/CP.23. Koronivia joint work on agriculture. Bonn, Germany.

Václavík, T. et al., 2013. Mapping global land system archetypes. Global Environmental Change, 23(6), pp.1637-1647.

Valin, H. et al., 2013. Agricultural productivity and greenhouse gas emissions: trade-offs or synergies between mitigation and food security? Environmental Research Letters, $8(3)$, p.35019.

Vancutsem, C. et al., 2012. Harmonizing and Combining Existing Land Cover/Land Use Datasets for Cropland Area Monitoring at the African Continental Scale. Remote Sensing, 5(1), pp.19-41.

Vignola, R. et al., 2009. Ecosystem-based adaptation to climate change: What role for policy-makers, society and scientists? Mitigat. Adapt. Strat. Global Change, 14, pp.691-696.

Villamor, G.B. \& van Noordwijk, M., 2011. Social role-play games Vs individual perceptions of conservation PES agreements for maintaining rubber agroforests in Jambi (Sumatra), Indonesia. Ecology and Society, 16(3), p.27.

Vollrath, A. et al., 2016. Open foris SAR toolkit-free and open source command line utilities for automatized sar data pre-processing. European Space Agency, (Special Publication) SP-740.

de Vries, W., 2018. Soil carbon 4 per mille: a good initiative but let's manage not only the soil but also the expectations. Comment on Minasny et al. (2017) Geoderma 292: 5986. Geoderma, 309, pp.111-112.

van Vuuren, D.P. et al., 2015. Pathways to achieve a set of ambitious global sustainability objectives by 2050: Explorations using the IMAGE integrated assessment model. Technological Forecasting and Social Change, 98, pp.303-323.

van der Werf, G.R. et al., 2009. CO2 emissions from forest loss. Nature Geoscience, 2(November), pp.737-738.

West, P.C. et al., 2010. Trading carbon for food: global comparison of carbon stocks vs. crop yields on agricultural land. Proceedings of the National Academy of Sciences of the United States of America, 107(46), pp.19645-19648.

Wilkes, A., Tennigkeit, T. \& Solymosi, K., 2013. National integrated mitigation planning in agriculture: A review paper, Mitigation of climate chanage in agriculture Working Paper Series 7. Rome, Italy.

Wollenberg, E. et al., 2016. Reducing emissions from agriculture to meet the $2{ }^{\circ} \mathrm{C}$ target. Global Change Biology, 22, pp.3859-3864. 
Woods, K., 2015. Commercial Agriculture Expansion in Myanmar: Links to Deforestation, Conversion Timber, and Land Conflicts. Forest Trend Report Series, p.58.

World Bank, 2012. The Worldwide Governance Indicators (WGI). Available at: www.govindicators.org.

World Bank, 2013. World DataBank. Available at: http://data.worldbank.org/.

World Bank, 2014. Investing across sectors. World Bank Data: Investing Across Bordes. Indicators of foreign direct investment regulations. Available at: http://iab.worldbank.org/Data/ExploreTopics/Investing-across-sectors [Accessed May 5, 2014].

World Resources Institute, 2017. Global Forest Watch. Available at: http://www.globalforestwatch.org/ [Accessed March 22, 2017].

World Resources Institute, 2016. Initiative 20x20. Available at: http://www.wri.org/ourwork/project/initiative-20x20 [Accessed August 2, 2016].

Wulder, M.A. et al., 2012. Opening the archive: How free data has enabled the science and monitoring promise of Landsat. Remote Sensing of Environment, 122(July), pp.2-10.

WWF, 2016. Jurisdictional Approaches To Zero Deforestation Commodities. Discussion Paper WWF International, Global Forest and Climate Programme.

Zarin, D.J. et al., 2016. Can carbon emissions from tropical deforestation drop by $50 \%$ in five years? Global Change Biology, 22, pp.1336-1347.

Zolkos, S.G., Goetz, S.J. \& Dubayah, R., 2013. A meta-analysis of terrestrial aboveground biomass estimation using lidar remote sensing. Remote Sensing of Environment, 128(January), pp.289-298.

Zomer, R.J. et al., 2016. Global Tree Cover and Biomass Carbon on Agricultural Land: The contribution of agroforestry to global and national carbon budgets. Scientific Reports, 6, p.29987. 


\title{
Appendices
}

\section{Appendices to chapter 2 of this thesis.}

\author{
Appendix S1
}

Methods - data preparation

Glossary of key terms

\begin{tabular}{|c|c|c|}
\hline $\begin{array}{l}\text { Abbreviation } \\
\text { / symbol }\end{array}$ & Description & Units \\
\hline $\mathrm{D}$ & Emissions from deforestation & $\mathrm{t} \mathrm{CO}_{2} \mathrm{yr}^{-1}$ \\
\hline ADD & Emissions from agriculture-driven deforestation & $\mathrm{t} \mathrm{CO}_{2} \mathrm{yr}^{-1}$ \\
\hline A & Deforestation area & $\mathrm{Km}^{2} \mathrm{yr}^{-1}$ \\
\hline $\mathrm{CB}$ & $\begin{array}{l}\text { The carbon in above- and below-ground forest biomass } \\
\text { (AGB + BGB; converted to } \mathrm{CO}_{2} \text { ) }\end{array}$ & $\mathrm{t} \mathrm{CO}_{2} \mathrm{~km}^{-1}$ \\
\hline$f_{\text {AAgri }}$ & $\begin{array}{l}\text { Fraction of forest area replaced by agricultural land use } \\
\text { (agriculture driver fraction) }\end{array}$ & Fraction \\
\hline$f_{C B L U}$ & $\begin{array}{l}\text { Fraction of } \mathrm{CB} \text { which is lost on the land following } \\
\text { deforestation (lost biomass fraction) in all land uses }\end{array}$ & Fraction \\
\hline$f_{C B A g r i}$ & $\begin{array}{l}\text { Fraction of } \mathrm{CB} \text { which is lost on the land following } \\
\text { deforestation (lost biomass fraction) in only agricultural } \\
\text { land uses }\end{array}$ & Fraction \\
\hline
\end{tabular}

All non-annex 1 (UNFCCC 2015a) countries located at least partially within a tropical ecoregion (Olson et al. 2001) or within the tropics, were considered for the study. Uruguay was also included, as it is involved in a number of REDD+ platforms (FCPF 2013; UN-REDD 2013). South Sudan has been included for the entire study, which is in line with FRA reports which include some forest data from 1990 onwards in South Sudan. Countries without data 
for one or more input variables were removed (19 countries), leaving a total of 91 countries in the study.

The FAO forest definition was used in the analysis: "land spanning more than 0.5 hectares with trees higher than 5 meters and a canopy cover of more than 10 percent, or trees able to reach these thresholds in situ", but the threshold of 0.5 ha for a forested area was only respected in one dataset. In line with this, the FAO deforestation definition was also used: "the conversion of forest to other land use or the permanent reduction of the tree canopy cover below the minimum 10 percent threshold" (FAO 2015a).

\section{Variability of components over time}

Although the only variable component over time is A, emissions from deforestation do not always follow the same trend as emissions from agriculture-driven deforestation, since the weights given to Hosonuma and De Sy2 are not the same in each time period, meaning that this component does vary over time.

\section{Area of deforestation}

\section{FRA data}

To convert FRA reporting periods for deforestation to the time periods for this study, weighted averages of the available FRA time periods (FAO 2015d) were used (Supplementary Table 1).

Supplementary Table 1. Multiplication factor used in weighted averages to convert FRA reporting periods for deforestation to the time periods for this study.

\begin{tabular}{|c|c|c|c|c|c|c|}
\hline & This study & $\begin{array}{l}1990- \\
1995\end{array}$ & $\begin{array}{l}1995- \\
2000\end{array}$ & $\begin{array}{l}2000- \\
2005\end{array}$ & $\begin{array}{l}2005- \\
2010\end{array}$ & $\begin{array}{l}2010 \\
2015\end{array}$ \\
\hline \multirow{4}{*}{ 幽 } & $1990(1988-1992)$ & $3 / 5$ & & & & \\
\hline & $2000(1998-2002)$ & $2 / 5$ & $3 / 5$ & & & \\
\hline & $2005(2003-2007)$ & & $2 / 5$ & $3 / 5$ & & \\
\hline & $2010(2008-2012)$ & & & $2 / 5$ & $3 / 5$ & \\
\hline
\end{tabular}

In the case of Argentina, and Indonesia, the gains were not used in the analysis as the data reported from the FRA were not consistent (Supplementary Table 2). Inconsistencies in the FRA data are reported in literature (Keenan et al. 2015; Grainger 2008). 
Supplementary Table 2. FRA reported data on forest loss and gain in Argentina and Indonesia 1990-2015 (gross losses use adjusted dates to allow comparability - see Supplementary Table 1)

\begin{tabular}{llcccc}
\hline \multicolumn{2}{c}{ Annual (km) } & $\mathbf{1 9 9 0 - 2 0 0 0}$ & $\mathbf{2 0 0 0 - 2 0 0 5}$ & $\mathbf{2 0 0 5 - 2 0 1 0}$ & $\mathbf{2 0 1 0 - 2 0 1 5}$ \\
\hline \multirow{2}{*}{ Argentina } & Net & -2933 & -3348 & -3180 & -2968 \\
& Gross loss & nodata & 2754 & 3220 & 3010 \\
& Gross gain & 320912 & 412396 & 56308 & 4540 \\
\hline \multirow{3}{*}{ Indonesia } & Net & -19136 & -3104 & -6850 & -6844 \\
& Gross loss & 25.26 & 25.74 & 8.82 & 4.5 \\
& Gross gain & 704.9836 & 4269.891 & 13272.1 & 19100.52 \\
\hline
\end{tabular}

Supplementary Table 2 shows that the individual reporting categories in the FRA can appear contradictory. For example, the 1990-2000 data for Argentina suggests that a large gains in forest cover occurred, meaning that where the net figure is adjusted to gross losses, an estimated $212,718 \mathrm{~km}^{2}$ of forest would be lost every year. This is higher than expected (when compared with the remote sensing derived data: RSS and Hansen), so this figure was not used, and the net value was used instead. Similarly, in the case of Indonesia, the net value was used instead of the gross losses, and this was adjusted to gross values as usual. These values are expected to be more reliable than the losses, as they were found to be in line with the remote sensing derived data used in this study (RSS, Kim and Hansen).

\section{RSS data}

In the RSS dataset, the data were not used for the countries where the standard error is greater than the mean value (see Carter et al. 2015).

\section{Adjustment for thematic mismatches (area data harmonization)}

Due to differences in the datasets, three potential thematic mismatches were identified, which could be quantified and accounted for (Supplementary Table 3). As is good practice, the area of deforestation was adjusted to account for this mismatch before the uncertainty analysis was carried out (IPCC 2006). 
Supplementary Table 3. Thematic mismatches identified in area datasets in comparison to this study's definition of deforestation. Mismatches are noted in brackets.

\begin{tabular}{llll}
\hline $\begin{array}{l}\text { Area } \\
\text { dataset }\end{array}$ & $\begin{array}{l}\text { Gross }\left(\mathbf{A}_{\text {gross }}\right) / \mathbf{n e t} \\
\left(\mathbf{A}_{\text {net }}\right)\end{array}$ & $\begin{array}{l}\text { Land use }\left(\mathbf{A}_{\text {landuse }}\right) / \text { Land } \\
\text { cover }\left(\mathbf{A}_{\text {landcover }}\right)\end{array}$ & $\begin{array}{l}\text { Canopy cover 10\% } \\
\left(\mathbf{A}_{10 \%}\right) / 30 \%\left(\mathbf{A}_{30 \%}\right)\end{array}$ \\
& $\begin{array}{l}\text { Thematic } \\
\text { mismatch } \mathbf{1}\left(\mathbf{B}_{1}\right)\end{array}$ & $\begin{array}{l}\text { Thematic mismatch } 2 \\
\left(\mathbf{B}_{2}\right)\end{array}$ & $\begin{array}{l}\text { Thematic mismatch } 3 \\
\left(\mathbf{B}_{3}\right)\end{array}$ \\
\hline FRA & Gross & Land use & 10 \\
FRA net & Net (under- & Land use & 10 \\
RSS & Gross & Land use & 10 \\
Kim & Gross & Land cover (over-estimate) & 30 (under-estimate) \\
Hansen & Gross & Land cover (over-estimate) & 10 \\
\hline
\end{tabular}

According to Supplementary Table 3, the following adjustments for thematic mismatches (B) are made (Eqs. S1-S3).

$$
\begin{gathered}
A_{\text {gross }}=A_{\text {net }}+B_{1} \\
A_{\text {land use }}=A_{\text {land cover }}-B_{2} \\
A_{10 \%}=A_{30 \%}+B_{3}
\end{gathered}
$$

The difference between net and gross data in the FRA (B1) should be equal to forest expansion. Some countries report forest expansion in their FRA submission, so area was directly used convert net to gross for those countries. To avoid missing data points, the average of all available data points for each time period per country was used. Countries which have data on forest expansion in 2005 account for $35 \%$ of the forest area within the countries included in this study. Where data were not available, the status of the forest in the forest transition curve (Hosonuma et al. 2012) was used to estimate the gain. Although the forest transition curve is often used in relation to deforestation (Hosonuma et al. 2012; DeFries et al. 2013; Köthke et al. 2014; Meyfroidt \& Lambin 2011) the theory also states that countries are expected to move from a state of net deforestation to net reforestation. Therefore, the amount of forest expansion is expected to be similar to other countries with the same status in the transition curve. This was tested using one-way ANOVA, which confirmed a difference between the means of $p<0.001$, however a posteriori Tukey's test 
found that the only difference is between those in transition state 4 and the other transitions (Supplementary Table 4). The mean gain of countries in transition states 1,2 and 3 was therefore used to adjust data from countries with this state $(0.34$ per annum, as a $\%$ of forest area in 2000).

Supplementary Table 4. Average forest expansion (as a \% of forest area 2000) in each transition class

\begin{tabular}{ll}
\hline & Mean annual forest expansion (as a \% of forest area in 2000) \\
\hline Transition state & Hosonuma \\
\hline $\mathbf{1}$ & \\
$\mathbf{2}$ & 0.212 \\
$\mathbf{3}$ & 0.113 \\
$\mathbf{4}$ & 0.635 \\
\hline $\mathbf{n}$ & 2.253 \\
Significance & $33^{*}$ \\
(Annova) & \\
Tukey & 0.00 \\
\hline
\end{tabular}

*Argentina was not included (see Supplementary Table 2)

Using land cover rather than land use (B2) leads to an overestimation of the area, as it includes losses in forest cover in areas which remain forest (for which there is no change in land use). We used planted forest area to adjust the value, and assume that an average harvest time period is 25 years, as harvest periods of 7-40 years are common in the tropics (Bauhus et al. 2010). Thus in this case $1 / 25^{\text {th }}$ of the area is assumed to be lost every year. This area was deducted from the losses with a land cover definition to get a land use definition. Plantation forest area from 2005 was used to adjust the 2000-2005 estimate and, area from 2010 was used for 2005-2010, and so on. Where a time period was missing, the mean of the other available time periods was used. Only 5 countries in our study were lacking plantation area in 2005, which account for less than $2 \%$ of the forest area in our study area. No data were available for South Sudan, so the planted forest area reported for Sudan according to FRA 2010 was divided according to the forest area in each country (75\% in Sudan, and 25\% in South Sudan).

The use of a forest definition of more than $30 \%$ tree cover rather than a $10 \%$ threshold (B3), will lead to an underestimation of deforestation since losses in forest cover between $10 \%$ and $30 \%$ will not be included. To account for this difference, data from Hansen et al. (2013) was 


\section{Appendix S1}

used to determine the percentage of forest with $10-30 \%$ tree cover per country, and this percentage was used in to adjust the value.

Where a negative loss was calculated following adjustment of all thematic mismatches, zero losses were assumed. Where two types of mismatch present; the forest cover definition, and the tree cover threshold of $30 \%$ (i.e. Kim), first the adjustment for using forest cover definition is made (by deducting the gains), then the tree cover threshold is addressed (accounting for the proportion of tree cover with 10-30\% canopy cover).

\section{Forest biomass}

Average carbon stock in forest biomass (CB) was calculated from three available sources. Where datasets provide only AGB, the method described by Saatchi et al. (2011) (Eq. S4) was used to estimate belowground biomass (BGB) from aboveground biomass (AGB) at pixel level.

$$
B G B=0.489 . A G B^{0.89}
$$

An extensive reference dataset of forest biomass is available (Avitabile et al. 2016), and this was used to adjust the bias in each map. This was done at the strata level, using strata which were identified by Avitabile et al. (2016), and which divide the map into regions having similar errors (see Appendix S2). The mean error calculated using the reference points within each strata was used to adjust all the pixel values in that strata. Total tree biomass was converted to carbon using a 0.5 conversion factor (Achard et al. 2014), in areas where canopy cover was at least $10 \%$ using the Modis derived mask (DiMiceli et al. 2011), otherwise it was not considered forest, so it was converted to no data. Countries with more than $25 \%$ no data were excluded.

\section{Proportion of biomass lost during deforestation}

The fraction of biomass lost during a deforestation event $\left(\mathrm{f}_{\mathrm{CB}}\right)$ is provided by only one dataset 'DeSy1'. Two fractions were calculated; the fraction of biomass which is lost on the land following deforestation $\left(f_{\mathrm{CB}}\right)$ in (1) all land uses $\left(f_{\mathrm{CBLU}}\right)$, and $(2)$ only agricultural land uses $\left(f_{\mathrm{CBAgri}}\right)$ (used in the calcuations of $\mathrm{D}$ and ADD respectively). The methods described in (De Sy 2016), were used, and describe the difference between stable forest biomass before deforestation $\left(\mathrm{CB}_{\text {before}}\right)$ and biomass after deforestation $\left(\mathrm{CB}_{\text {after }}\right)$ in follow-up land uses (Eq. S5). 


$$
f_{C B}=1-\left(\frac{C B_{\text {after }}}{C B_{\text {before }}}\right)
$$

The activity data were derived from the 1990-2000 period of the RSS dataset, and biomass data were derived from a pan-tropical map of above-ground live woody biomass density at $30 \mathrm{~m}$ resolution for circa the year 2000 (Zarin et al. 2016). Data were computed at the sample unit level $(10 \times 10 \mathrm{~km})$, and were processed and scaled to the country level using the methods described in (De Sy et al. 2015). Mean data were provided at the continental level (Africa, Asia and Latin America). In the case of Asia, two continental averages were derived, as here the fraction of biomass lost during deforestation was found to be highly related to the amount of follow-up land use that was tree crops (De Sy 2016). One average was derived from countries whose follow-up land use was dominated by tree crops (Brunei, Indonesia, Malaysia, Philippines, Sri Lanka, Thailand, Vietnam), and another from those whose was not (Bangladesh, Bhutan, Cambodia, India, Indonesia, Laos, Myanmar, Nepal, PNG, Timor Leste). These figures were applied to countries in Asia depending on the current (2013) proportion of tree crops (identified as 'permanent cropland') (FAO 2014b), and countries with $>20 \%$ tree crops were allocated the average derived from those countries whose followup land use was dominated by tree crops.

\section{Deforestation driver data}

\section{Hosonuma data}

Hosonuma et al. (2012) describe the fraction of agriculture-driven deforestation using a number of datasets. Although these approximately reflect the period 2000-2010, they were assumed to be applicable for the entire period of interest, Data were also updated using more recent (post-2012) datasets including documents submitted by countries to FCPF (FCPF 2015) and UNREDD (UN-REDD 2013). In cases where there are no data available for a country, a decision tree presented in Hosonuma et al. (2012) was used to calculate the stage of the country in the forest transition (FT) curve, and a proxy value for each stage was used from existing data. Countries which were not included in the Hosonuma et al. (2012) study were added using the same methodology.

\section{De Sy2 data}

For De Sy2, this fraction was calculated from the total area of deforestation (A) and the area of deforestation driven by agriculture (Aagriculture) using Eq. S6.

$$
f_{\text {AAgri }}=\frac{\text { Aagriculture }}{A}
$$




\section{Appendix S2}

\section{Methods - uncertainty of datasets}

The errors identified in Table 2.4 of the main paper were estimated for each dataset. In the case of errors related to the adjustment for thematic mismatches and for the removal of bias in $\mathrm{CB}$, a relatively low value $( \pm 3 \%)$ was given to this, based on expert judgement. Expert judgement has been used in other studies to estimate uncertainties from Agriculture, Forestry and Other Land Use (AFOLU) and deforestation emissions (Roman-Cuesta et al. 2016; Grassi et al. 2017). For the uncertainty related to error related to lack of data, an uncertainty of $\pm 15 \%$ was allocated.

\section{Area of deforestation}

\section{FRA data}

FRA data uncertainty was assessed with the assumption that the capacity of a country will affect the certainty of the data. Forest area change monitoring and remote sensing capacity has been assessed by Romijn et al. $(2015,2012)$ who produced a scoring system based on the regularity and the source of the forest cover maps (external or produced by the country itself). These data are available in the country reports and countries were given a 'low', 'limited', 'intermediate', 'good' or 'very good' capacity. Where data area not available from Romijn et al. (2015), countries who have a high income (World Bank 2013) are also considered to provide reliable data and are allocated an 'intermediate' capacity, otherwise a capacity of 'limited' is assigned. To assess the impact of a country having a low capacity on the uncertainty of the estimates it provides, data on the impact of a countries' increased reporting capacity on its estimates of net area change were used. Data on updates to area estimates for historical time periods following a change in capacity are provided in Romijn et al. (2015). Averaging the reported change 2000-2005 following a capacity increase in 2005-2010, and the reported change 2005-2010 following a capacity increase in 2010-2015 as a percentage of the total change (only for countries with an increased capacity in those periods) gives in some cases ca. $30 \%$ increase, or a slightly lower decrease (Supplementary Table 5). A confidence interval of $\pm 30 \%$ was therefore applied for countries with a 'low' capacity and these values were used for both the net forest change and the deforestation data, which fits with findings that these data have large uncertainties or are 'weak' (see for example Grainger, (2008) and FAO, (2015c)). This $\pm 30 \%$ was reduced stepwise to $\pm 25 \%$ for 'limited capacity' countries, $\pm 20 \%$ for 'intermediate' capacity countries, $\pm 15 \%$ for good capacity countries to $\pm 10 \%$ for countries with a 'very good' capacity. This is in line with the error of industrialized countries' estimates which is assumed to be $\pm 3 \%$ (IPCC 2006), and is expected to be lower than for the countries in our study. 
Supplementary Table 5. Percent difference in forest area estimates from the FRA reports 2005, 2010 and 2015, for countries which altered their estimates of forest area, between either of the two periods of interest (2005-2010 and 2010-2015). The capacity change value represents the magnitude of the change, thus 0 is no change, and a capacity change of 1 represents a change of one level (from low to limited, or from limited to intermediate, for example). Capacity data are derived from Romijn et al. (2015). Weighted means were calculated using the number of countries with capacity increases.

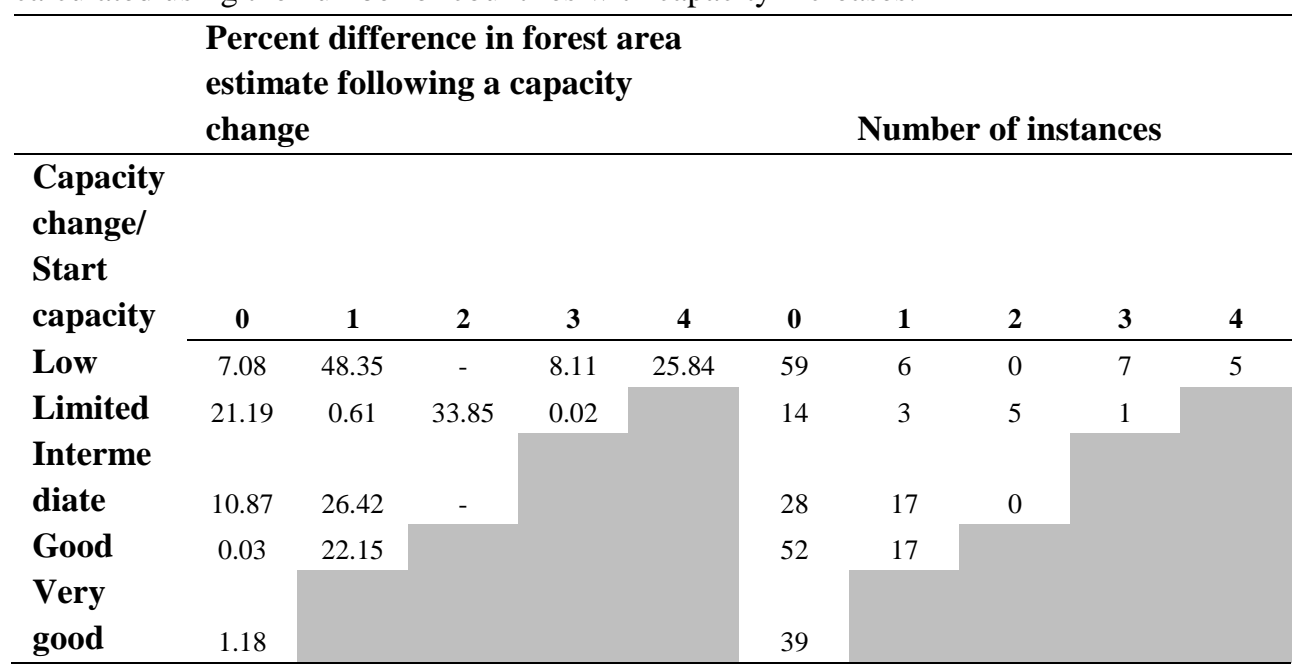

\section{RSS data}

For the RSS data, uncertainty of A related to the sampling error was calculated for the periods 1990-2000 and 2000-2005. Standard deviation is calculated using the deforested area $\left(\mathrm{A}_{\mathrm{i}}\right)$ for the $\mathrm{i}^{\text {th }}$ sample unit, a latitude correction factor or weighting $\left(w_{i}\right)$ in the $\mathrm{i}^{\text {th }}$ sample unit, and the mean deforested area across all samples $(\bar{A})$ (see also Eqs. 2.3 to 2.5). Absolute confidence intervals $(C I \pm)$ were calculated from the standard deviation $(\sigma)$, the number of observations (n) within the country; and the area of the country(C) (Eq. S7 and S8).

$$
\begin{gathered}
\sigma=\sqrt{\frac{\sum w_{i} \cdot\left(A_{i}-\bar{A}\right)^{2}}{\sum w_{i}}} \\
C I \pm=C \cdot \frac{\sigma}{\sqrt{n}} \cdot 1.96
\end{gathered}
$$


Where $\mathrm{n}=1$ for any country, the $\sigma$ cannot be calculated using Eq. $\mathrm{S} 8$ (as $x-\bar{x}=0$ ), and in that case an error of $\pm 100 \%$ was assumed.

\section{Kim and Hansen data}

Error matrices for Kim et al. (2015) are given for the 1990-2000 time period (Kim et al., 2014). These data however were not used, as they were not at the country level, so were not directly comparable with the uncertainties of the other datasets in these studies. Instead we based accuracies in the datasets on the agreement at the country level between Kim and Hansen. Both datasets were based on Landsat data, so large differences between the datasets, would indicate that the estimates were both more uncertain. We considered it to be more likely that both were correct, than both wrong. Since at the country level there are no better data which describe the uncertainty of the two maps, we use this approach to provide a best estimate. In this case the variation between the Kim and Hansen data or coefficient of variation (computed as standard deviation relative to the mean) at the country level for each time period was used as an indicator of uncertainty. Where one estimate was zero deforestation the data were not used in the analysis. The average variation per continent was used as the confidence interval (Supplementary Table 6).

Supplementary Table 6. Mean variation (coefficient of variation (\%)) per continent between Hansen and Kim estimates of forest loss (after adjustments for thematic mismatches) for each time period in each country, and number of available data points per continent $(\mathrm{N})$.

\begin{tabular}{lcc}
\hline Continent & Mean variation & N \\
\hline Africa & 28.25 & 15 \\
Asia & 35.52 & 17 \\
Latin America & 27.68 & 27 \\
\hline
\end{tabular}

\section{Uncertainty of the trend}

Uncertainties related to the area data calculated using the trend method have two error sources: the uncertainty of the original estimate A from the 2000-2005 time period, and the uncertainty of the trend itself. Uncertainties of these two components are combined using Eq. 2.8 in the main paper. The uncertainty of the trend itself is based on the weighted uncertainty of the datasets used to calculate the trend, according to their contribution to the trend estimate. 


\section{Forest biomass}

Uncertainty information is provided by the forest biomass datasets, however, since they do not provide information at the country level which can be directly compared, this information was not used in this analysis. Baccini for example provides AGB prediction as a standard deviation of errors as a percentage of the biomass at the continental level. Saatchi and Avitabile provide pixel level estimates; Saatchi providing systematic errors for the total biomass carbon at the pixel level, and Avitabile providing model uncertainties for each stratum. The different spatial resolutions alone (continental, strata, pixel) make comparisons difficult. To overcome these issues, uncertainties for each map were produced using the same method, based on comparisons to an extensive reference dataset (Avitabile et al. 2016). All data were first converted from AGB to AGB+BGB using Eq. S4. The standard error was calculated from the number of reference data observations (n) within each strata, and was used to calculate the variance $\left(\sigma^{2}\right)$ within each strata. The variance at country level $(\mathrm{C})$ was calculated using the variance of each strata $(\mathrm{S})$, and the proportion or weight of each strata within forested areas within the country (w) (Eq. S9), which is applicable for stratified random sampling. Thirty-two strata from Avitabile et al., (2016) were used. These were based on the two maps estimating the errors of the Baccini and Saatchi maps using several inputs (e.g., the estimated biomass and forest parameters as tree cover, forest height), which were then combined using a K-means clustering approach. Strata were considered useful in this analysis for two reasons. Firstly the reference data were not randomly distributed, and in some countries there were no reference data. Secondly, the strata were representative of the error of the biomass maps, each strata having the lowest error variances compared to those obtained with other stratification approaches. Even though the Avitabile map was not independent from the reference dataset used to assess the maps uncertainties, we used it as it is the most comprehensive open-access reference dataset on forest biomass currently available for the tropics, and because Avitabile et al. (2016) showed that this map reached higher accuracies (hence, weights) than the Saatchi and Baccini maps also when using an independent subset of the reference data.

$$
\sigma_{c}^{2}=\sum W_{s}^{2} \cdot \sigma_{s}^{2}
$$

\section{Proportion of biomass lost during deforestation}

Standard error was calculated using the same method as for the RSS dataset (Eq. S8). The uncertainty related to the errors made in the visual interpretation of the satellite imagery for the data referring to the fraction when agriculture is the follow up land use were considered 
in the De Sy2 data. Visual interpretation of high-resolution satellite data is frequently used as a validation method, so a low uncertainty $( \pm 5 \%)$ was selected.

\section{Deforestation driver data}

\section{De Sy2 data}

Uncertainty in the De Sy2 dataset was calculated using the same method as for the RSS dataset (Eq. S8) for both the total deforested area, and the agriculture-driven deforestation. Uncertainty related to the errors made in the visual interpretation of the satellite imagery were also considered. Uncertainty related to the time periods for which there was no data (where the mean of available data was used) was calculated using the mean of the input uncertainties. Uncertainty related to the fraction (see Eq. S6) was calculated using the variance of the total area of deforestation $\sigma^{2}(\mathrm{~A})$ and the deforestation driven by agriculture $\sigma^{2}$ (Aagriculture) using the Taylor series approximation with the assumption that the errors are not correlated. (Eq. S10).

$$
\sigma^{2}\left(f_{\text {AAgri }}\right)=\frac{\sigma^{2}(\text { Aagriculture })}{A^{2}}+\sigma^{2}(\text { Dtotal }) \cdot \frac{\text { Aagriculture }^{2}}{A^{4}}
$$

\section{Hosonuma data}

Hosonuma used data in a number of different formats to derive the fraction of deforestation driven by agriculture (see Appendix S1). Countries which have quantitative information (ratio) data on drivers on drivers were preferred over ordinal (ranking, for which a ratio e.g. 3:2:1 was used), and ordinal preferred over nominal data sources (listing, for which ratios were assumed equal). Countries which did not have information or were not included in the study used a continental proxy per forest transition (FT) stage, and are likely to have the most uncertainty. We allocate an error to the most certain (ratio) data of $\pm 20 \%$, for the ordinal data $\pm 30 \%$, for the nominal data $\pm 40 \%$, and for the data where the FT curve is used alone $\pm 50 \%$. These uncertainty magnitudes were based on the uncertainty identified in De Sy2 which ranged from $\pm 22 \%$, up to $\pm 200 \%$. 


\section{Sensitivity analysis}

Supplementary Table 7. Mean uncertainty change per country (absolute confidence interval change, and percent of original uncertainty) in estimates of D and ADD (1990-2015) when the uncertainty for various elements which contribute to uncertainty are altered (see section 2.2.3)

\begin{tabular}{|c|c|c|c|c|}
\hline $\begin{array}{l}\text { Assumptions made for } \\
\text { errors / Type of error }\end{array}$ & $\begin{array}{l}\text { Origina } \\
\text { l } \\
\text { uncertai } \\
\text { nty } \\
\text { estimate }\end{array}$ & $\begin{array}{l}\text { Estimation of } \\
\text { uncertainty } \\
\text { for sensitivity } \\
\text { analysis }\end{array}$ & $\begin{array}{l}\text { Absolute and } \\
\text { change in unc } \\
\text { ADD when th } \\
\text { changed } \\
\text { D }\end{array}$ & $\begin{array}{l}\text { ercent) mean } \\
\text { rtainty of } D \text { or } \\
\text { uncertainty is } \\
\text { ADD }\end{array}$ \\
\hline $\begin{array}{l}\text { Lack of data } \\
\text { Measurement error: }\end{array}$ & 15 & 30 & $0.37(1.5)$ & $2.44(4.46)$ \\
\hline $\begin{array}{l}\text { Visual interpretation } \\
\text { error }\end{array}$ & 5 & 30 & $0(0)$ & $8.25(16.01)$ \\
\hline $\begin{array}{l}\text { Measurement-error: } \\
\text { adjustment for } \\
\text { thematic mismatch or } \\
\text { bias adjustment in CB }\end{array}$ & 3 & 30 & $17.74(63.73)$ & $11.77(15.78)$ \\
\hline
\end{tabular}




\section{Appendix S3}

\section{Comparisons with other datasets}

Supplementary Table 8. Estimates of emissions from deforestation, from gross loss of forest cover (Harris et al., 2012, 'Harris'), and forest land use (this study) 2000-2005. Estimates are in forests $>25 \%$ forest cover (Harris et al., 2012), and $>10 \%$ (this study). This study uses a weighted mean best estimate, and low and high represent the $90 \%$ confidence interval. Harris low and high estimates represent the $90 \%$ prediction interval, derived from a Monte Carlo style sampling technique including all critical sources of uncertainty.

\begin{tabular}{|c|c|c|c|c|c|c|}
\hline & & & Latin America & Africa & Asia & Global \\
\hline \multirow{6}{*}{$\begin{array}{c}\text { Emissions from } \\
\text { deforestation } \\
2000-2005(\mathrm{Mt} \\
\left.\mathrm{CO}_{2} \text { year }^{-1}\right)\end{array}$} & \multirow{3}{*}{ This study } & Low & 1137 & 378 & 493 & 2008 \\
\hline & & Mean & 1240 & 420 & 555 & 2215 \\
\hline & & High & 1344 & 461 & 617 & 2422 \\
\hline & \multirow{3}{*}{ Harris } & Low & 1129 & 183 & 664 & 1976 \\
\hline & & Median & 1599 & 411 & 946 & 2955 \\
\hline & & High & 2519 & 829 & 1375 & 4723 \\
\hline \multirow{6}{*}{$\begin{array}{c}\text { Area of forest } \\
\text { loss (gross) } \\
\text { 2000-2005 }\left(\mathrm{km}^{2}\right. \\
\left.\mathrm{yr}^{-1}\right)\end{array}$} & \multirow{3}{*}{ This study } & Low & 49683 & 22197 & 13842 & 85722 \\
\hline & & Mean & 52458 & 24555 & 15239 & 92252 \\
\hline & & High & 55233 & 26912 & 16636 & 98781 \\
\hline & \multirow{3}{*}{ Harris } & Low & 17950 & 7350 & 11390 & 36690 \\
\hline & & Median & 48430 & 18830 & 17830 & 85090 \\
\hline & & High & 84360 & 33660 & 25080 & 143100 \\
\hline
\end{tabular}


Supplementary Table 9. Emissions from gross deforestation from in this study and Achard et al., (2014), (Table 2) 'Achard'

\begin{tabular}{|c|c|c|c|c|c|c|}
\hline \multicolumn{7}{|c|}{ Emissions from deforestation (Mt CO2/year) } \\
\hline & & & Latin America & Africa & Asia & Tropics \\
\hline \multirow[t]{6}{*}{ 1990-2000 } & \multirow{3}{*}{ This study } & Lower & 833 & 190 & 683 & 1705 \\
\hline & & Mean & 930 & 231 & 799 & 1960 \\
\hline & & Upper & 1027 & 272 & 915 & 2214 \\
\hline & \multirow{3}{*}{ Achard } & Min & 1124 & 374 & 869 & 2369 \\
\hline & & Mean & 1873 & 718 & 1166 & 3757 \\
\hline & & Max & 2460 & 975 & 1542 & 4869 \\
\hline \multirow[t]{6}{*}{ 2000-2010 } & \multirow{3}{*}{ This study } & Lower & 962 & 391 & 492 & 1846 \\
\hline & & Mean & 1093 & 469 & 584 & 2146 \\
\hline & & Upper & 1223 & 548 & 676 & 2446 \\
\hline & \multirow{3}{*}{ Achard } & Min & 1183 & 160 & 864 & 2207 \\
\hline & & Mean & 1938 & 562 & 1128 & 3628 \\
\hline & & Max & 2483 & 809 & 1346 & 4543 \\
\hline
\end{tabular}


Supplementary Table 10 Gross forest cover loss (Tyukavina), and gross forest land use loss (this study) $\left(\mathrm{M} \mathrm{km}^{-2} \mathrm{yr}^{-1}\right)$ and emissions

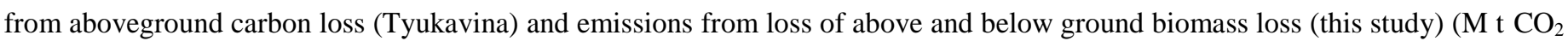
$\left.\mathrm{yr}^{-1}\right), 2000$ 2012. Uncertainties are representative of the $95 \%$ confidence interval.

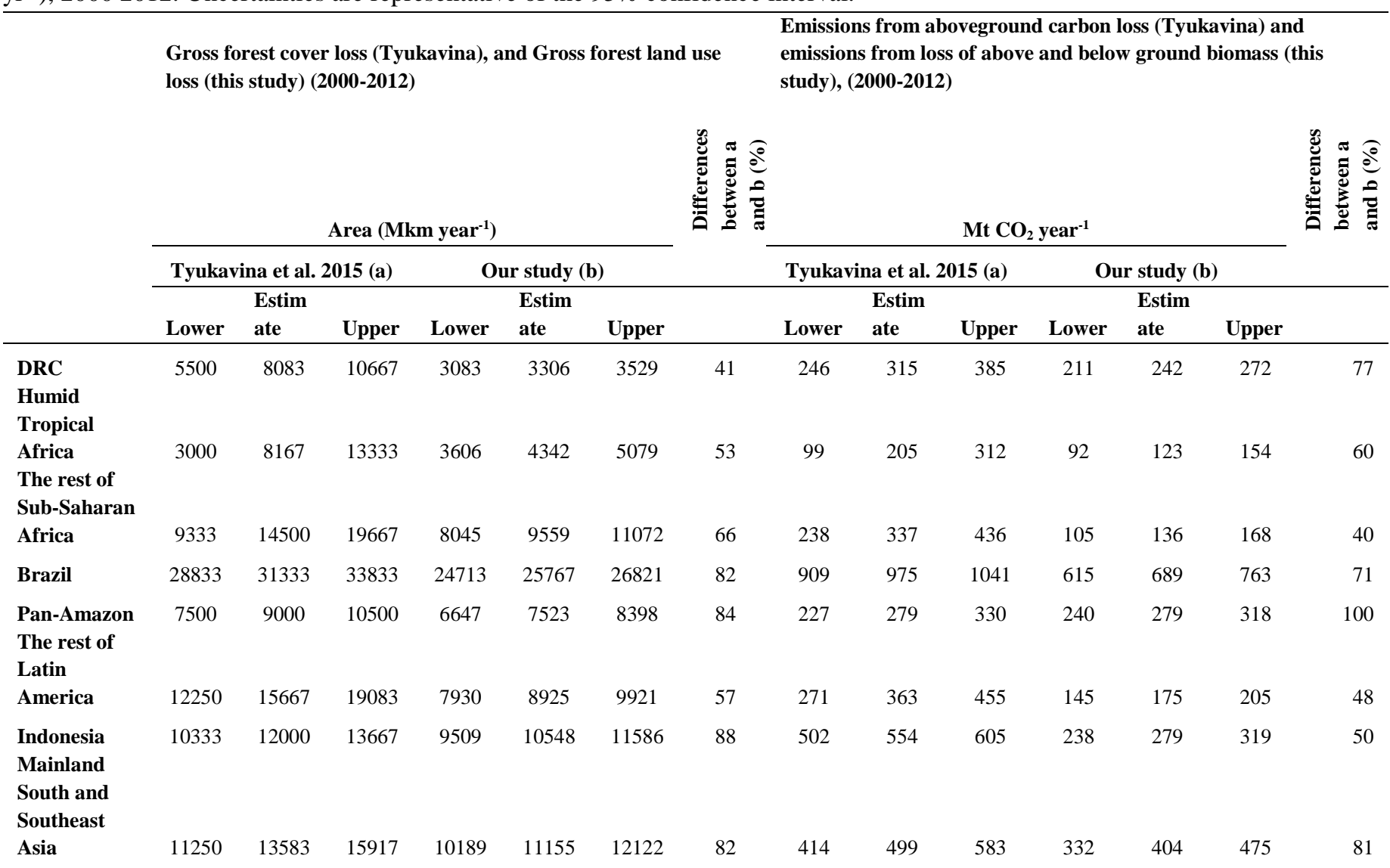




\begin{tabular}{|c|c|c|c|c|c|c|c|c|c|c|c|c|c|c|}
\hline $\begin{array}{l}\text { Insular } \\
\text { Southeast }\end{array}$ & & & & & & & & & & & & & & \\
\hline Asia & 3500 & 4583 & 5667 & 3217 & 3773 & 4328 & 82 & 169 & 213 & 257 & 86 & 101 & 116 & 47 \\
\hline $\begin{array}{l}\text { Africa total } \\
\text { Latin }\end{array}$ & 23083 & 30750 & 38417 & 14734 & 17207 & 19681 & 56 & 697 & 858 & 1019 & 408 & 501 & 594 & 58 \\
\hline $\begin{array}{l}\text { America } \\
\text { total } \\
\text { South and } \\
\text { Southeast }\end{array}$ & 51000 & 56083 & 61167 & 39290 & 42215 & 45141 & 75 & 1500 & 1621 & 1742 & 1000 & 1143 & 1286 & 71 \\
\hline Asia total & 27167 & 30333 & 33500 & 22915 & 25475 & 28036 & 84 & 1151 & 1269 & 1386 & 656 & 783 & 910 & 62 \\
\hline $\begin{array}{l}\text { Pan-tropical } \\
\text { total }\end{array}$ & $\begin{array}{c}10741 \\
7\end{array}$ & $\begin{array}{c}11708 \\
3\end{array}$ & $\begin{array}{c}12675 \\
0\end{array}$ & 76938 & 84898 & 92858 & 73 & 3513 & 3747 & 3982 & 2064 & 2427 & 2790 & 65 \\
\hline
\end{tabular}




\section{Acknowledgements}

There are many people to whom I need to give thanks for their support and for their contributions to this thesis.

First I have to thank my promotor Martin who has provided excellent inputs which have vital to the PhD thesis. My co-promotors Lammert, Mariana and Lou whose experience has been extremely valuable, have together guided me through the $\mathrm{PhD}$ process. Many thanks to the opponents, who are giving their time to attend the defence, to the numerous anonymous referees, co-authors, and many others in science who have influenced my work.

For making office life fun, I must thank my PhD colleagues past and present. These include: Anne, Alvaro, Arun, Astrid, Ben B, Ben DV, Beni, Daniela, Diego, Eliakim, Eskender, Hans, Jalal, Johannes, Jose, Konstantin, Kalkidan, Kim, Loïc, Maria, Marian, Marston, Mathieu, Michi, Na, Nadine, Nandika, Niki, Patric, Peter, Qijun, Richard, Roberto, Sabina, Samantha, Simon, Shivangi, and Yang. Special thanks to my two paranymphs and squash partners, Alvaro and Nandika. My thanks also go to the staff at the department some of whom have provided valuable support: Aldo, Antoinette, Arend, Arnold, Corne, Danaë, Devis, Erika R, Erika S, Frans, Harm, Jan C, Jan V, Joao, Johannes, John S, John V, Lukasz, Marcello, Ron, Sylvain, Sytze, Truus, and Willy. Thanks also to my friends and past colleagues, Brice, Rosa, and Valerio.

There are a number of people in my network who have also extended my horizons. Thanks to those at CIFOR (past and present), including Christopher, Arief, Maria, Marjanneke, and many others. Thanks also go to Marjan, who during and even before starting the $\mathrm{PhD}$, provided me with insights into academic life.

A big thankyou to my family; my parents who have supported me in too many ways to mention, and my brother, my grandparents and extended family who have all been there for me at one time or another. And of course the biggest thanks go to Mathieu who has been with me through almost all of the $\mathrm{PhD}$ process.

Without all of these people, and others who I may have omitted to mention, this would not have been possible, so again, my sincere thanks go to everyone. 



\section{Author publications}

\section{Peer reviewed publications}

S Carter, B Arts, KE Giller, C Soto Golcher, K Kok, J de Koning, M van Noordwijk, P Reidsma, MC. Rufino, G Salvini, L Verchot, E Wollenberg, and M Herold. Climate-smart land use requires local solutions, transdisciplinary research, policy coherence, and transparency. Carbon Management. Accepted, on condition of minor revisions.

S Carter, M Herold, V Avitabile, S de Bruin, V De Sy, L Kooistra and MC Rufino. 2017. Agriculture-driven deforestation in the tropics from 1990 to 2015: emissions, trends, and uncertainties. Environmental Research Letters 13 (1), 014002

S Carter, AM Manceur, R Seppelt, K Hermans-Neumann, M Herold, L Verchot. 2017. Large scale land acquisitions and REDD+: a synthesis of conflicts and opportunities. Environmental Research Letters 12 (3), 035010.

M Schultz, J Voss, M Auer, S Carter, A Zipf. 2017. Open land cover from Open Street Map and remote sensing International Journal of Applied Earth Observation and Geoinformation. 63, 206-213.

M Schultz, JGPW Clevers, S Carter, J Verbesselt, V Avitabile, HV Quang, M Herold. 2016. Performance of vegetation indices from Landsat time series in deforestation monitoring. International Journal of Applied Earth Observation and Geoinformation 52 (2016), 318327.

E Wollenberg, M Richards, P Smith, P Havlík, M Obersteiner, FN. Tubiello, M Herold, P Gerber, S Carter, A Reisinger, DP van Vuuren, A Dickie, H Neufeldt, BO Sander, R Wassmann, R Sommer, JE. Amonette, A Falcucci, M Herrero, C Opio, RM Roman-Cuesta, E Stehfest, H Westhoek, I Ortiz-Monasterio, T Sapkota, MC. Rufino, PK Thornton, L Verchot, PC. West, J-F Soussana, T Baedeker, M Sadler, S Vermeulen, BM Campbell. 2016. Reducing emissions from agriculture to meet the $2{ }^{\circ} \mathrm{C}$ target. Global Change Biology 22, 3859-3864. 
S Carter, M Herold, MC Rufino, K Neumann, L Kooistra, L Verchot. 2015. Mitigation of agriculture emissions in the tropics: comparing forest land-sparing options at the national level. Biogeosciences 12, 4809-4825.

S Carter, S Shackley, S Sohi, TB Suy, S Haefele. 2013. The Impact of Biochar Application on Soil Properties and Plant Growth of Pot Grown Lettuce (Lactuca sativa) and Cabbage (Brassica chinensis). Agronomy 3 (2), 404-418.

R Jindal, JM Kerr, S Carter. 2012. Reducing Poverty Through Carbon Forestry? Impacts of the N'hambita Community Carbon Project in Mozambique. World Development 40 (10), 2123-2135.

S Shackley, S Carter, T Knowles, E Middelink, S Haefele, S Sohi, A Cross, S Haszeldine. 2012. Sustainable gasification-biochar systems? A case-study of rice-husk gasification in Cambodia, Part I: Context, chemical properties, environmental and health and safety issues. Energy Policy 42, 49-58.

S Shackley, S Carter, T Knowles, E Middelink, S Haefele, S Haszeldine. 2012. Sustainable gasification-biochar systems? A case-study of rice-husk gasification in Cambodia, Part II: Field trial results, carbon abatement, economic assessment and conclusions. Energy Policy 41, 618-623.

S Shackley, S Carter, K Sims, S Sohi. 2011. Expert perceptions of the role of biochar as a carbon abatement option with ancillary agronomic and soil-related benefits. Energy \& Environment 22 (3), 167-187.

\section{Other selected publications}

MG Bastos Lima, J Braña-Varela, H Kleymann, S Carter. 2014. The Contribution of Forests and Land Use to Closing the Gigatonne Emissions Gap by 2020. WWF / WUR Policy Brief 2.

S Carter, R van Mansvelt, M Verles. 2012. Rural Energy \& Climate Initiative: Key considerations, best practices and potential projects: Carbon finance-supported rural energy access projects in Asia. Nexus-Carbon for Development.

P Karve, S Shackley, S Carter. 2012. Biochar, Carbon Reduction and Sustainable Soils: Role in Asia and the Pacific? APN science bulletin: global environmental change 2, 17-21. 
S Carter, S Shackley. 2012. Biochar: biomass energy, agriculture and carbon sequestration. Boiling Point 60, 42-45.

S Shackley, S Sohi, P Brownsort, S Carter, J Cook, C Cunningham, J Gaunt, J Hammond, R Ibarrola, O Mašek, K Sims, P Thornley. 2010. An assessment of the benefits and issues associated with the application of biochar to soil. DEFRA \& DECC, UK Government.

S Carter. 2009. Socio-economic benefits in Plan Vivo projects: trees for global benefits, Uganda, Plan Vivo Foundation and Ecotrust Uganda. 


\section{About the author}

Sarah Carter grew up in Newcastle-upon-Tyne, UK. After finishing school, she completed a BSc. in Environment, Economics and Ecology (2:1) at the University of York, UK (2005). She was awarded a scholarship to complete a MSc. in Resource Management at the University of Edinburgh, UK (2006). Her BSc. and MSc. included fieldwork in Tanzania.

She then worked at Edinburgh University, and at the same time for the Plan Vivo foundation. During the weekends she worked for a time at the National Museum of Scotland presenting science to children. At the University of Edinburgh she had various roles including as a researcher on a carbon sequestration research project in Mozambique. She also worked at Edinburgh University's Biochar Research Centre on desk based studies and, for almost a year managing field campaigns in Cambodia and India. For the Plan Vivo foundation; an NGO administering a framework for community land use and forestry projects, she worked on project management, and this role also took her to Uganda for fieldwork.

Following this she moved to Cambodia to work for Nexus; an NGO specializing in carbon finance for rural energy projects, where she spent 2 years. She was the primary contact for project developers in the Asia region.

In December 2012, she began her PhD. After a couple of years, she, alongside the $\mathrm{PhD}$ work, coordinated a World Bank funded project on capacity building for REDD+ MRV. She has also managed the GOFC-GOLD (Global Observation for Forest Cover and Land Dynamics) Land Cover office, and the Research and Development component of the GFOI (Global Forest Observations Initiative) for the last year.

Sarah's current research interests include REDD+ MRV, monitoring SDGs using remote sensing data, monitoring for land use conflicts, food security, forest protection, carbon finance, and climate change.

Following her $\mathrm{PhD}$, Sarah will continue to work on a number of projects at Wageningen University. 


\section{PE\&RC Training and Education Statement}

With the training and education activities listed

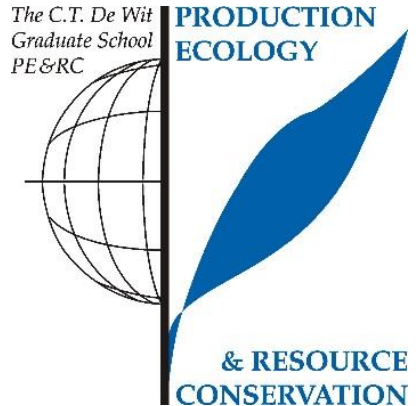
below the $\mathrm{PhD}$ candidate has complied with the requirements set by the C.T. de Wit Graduate School for Production Ecology and Resource Conservation (PE\&RC) which comprises of a minimum total of 32 ECTS (= 22 weeks of activities)

\section{Review of literature (6 ECTS)}

CSA \& REDD+ (policy brief draft)

\section{Writing of project proposal (4.5 ECTS)}

Integrated monitoring for estimating GHG emissions from forests and agriculture in tropical countries

\section{Post-graduate courses (4.6 ECTS)}

Introduction to R for statistical analysis; PE\&RC (2013)

Sustainable agricultural land management projects: soil carbon monitoring; World Bank (2013)

Carbon monitoring in CDM afforestation and reforestation projects; World Bank (2014) Climate-Smart agriculture; WUR (2016)

\section{Laboratory training and working visits (4.5 ECTS)}

REDD+ working visit; CIFOR Indonesia (2014)

Analysis of deforestation and livestock production in Kenya; CIFOR Kenya (2015)

\section{Invited review of (unpublished) journal manuscript (3 ECTS)}

Journal of Environmental Quality (2013), African Journal of Environmental Science and Technology (2014), Scientia Agricola (2017), Biogeosciences (2017), Nutrient Cycling in Agroecosystems (2017).

Deficiency, refresh, brush-up courses (7.5 ECTS)

Advanced earth observation; WUR (2013) 
PE\&RC Training and Education Statement

Capita Selecta geo-information science: contribution to global land cover datasets; WUR (2013)

Competence strengthening / skills courses (4.5 ECTS)

Data management; WUR (2013)

Media training; CIFOR (2013)

Dutch lessons; WUR (2013-2017)

Storymaps; WUR-GRS (2014)

Basic security in the field; UN (2016)

Techniques for writing and presenting a scientific paper; WUR (2016)

PE\&RC Annual meetings, seminars and the PE\&RC weekend (2.1 ECTS)

PE\&RC Weekend (2013)

PE\&RC Day $(2014,2016)$

Climate smart agriculture @ WUR, challenges and opportunities (2015)

SENSE Carbon climate interactions (2015)

Discussion groups / local seminars / other scientific meetings (6 ECTS)

Hotspots of emissions from land use change; WUR/ILRI/CIFOR (2013)

REDD+ discussion groups, and later REDD+ and CSA discussion group (2014-2017)

GOFC-GOLD Land monitoring symposium (2013)

Workshop: forest and agriculture; WUR (2016)

GOFC-GOLD Land cover \& GFOI R\&D science meeting (2016)

Accuracy assessments for area estimates (2017)

International symposia, workshops and conferences (7.8 ECTS)

Global landscapes forum and COP19 (2013)

ESA Living planet symposium (2013)

Global landscapes forum and COP20 (2014)

Our common future under climate change (2015)

REDD+ MRV "training the trainers" (2016)

\section{Supervision of MSc students (6 ECTS)}

Predicting oil palm land use following deforestation using available spatial parameters. Quantifying pasture expansion and associated deforestation: a case study in Ethiopia and Kenya.

Assessing the impact of land management on forest carbon stocks: a case study from Kenya. 
The research described in this thesis was financially supported by CIFOR's Global Comparative Study on REDD+.

Financial support from Wageningen University for printing this thesis is gratefully acknowledged.

Printed by ProefschriftMaken, www.proefschriftmaken.nl on recycled paper. 

Propositions

1. Agriculture is the main source of land-based carbon emissions in the tropics.

(this thesis)

2. Initiatives to reduce deforestation implemented in the forest sector alone, will not reduce deforestation.

(this thesis)

3. Valuing ecosystem services economically devalues them.

4. Science for impact is not achieved by promotion on social media.

5. Polymaths are specialists.

6. In order to achieve gender equality in today's society, women need to be given an advantage.

Propositions belonging to the thesis, entitled

'Deforestation and agriculture in the tropics: carbon emissions and options for mitigation'.

Sarah Carter, 21 March 2018. 